\title{
Um modelo de referência para o desenvolvimento ágil de software
}

\author{
Gustavo Vaz Nascimento
}

Orientadora: Profa. Dra. Rosely Sanches

Dissertação apresentada ao Instituto de Ciências Matemáticas e de Computação - ICMC/USP, como parte dos requisitos para obtenção do título de Mestre em Ciências de Computação e Matemática Computacional.

\section{"VERSÃO REVISADA APÓS A DEFESA"}

Data da Defesa: 13 de fevereiro de 2008

Visto do Orientador:

USP - São Carlos

Fevereiro/2008 
Um modelo de referência para o desenvolvimento ágil de software

Gustavo Vaz Nascimento 


\section{Agradecimentos}

Agradecimentos iniciais a Deus, por me dar força e saúde para superar as dificuldades encontradas.

Agradecimentos a professora Rosely Sanches, por sua constante disposição, paciência, sensatez, orientação e incentivo, em todos os momentos.

Agradecimentos a Wesley Peron Seno, por ter me dado a primeira oportunidade profissional, pelo incentivo ao ingresso no mestrado e na vida acadêmica, e pela compreensão e apoio indispensáveis para a realização deste trabalho.

Agradecimentos ao Instituto de Ciências Matemáticas e de Computação e a USP, pela excelência em seus cursos de graduação e pós-graduação.

Agradecimentos imensuráveis a meus pais Nelson e Luzia e a meus irmãos Elby e Samuel, que em todos os momentos me incentivaram e me apoiaram nessa realização.

Agradecimentos especiais e com muito carinho a minha amada esposa Vivian. Agradeço-a pela paciência, pela compreensão, pela dedicação e por todo amor dispensado.

Agradecimentos finais a todos que, direta ou indiretamente, participaram ou torceram pela finalização de mais essa etapa. 
A crescente procura por software de qualidade vem causando grande pressão sobre as empresas que trabalham com desenvolvimento de software. As entregas de produtos de software dentro do prazo e custo previstos vêm se tornando, a cada dia, um diferencial importante nesse ramo de atividade. Nesse sentido, as empresas procuram por metodologias que propiciem o desenvolvimento de produtos com qualidade, e que respeitem o custo e prazo previstos. Em resposta a essas necessidades, surgiu uma nova classe de metodologias de desenvolvimento de software, conhecidas como metodologias ágeis.

Este trabalho apresenta um estudo realizado sobre as principais características existentes nessa nova classe de metodologias. Uma análise permitiu a identificação de semelhanças e diferenças existentes entre elas, o que possibilitou a criação de um modelo de referência para o desenvolvimento ágil de software. O modelo foi utilizado em uma avaliação de processo baseada no modelo de avaliação da ISO/IEC 15504. A avaliação permitiu a identificação de forças e fraquezas no processo avaliado e possibilitou a definição de ações de melhoria para que o processo avaliado se assemelhasse à um processo de desenvolvimento ágil.

Palavra-chave: Metodologia ágil de desenvolvimento. Modelo de referência. Processo de desenvolvimento de software. Avaliação de processo de software. 
The vast demand for software with quality is causing a great pressure on the companies which work with software development. The delivery of software products within the schedule and cost is becoming, every day, an important issue in this area. Therefore, companies are seeking for methodologies to develop products with quality, within the timetable and the cost. Considering these needs, it became a new class of software development methodologies, known as agile methodologies.

This research shows a work done upon the main existing characteristics in this new class of methodologies. An analysis allowed the identification of the existing similarities and differences among them, which it made possible to create a new reference model for agile software development. The agile model was used in process assessment based on assessment model from ISO/IEC 15504. The assessment alowed a identification of power and weakness on the process and alowed a definition of improvement action to the process with the intention of to approach the agile development process.

Palavra-chave: Agile Methodology. Reference Model. Software Development Process. Software Process Assessment. 
$\begin{array}{ll}\text { Resumo } & \text { ii }\end{array}$

$\begin{array}{ll}\text { Abstract } & \text { iii }\end{array}$

1 Introdução $\quad 1$

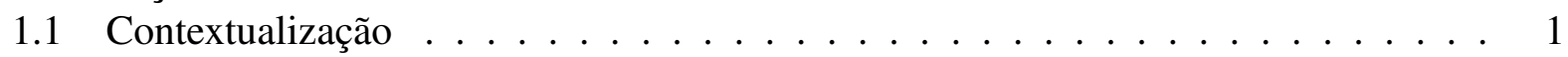

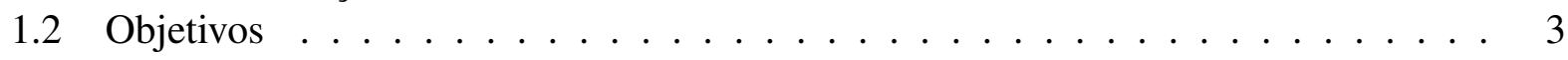

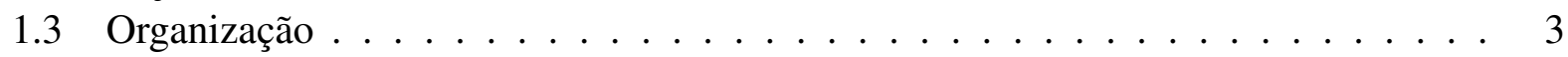

2 Metodologias ágeis de desenvolvimento de software 4

2.1 Considerações Iniciais . . . . . . . . . . . . . . . . . . . . 4

2.2 Conceitos envolvidos com as metodologias ágeis de desenvolvimento . . . . . . . 5

2.3 Metodologia Extreme Programming . . . . . . . . . . . . . . . . . . . 7

2.4 Metodologia SCRUM . . . . . . . . . . . . . . . . . . . 10

2.5 Metodologia Feature Driven Development . . . . . . . . . . . . . . . . . . . . . . . 12

2.6 Metodologia Dynamic System Development Method . . . . . . . . . . . . . . . . . 14

2.7 Metodologia Adaptive Software Development . . . . . . . . . . . . . . . . . . . 17

2.8 Metodologia Crystal . . . . . . . . . . . . . . . . . . . . . . . . . . . . . . . . . . . . . . . .

2.9 Produzindo documentação de forma ágil . . . . . . . . . . . . . . . . 22

2.10 Considerações Finais . . . . . . . . . . . . . . . . . . 24

3 Gerência e planejamento de projetos $\quad 25$

3.1 Considerações Iniciais . . . . . . . . . . . . . . . . . . . . 25

3.2 Técnicas de auxílio à gestão de projetos . . . . . . . . . . . . . 25

3.3 Considerações Finais . . . . . . . . . . . . . . . . . . 28

4 O norma ISO/IEC 15504 30

4.1 Considerações Iniciais . . . . . . . . . . . . . . . . . . . . . . . . . . . . . .

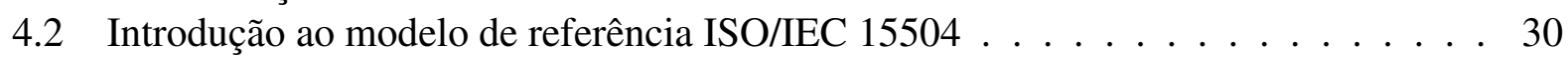

4.3 As cinco partes do modelo de referência ISO/IEC $15504 \ldots \ldots$. . . . . . . . 31

4.4 Considerações finais . . . . . . . . . . . . . . . . 37 
5 Uma proposta de um modelo de referência para o desenvolvimento ágil de software 38

5.1 Considerações Iniciais . . . . . . . . . . . . . . . . . . . 38

5.2 Categorização das metodologias ágeis . . . . . . . . . . . . . . . . . . . . . . . . . . . . . . .

5.3 Requisitos para um modelo de referência de processo . . . . . . . . . . . . . 41

5.4 Um modelo de referência para o desenvolvimento ágil de software . . . . . . . . . 42

5.4.1 Declaração do domínio . . . . . . . . . . . . . . . . . 42

5.4 .2 Processos do modelo de referência . . . . . . . . . . . . . . . . 42

5.4.3 Grupo de Processos de Inicialização (INI) . . . . . . . . . . . . . . . . . . . 44

5.4.4 Grupo de Processos de Desenvolvimento Iterativo (DES) . . . . . . . . . . 54

5.4.5 Grupo de Processos de Operação (OPE) . . . . . . . . . . . . . . . . . . 62

5.4.6 Grupo de Processos de Apoio (APO) . . . . . . . . . . . . . . . 66

5.4.7 Relacionamentos entre os processos . . . . . . . . . . . . 73

5.5 Considerações Finais . . . . . . . . . . . . . . . . . . 81

$\begin{array}{lll}6 & \text { Estudo de caso } & 83\end{array}$

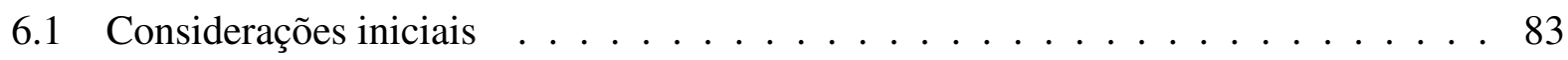

6.2 O processo de avaliação . . . . . . . . . . . . . . . . . 83

6.2.1 O processo de avaliação segundo a norma ISO/IEC $15504 \quad \ldots \ldots$. . . . . . 84

6.3 Avaliação do processo de desenvolvimento do Centro de Informática . . . . . . . . 85

6.3.1 Descrição do processo de desenvolvimento do Centro de Informática . . . 85

6.3 .2 O processo de avaliação documentado . . . . . . . . . . . . . . 86

6.3 .3 Resultados da avaliação . . . . . . . . . . . . . . . 89

6.4 Considerações finais . . . . . . . . . . . . . . . . . . 93

7 Conclusões e trabalhos futuros $\quad 96$

7.1 Síntese do trabalho . . . . . . . . . . . . . . . . . . . . 96

7.2 Contribuições do trabalho . . . . . . . . . . . . . . . . . . . 97

7.3 Trabalhos futuros . . . . . . . . . . . . . . . . . 97

$\begin{array}{ll}\text { A Características chave dos produtos de trabalho } & 105\end{array}$

B Framework de medidas $\quad 112$

B.1 Níveis de Capacidade de Processo . . . . . . . . . . . . . . . . . . . . . . . 112

B.1.1 Nível 0: Processo Incompleto . . . . . . . . . . . . . . . . . . 112

B.1.2 Nível 1: Processo Executado . . . . . . . . . . . . . . . . . 113

B.1.3 Nível 2: Processo Gerenciado . . . . . . . . . . . . . . . . . . . . . 113

B.2 Avaliação dos Atributos de Processo . . . . . . . . . . . . . . . . . 113

B.2.1 Indícios de Atributos de Processo (IAP) . . . . . . . . . . . . . . 113

B.2.2 Escala de classificação dos atributos de processo . . . . . . . . . . . . . 114

B.3 Classificação dos atributos de processo . . . . . . . . . . . . . . . . . 115

B.4 Modelo de nível de capacidade de processo . . . . . . . . . . . . . . 115 


\section{Lista de Figuras}

2.1 Ciclo de vida de Extreme Programming (Abrahamsson et al., 2002) . . . . . . . 8

2.2 Ciclo de vida de Scrum (Abrahamsson et al., 2002) . . . . . . . . . . . . . . . . 11

2.3 Ciclo de vida de Feature Driven Development (Abrahamsson et al., 2002) . . . . . 12

2.4 Parte iterativa de Feature Driven Development (Abrahamsson et al., 2002) . . . . . 14

2.5 Ciclo de vida de Dynamic System Development Method (Abrahamsson et al., 2002) 15

2.6 Ciclo de vida Adaptive (Highsmith, 2000) . . . . . . . . . . . . . . . . 17

2.7 Atividades do ciclo de vida Adaptive (Highsmith, 2000) . . . . . . . . . . . . 18

2.8 Categorias de projeto da metodologia Crystal (Abrahamsson et al., 2002). . . . . . 20

2.9 Um incremento de Crystal para equipes com mais de quarenta membros (Keith Everette, 2006). . . . . . . . . . . . . . . . . . 21

3.1 Exemplo de uma EAP para um projeto (Project Management Institute, 2004) . . . 26

3.2 Exemplo de um MDP que representa o sequenciamento de atividades (Project Management Institute, 2004) . . . . . . . . . . . . . . . . . . . 27

3.3 Exemplo de um MDS que representa o sequenciamento de atividades (Project Management Institute, 2004) . . . . . . . . . . . . . . . . . . 28

4.1 Partes que compõem a norma ISO/IEC $15504 \ldots \ldots$. . . . . . . . . . . 31

4.2 Níveis de capacidade e respectivos atributos de processo . . . . . . . . . . . 32

4.3 Níveis de capacidade e respectivos significados . . . . . . . . . . . . . . . 33

4.4 Dimensões do modelo de avaliação de processo . . . . . . . . . . . . . . . 33

4.5 Pontuações sugeridas para os atributos de processo e seus respectivos significados . 34

4.6 Pontuações dos atributos de processo e respectivos níveis de capacidade . . . . . . 35

4.7 Estrutura do processo de avaliação . . . . . . . . . . . . . . . . 36

5.1 Categorização das metodologias ágeis de desenvolvimento. . . . . . . . . . . . . 41

5.2 Grupos de processos do modelo de referência ágil e as interações entre eles. . . . . 43

5.3 Grupos de processos do modelo de referência ágil e seus respectivos processos. . . 44

5.4 Template para um modelo de avaliação de processos (ISO/IEC, 2003d). . . . . . . 45

5.5 Exemplo de uma Lista de Estórias e de Requisitos Não-funcionais já priorizada. . . 46

5.6 Template para a elaboração de um Plano Global para um projeto ágil. . . . . . . . . 54

5.7 Template para a elaboração de um Plano para a Iteração. . . . . . . . . . . . . . . 56

5.8 Exemplo de um checklist para a padronização e documentação do código-fonte (Microsoft, 2007) . . . . . . . . . . . . . . . . . 58

5.9 Template de um Plano de Implantação de Gerência de Configuração. . . . . . . . . . 67 
5.10 Conjunto mínimo de itens de configuração em um projeto ágil e os respectivos processos que os produzem. . . . . . . . . . . . . . . . 68

5.11 Exemplo de um esquema de identificação com o conjunto mínimo de itens de configuração exigidos. . . . . . . . . . . . . . . . . . . 68

5.12 Conjunto mínimo de documentos que devem ser produzidos em um projeto ágil e os respectivos processos que os produzem. . . . . . . . . . . . . . . . . 69

5.13 Fatores de qualidade para as metodologias de desenvolvimento ágil (Mnkandla e Dwolatzky, 2006). . . . . . . . . . . . . . . . . 71

5.14 Template para o plano de qualidade. . . . . . . . . . . . . . . . 72

5.15 Representação das dependências existentes entre os processos do modelo. . . . . . 73

5.16 EAP criada para o modelo de referência ágil. . . . . . . . . . . . . . . . . 74

5.17 Exemplo de um MDS que representa o sequenciamento de atividades (Project Management Institute, 2004) . . . . . . . . . . . . . . . . . . . 80

5.18 MDS que representa o sequenciamento das atividades que ocorrem nos processos do modelo de referência ágil . . . . . . . . . . . . . . . . . 82

6.1 Cronograma para a realização da avaliação. . . . . . . . . . . . . . . . . . . 89

6.2 EAP que representa o estado no qual o processo de desenvolvimento realizado pelo CI foi encontrado. . . . . . . . . . . . . . . . . . . . . . 90 90

6.3 Plano de implantação de gerência de configuração. . . . . . . . . . . . . . . . . . 94

6.4 Relatório de Apresentação de Resultados. . . . . . . . . . . . . . . . . . . . . 95 


\section{Lista de Tabelas}

5.17 Atividades necessárias para a produção dos produtos de trabalho . . . . . . . . . 75

6.1 Mapeamento da dimensão de processos do Modelo de Avaliação para os processos realizados pelo CI. . . . . . . . . . . . . . . . . . . 87

6.2 Processos avaliados e pontuações dos atributos de processo. . . . . . . . . . . . 91

B.1 Modelo de nível de capacidade de processo. . . . . . . . . . . . . . . 116 


\subsection{Contextualização}

A engenharia de software pode ser vista como um processo, composto de atividades e tarefas, que abrange todos os aspectos da produção de software. Ela auxilia no desenvolvimento/evolução do software, fazendo com que sua construção seja realizada dentro de determinado custo, tempo, escopo e qualidade (da Rocha et al., 2001).

Os processos de construção de software tradicionalmente utilizados, conhecidos como metodologias tradicionais ou "pesadas", são geralmente aplicados em situações onde os requisitos do sistema são estáveis e requisitos futuros são previsíveis. Tais processos possuem, como uma de suas características, o alto custo para realizar alterações e correções. Nessa forma de desenvolvimento, o software é todo planejado e documentado antes de ser implementado (Fowler, 2005).

Como alternativa às metodologias tradicionais, surgem as metodologias ágeis. Essa nova forma de desenvolvimento visa a construção de software de forma rápida e consistente. Entre outros aspectos, essa abordagem sugere a existência de equipes pequenas e multidisciplinares, prazos de entrega curtos e freqüentes e ambientes de desenvolvimento dinâmicos, onde a criatividade e inovação são características imprescindíveis. Tais metodologias possibilitam a realização de alterações e correções dos requisitos de forma rápida e com baixo custo (Rodrigues et al., 2005; dos Santos Soares, 2004).

Alguns conceitos envolvidos com metodologias ágeis diferem das metodologias tradicionais. Segundo Rising (Rising, 2002): 
[..] Algumas características das metodologias tradicionais entram em conflito com as atitudes ágeis. Por exemplo, a idéia de que a maior qualidade do processo acarreta a maior qualidade do produto não é bem aceita pela comunidade ágil. A controvérsia está, na verdade, na importância do processo.

Nas metodologias tradicionais, o foco está voltado para os processos. Segundo Pressman, em (Pressman, 2006), um processo de software pode ser definido como

[..] uma seqüência coerente de práticas que objetiva o desenvolvimento ou evolução de sistemas de software. Estas práticas englobam as atividades de especificação de requisitos, projeto, implementação e testes e caracterizam-se pela interação de ferramentas, pessoas e metodologias.

Os adeptos das metodologias tradicionais acreditam que a melhoria e a definição do processo utilizado tem influência direta no aumento da qualidade dos produtos (Corrêa et al., 2004; lawrence Pfleeger, 2004).

Por outro lado, nas metodologias ágeis, o enfoque deixa de ser os processos e passa a ser as pessoas. Essa mudança de enfoque aumenta a importância das pessoas no processo de desenvolvimento, porém, os processos continuam a existir. Um aspecto importante é que a interação entre os membros da equipe de desenvolvimento e a atitude deles é de suma importância para essas metodologias. Segundo Rodrigues, em (Rodrigues et al., 2005), esses aspectos são os maiores determinantes do grau de sucesso de um projeto.

Para um processo ser considerado ágil, ele deve realizar um conjunto de tarefas e seguir disciplinadamente um conjunto de regras, definidas pela metodologia. O não cumprimento dessas premissas, muitas vezes, fazem com que um processo deixe de ser ágil para tornar-se "caótico". Portanto, o termo "ser ágil" não significa negligenciar as atividades de engenharia de software, e sim praticá-las de forma diferente da tradicional.

Em resumo, as metodologias de desenvolvimento, ágeis e tradicionais, visam organizar o processo de desenvolvimento e evitar que o mesmo torne-se caótico. O fato é que não existe metodologia perfeita. A cada situação é preciso analisar qual é a metodologia mais adequada e que trará maiores benefícios ao projeto. Nesse sentido, as organizações que trabalham com desenvolvimento de software tendem a procurar a metodologia que mais se adeque às suas necessidades. O objetivo principal das empresas é a realização de um processo com qualidade, para que possam produzir software de qualidade.

Nesse ponto entram os modelos de referência. Os modelos de referência são importantes por auxiliarem no direcionamento do processo a ser realizado e, com isso, podem assegurar a produção de software de qualidade, através de um processo de qualidade.

Um modelo de referência bastante conceituado é o modelo contido na norma ISO/IEC 15504. Esse modelo é utilizado para avaliar processos de software, com o intuito de orientar um processo de melhoria ou determinar sua capacidade. A norma permite a identificação de fraquezas e riscos do projeto, possibilitando um direcionamento para a melhoria (ISO/IEC, 2003a). 
A aplicação do processo de avaliação especificado pela norma ISO/IEC 15504, basendo-se em características das metodologias ágeis de desenvolvimento, pode tornar possível a definição do que é um processo de desenvolvimento ágil e direcionar um processo de desenvolvimento para torná-lo ágil.

\subsection{Objetivos}

O objetivo deste trabalho é apresentar uma proposta de um modelo de referência para o desenvolvimento ágil de software. O modelo objetiva servir para direcionar um processo de desenvolvimento de software, com o intuito de torná-lo ágil.

Para atingir os objetivos pretendidos, foram analisadas seis das principais metodologias ágeis de desenvolvimento presentes no manifesto ágil, além de técnicas de documentação, gerência e planejamento. A análise permitiu a identificação de características existentes nas metodologias e direcionou a criação do modelo referência.

O modelo criado é composto por dezesseis processos que descrevem todo o ciclo de desenvolvimento. Os processos são descritos segundo seus objetivos, atividades, tarefas e resultados esperados.

\subsection{Organização}

Este trabalho encontra-se dividido da seguinte forma. No Capítulo 2 são introduzidos os conceitos que envolvem as metodologias ágeis, suas origens, contexto e algumas metodologias ágeis existentes são descritas. Além disso, algumas características que envolvem a documentação ágil são apresentadas. No Capítulo 3 são abordadas algumas técnicas e trabalhos existentes sobre gerência e planejamento de projetos. No Capítulo 4 é descrita a estrutura de uma avaliação de processos proposta pela norma ISO/IEC 15504. No Capítulo 5 são apresentadas algumas características encontradas nos estudos realizados sobre as metodologias ágeis e um modelo de referência para o desenvolvimento ágil de software é proposto. No Capítulo 6 é apresentada a avaliação de um processo de desenvolvimento de software, baseada na norma ISO/IEC 15504. A avaliação realizada teve o intuito de determinar a capacidade do processo avaliado e direcioná-lo para torná-lo ágil. Por fim, no Capítulo 7 são apresentadas algumas conclusões deste trabalho e sugestões de trabalhos futuros. 


\section{Metodologias ágeis de desenvolvimento de software}

\subsection{Considerações Iniciais}

As empresas desenvolvedoras de software procuram, cada vez mais, uma forma eficiente de fazer software com qualidade. As metodologias tradicionais de desenvolvimento propõem-se a realizar essa tarefa, porém, são mais adequados a sistemas onde os requisitos são relativamente previsíveis. Para sistemas onde os requisitos são variáveis, diz-se que as metodologias ágeis produzem um melhor resultado, já que as mudanças de requisitos, dentro dessas metodologias, são mais bem aceitas (dos Santos Soares, 2004).

As metodologias ágeis propõem formas de desenvolvimento iterativo, disciplinado e criativo, visando entregas rápidas e freqüentes de versões. Isso possibilita ao cliente ter e fornecer feedback com freqüência, permitindo o aumento de sua satisfação, já que ele passa a ter melhor visão do andamento do projeto e do sistema em desenvolvimento (Williams e Cockburn, 2003).

Este capítulo tem o objetivo de descrever os conceitos envolvidos nessa nova forma de desenvolvimento, citando algumas das principais metodologias ágeis existentes atualmente. Na Seção 2.2 são descritos os principais conceitos que envolvem as metodologias ágeis. Na Seção 2.3 a metodologia Extreme Programming é descrita. Na Seção 2.4 a metodologia Scrum é descrita. Na Seção 2.5 a metodologia Feature Driven Development é descrita. Na Seção 2.6 a metodologia Dynamic System Development Method é descrita. Na Seção 2.7 a metodologia Adaptive Software Development é descrita e na Seção 2.8 a metodologia Crystal é descrita. Na Seção 2.9 são apre- 
sentadas algumas informações que envolvem a produção de documentação de forma ágil. Por fim, na Seção 2.10 são apresentadas algumas considerações finais sobre este capítulo.

\subsection{Conceitos envolvidos com as metodologias ágeis de desenvolvimento}

O desenvolvimento de software é realizado, muitas vezes, de forma descontrolada. Para orientar o processo de desenvolvimento, surgiram os conceitos da engenharia de software. Essa disciplina objetiva possibilitar maior controle e planejamento da construção de software, permitindo que os produtos de software sejam construídos com qualidade.

As metodologias de desenvolvimento tradicionais possibilitam a produção de software eficientemente e com qualidade, tornando o processo de desenvolvimento mais previsível (Fowler, 2005). No entanto, essas metodologias geralmente são burocráticas e exigem, na maioria das vezes, prazos longos para a entrega de uma primeira versão do software em construção. Tais características têm sido alvo de críticas em relação a essas metodologias.

Esse fato incentivou pesquisadores a elaborarem alternativas a essa forma de desenvolvimento. Em 2001, alguns pesquisadores reuniram-se em uma conferência para discutirem semelhanças e diferenças existentes entre suas abordagens para o desenvolvimento de software. Como resultado dessa conferência surgiu o Manifesto para desenvolvimento ágil de software. O manifesto define, além de outras coisas, quatro valores chave de toda metodologia ágil, descritos como segue em (Beck et al., 2001a):

[...] Através deste trabalho, nós valorizamos:

Indivíduos e interações sobre processos e ferramentas.

Software funcional sobre documentação abrangente.

Colaboração do cliente sobre negociação de contratos.

Responder a mudanças sobre seguir um plano.

Ou seja, apesar dos itens da direita serem importantes, nós valorizamos mais os da esquerda.

Uma das características comuns encontradas nas abordagens dos diversos pesquisadores, e que faz parte do manifesto ágil, é a priorização da satisfação do cliente. Para alcançá-la, é necessário que produtos de software intermediários sejam entregues em prazos curtos e de forma contínua. Tais produtos devem ser funcionais, permitindo que os clientes aprendam com sua utilização. Isso possibilita a identificação de necessidades não especificadas e resulta em requisitos mais claramente definidos e em um produto de software final mais próximo das necessidades reais do cliente. Os produtos de software podem também ser utilizados como a primeira medida do progresso de projeto (Beck et al., 2001b; Highsmith, 1999).

Para aumentar ainda mais a satisfação do cliente, é necessário que pessoas com domínio do negócio sejam parte integrante da equipe de desenvolvimento. A existência desse elo entre o cliente 
e os desenvolvedores é imprescindível para o sucesso do projeto. A troca de informações precisa ser intensa. Nessa troca de informações, é importante que os clientes identifiquem e definam necessidades e prioridades e passem essas informações para os desenvolvedores; os quais devem apontar riscos, alternativas, etc. Quanto mais rápida essa troca for realizada, mais rápido será o processo de construção e mais próximo da satisfação do cliente o projeto estará.

Essa proximidade do cliente ao ambiente de desenvolvimento geralmente estimula a mudança de requisitos. Mudanças de requisitos ocorrem em qualquer projeto, independente da metodologia utilizada. Os custos dessas mudanças podem variar, de acordo com a metodologia utilizada e situação corrente do projeto.

Nas metodologias tradicionais, o custo referente a essas mudanças pode variar, dependendo da etapa de desenvolvimento que ela ocorre. Quanto mais tarde a mudança for identificada, maior será o custo de sua realização. Uma das causas é o fato do cliente poder observar o funcionamento do produto apenas na versão final do software (ou no caso de metodologias evolutivas, na primeira versão, que pode ser demorada). Ao testar a versão, o cliente passa a ter uma visão mais clara de suas necessidades. Uma alteração de requisitos nessa etapa de desenvolvimento pode ser inviável.

Nas metodologias ágeis, a mudança de requisitos não gera grandes transtornos, pois a proximidade do cliente à equipe de desenvolvimento, as entregas contínuas e em períodos curtos de tempo, possibilitam que requisitos sejam identificados de forma dinâmica, permitindo mudanças rápidas e sem grandes custos (Martin Fowler, 2006).

As alterações são fatos freqüentes nessas metodologias e a equipe de desenvolvimento deve estar preparada para realizá-las. A resposta rápida a essas mudanças é importante nesse tipo de desenvolvimento.

A equipe de desenvolvimento também deve estar apta à auto-organização. A equipe é responsável por definir arquitetura, estrutura e projeto do software a ser desenvolvido. A melhor combinação dos elementos da equipe, e suas funções dentro da mesma, deve ser definida e respeitada pela própria equipe. Quando o processo de construção possui essas características, diz-se que é um processo adaptativo (Martin Fowler, 2006).

A equipe de desenvolvimento ainda deve promover reuniões regulares, a fim de acompanhar o andamento do projeto e manter todos os membros da equipe cientes dos problemas encontrados e das tarefas realizadas. Em intervalos de tempo pré-determinados, os envolvidos reúnem-se e discutem as dificuldades encontradas, as tarefas realizadas e as tarefas previstas até a próxima reunião. Segundo Rising (Rising, 2002), as reuniões devem ser curtas e devem servir apenas para levantar problemas, não para resolvê-los. A resolução deve ser discutida mais tarde, com a participação apenas dos envolvidos.

As características existentes nas metodologias ágeis ressaltam a importância das pessoas envolvidas em um processo de desenvolvimento, que utiliza os princípios ágeis. Como já mencionado, as metodologias ágeis enfocam as pessoas e não os processos. Contudo, é importante que os indivíduos envolvidos sejam capacitados o suficiente para exercer as diversas funções existentes 
nessas metodologias. Além disso, os indivíduos devem estar motivados, com ambiente e apoio necessários para realizarem seus papéis com a qualidade e a agilidade necessárias.

No projeto a ser desenvolvido, o trabalho deve ser feito de forma simples e objetiva. O desenvolvedor deve implementar exatamente o que o cliente deseja, nem mais nem menos, da forma mais simples possível (Kuhn e Pamplona, 2004). A simplicidade é um dos princípios dessas metodologias, pois agiliza o processo de desenvolvimento, fazendo com que o desenvolvedor produza somente o que foi solicitado.

Para que uma metodologia possa ser considerada ágil, ela precisa aplicar os princípios descritos no manifesto ágil (Beck et al., 2001b). As metodologias que aplicam esses princípios, de diferentes formas, visam a produção de software de forma eficiente e que satisfaça o cliente, possibilitando a entrega dentro do prazo e custo previstos.

Nas seções seguintes são apresentadas algumas metodologias ágeis que compõem o manifesto ágil e são descritas algumas técnicas e trabalhos realizados sobre a documentação ágil.

\subsection{Metodologia Extreme Programming}

A metodologia Extreme Programming, mais conhecida como XP, é uma metodologia ágil que prima pela qualidade do software construído e pela satisfação do cliente. Criado por Kent Beck e Ward Cunningham, o XP é um refinamento de práticas aplicadas em numerosos projetos nos anos 80 e evoluídas, nos anos 90, para uma abordagem de desenvolvimento adaptativo e orientado a pessoas (Fowler, 2005; Goldman et al., 2004). Alguns praticantes definem XP como a prática e a perseguição da simplicidade, aplicada ao desenvolvimento de software (Kuhn e Pamplona, 2004).

Esta metodologia é composta por seis etapas: Exploração, Planejamento, Iterações para versões, Produção, Manutenção e Morte (Paulk, 2001; da Silva et al., 2005). O ciclo de vida de XP é apresentado na Figura 2.1.

$\mathrm{Na}$ fase de Exploração os clientes descrevem as estórias (recursos) que precisam ser desenvolvidas. Em paralelo, iniciam-se atividades de familiarização da equipe de desenvolvimento com ferramentas, tecnologias e práticas a serem utilizadas durante o projeto. São realizados testes com a tecnologia escolhida e possibilidades de arquitetura do sistema são exploradas através de protótipos. Essa fase pode durar de semanas a alguns meses, dependendo do grau de familiaridade dos desenvolvedores com a tecnologia.

Após essa fase, inicia-se a fase de Planejamento, onde as estórias descritas são priorizadas e as estórias que farão parte da primeira pequena versão do software são definidas. Para isso, os desenvolvedores fazem uma previsão do esforço necessário para desenvolver cada estória e definem um plano para a construção da primeira versão. Geralmente o tempo de construção da primeira versão é menor do que dois meses.

A construção das versões do software acontece na fase de Iterações para as versões. Nessa fase são realizadas várias iterações antes da primeira versão. A primeira iteração cria uma arquite- 


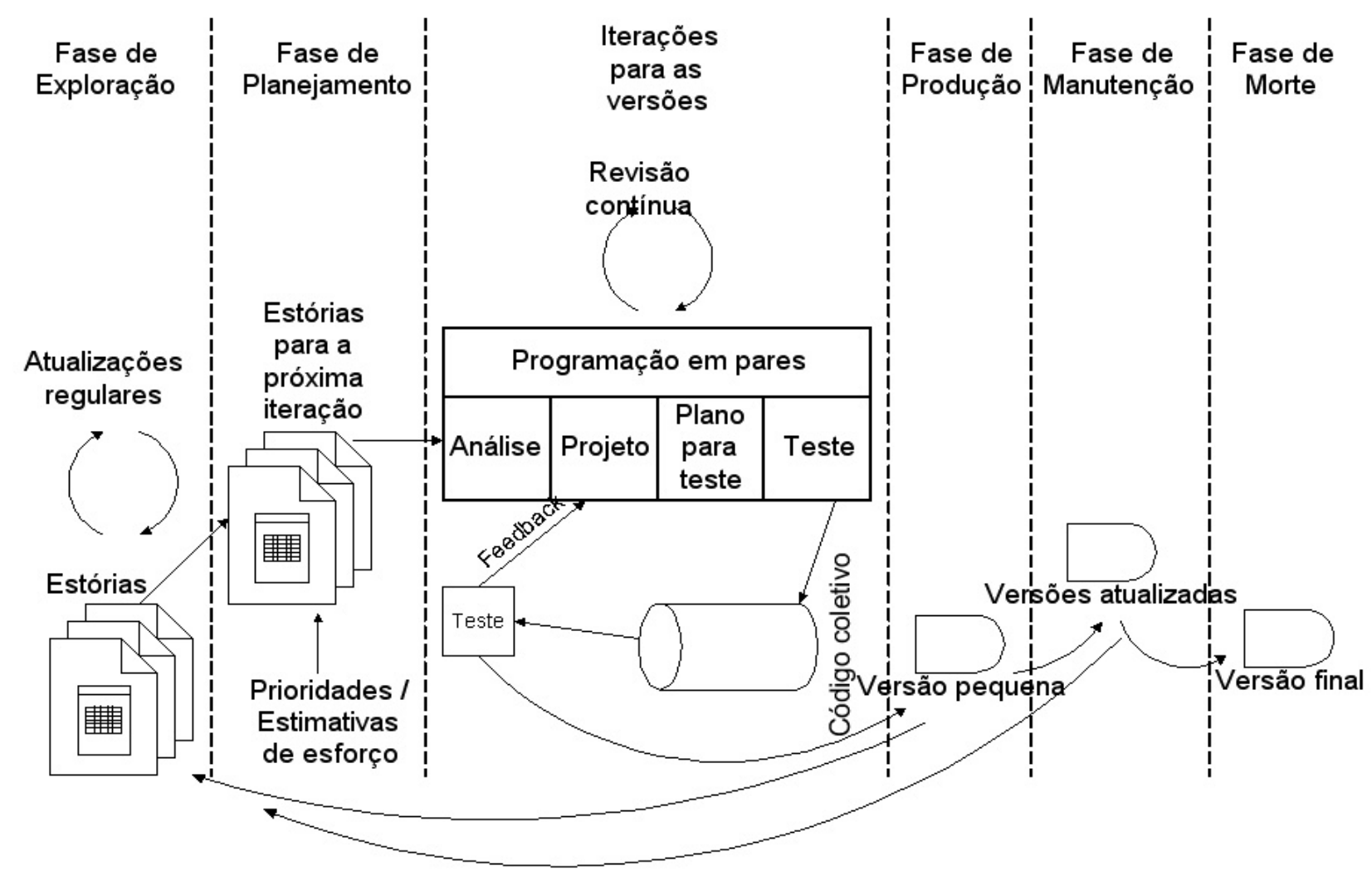

Figura 2.1: Ciclo de vida de Extreme Programming (Abrahamsson et al., 2002)

tura para o sistema. Em seguida, os clientes selecionam as estórias a serem desenvolvidas durante a próxima iteração. Ao final de cada iteração são realizados os testes funcionais criados pelos clientes e, após a última, o sistema é colocado em produção (Tijman, 2003).

Antes que a versão seja entregue para o cliente, são realizados testes extras e a performance do sistema é checada. Essa é a fase de Produção, quando podem ser encontradas novas necessidades de alteração e, nesses casos, decidi-se se as necessidades farão parte da versão corrente ou de uma futura versão. Durante essa fase, as iterações podem ter a necessidade de serem realizadas em períodos mais curtos (de uma a três semanas). As sugestões e idéias adiadas são documentadas para uma posterior implementação, ou seja, para a fase de manutenção.

A fase de Manutenção inicia-se depois da entrega da primeira versão. Nessa fase é preciso dar manutenção ao software que está em funcionamento e prosseguir com as várias iterações que promovem o desenvolvimento de novas versões. Por esse motivo, essa fase pode reduzir a velocidade de desenvolvimento e introduzir novas pessoas a equipe, podendo inclusive, mudar a estrutura da mesma.

O ciclo de vida de XP termina com a fase de Morte. Essa fase inicia-se quando restam poucas estórias a serem implementadas e a atenção volta-se para a documentação. Quando não existem mais alterações na arquitetura, projeto e código do software, a documentação do software é finalmente produzida, encerrando-se o ciclo de vida. 
As cinco fases do ciclo de vida XP foram concebidas em conjunto com quatro valores e doze práticas. Os valores são as diretrizes de XP. Eles definem as atitudes que devem ser seguidas por todos os integrantes da equipe e as principais prioridades da metodologia. As práticas definem o conjunto de atividades que devem ser realizadas pela equipe.

Um dos valores de XP envolve o conceito de troca de informações intensa entre o cliente e o desenvolvedor. Conhecido como feedback, esse valor baseia-se no aprendizado do cliente e do desenvolvedor, por meio da utilização do produto de software.

O feedback possibilita que o cliente conduza o desenvolvimento do produto, estabeleça prioridades e informe o que é realmente importante. Do lado do desenvolvedor, ofeedback permite que ele aprenda o que o cliente deseja, possibilitando que ele aponte riscos, alternativas, estimativas, etc. Com isso, a metodologia pretende proporcionar uma minimização de falhas na interpretação das necessidades e prioridades estabelecidas pelos clientes.

Para que o feedback seja efetivo, é necessário que haja um mecanismo eficaz de comunicação entre os envolvidos. A comunicação é outro valor empregado por XP. De acordo com a metodologia, esse valor deve ser empregado da forma mais direta possível, preferivelmente face-a-face.

Aliada ao feedback e a comunicação estão a simplicidade e a coragem. Os desenvolvedores devem produzir o que o cliente precisa da forma mais simples possível e devem ter coragem para cumprir as premissas definidas pela metodologia. Algumas dessas premissas são: permitir que o cliente defina prioridades, expor código a todos os membros da equipe, propor contratos de escopo variável, fazer os desenvolvedores trabalharem em pares, integrar o sistema diversas vezes ao dia, entre outros.

Os valores de XP, somados as suas práticas, formam um conjunto de boas atitudes que compõem sua filosofia (Kuhn e Pamplona, 2004).

Dentro dessa filosofia destacam-se as reuniões regulares e a programação em pares. As reuniões propiciam o entendimento de problemas enfrentados por elementos da equipe e a disseminação de informações sobre o andamento do projeto. A programação em pares possui uma produtividade semelhante a da programação sozinha, porém, a maior qualidade do código que ela produz gera facilidades na manutenção e outros ganhos a médio e longo prazo (Kuhn e Pamplona, 2004; Williams et al., 2000).

Em resumo, a metodologia XP trabalha em função de estórias, que são descritas e priorizadas pelo cliente. No momento de sua implementação, a equipe pode fazer estimativas de custo de cada estória e planejar as release ${ }^{1}$ e as iterações. Ao final de cada iteração é obtido um feedback do cliente e, com isso, pode-se planejar a próxima iteração. Ao final de cada ciclo é entregue uma versão funcional do software e o planejamento para o próximo release é realizado.

A metodologia dá grande importância para testes e integração. Antes de qualquer implementação, um teste automatizado deve ser codificado, para que imediatamente após a codificação de

\footnotetext{
${ }^{1}$ Um realease é um conjunto de iterações responsável pela produção de uma versão do software
} 
alguma funcionalidade, ela possa ser validada (Tijman, 2003). Além disso, XP sugere que a integração do sistema seja feita várias vezes ao dia, evitando complicações na hora de integrar as novas estórias desenvolvidas.

\subsection{Metodologia SCRUM}

A metodologia Scrum foi aplicada pela primeira vez, por Ikujiro Nonaka e Hirotaka Takeuchi, no desenvolvimento de um jogo, em 1986. Após a experiência da primeira aplicação e baseados em suas idéias e pesquisas na área de teoria de processos, realizadas em colaboração com a $D u$ Pont Advanced Research Facility, Nonaka e Takeuchi formularam e apresentaram a metodologia Scrum, pela primeira vez, para o grupo de gerenciamento de objetos (Object Management Group) em 1995. Em 2001, Ken Schwaber e Mike Beedle lançaram um livro intitulado Agile Software Development with Scrum, que descreve a metodologia Scrum por completo (Schwaber e Beedle, 2004).

A metodologia segue o princípio de que o processo de desenvolvimento é imprevisível. Ela define que o processo é um conjunto solto de atividades que combinam conhecimento, ferramentas e técnicas, com o melhor que a equipe de desenvolvimento pode oferecer. Dentro do conjunto de atividades estão algumas atividades de gerência de riscos e do próprio processo, que são necessárias para um desenvolvimento satisfatório (Scrum Web Site, 2005).

Scrum utiliza algumas práticas que são importantes para o controle e planejamento do projeto, o Backlog e Sprint. O Backlog é uma lista de atividades, já priorizadas e estimadas, a serem realizadas durante o projeto. Dentre essas atividades, algumas são selecionadas para serem realizadas dentro de um período de tempo determinado. Tal período é chamado de Sprint e o conjunto de atividades selecionadas é denominado Backlog do Sprint. A cada Sprint, todas as atividades pertencentes ao Backlog do Sprint são realizadas, resultando em uma nova versão do produto, que deve ser entregue ao cliente.

Um Sprint inicia com uma reunião de planejamento, onde é definido o Backlog do Sprint. Nenhuma atividade pode ser adicionada durante um Sprint, exceto atividades originadas de uma previamente selecionada. Quando alguma atividade externa é identificada, ela é adicionada ao Backlog. Ao final de cada Sprint, uma reunião de revisão é realizada. Qualquer modificação ou novidade é adicionada ao Backlog e poderá ser incluída em futuros Sprints.

Com os termos Backlog e Sprint já definidos, é possível entender o ciclo de vida de Scrum, que é composto de Pré-jogo, Desenvolvimento e Pós-jogo. O ciclo de vida de Scrum é apresentado na Figura 2.2.

As atividades realizadas na fase Pré-jogo podem ser divididas em duas outras fases. Na fase de Planejamento são realizadas definições sobre o sistema que será desenvolvido. Uma Lista de Backlog do Produto é criada contendo todos os requisitos conhecidos. Os requisitos são priorizados e uma estimativa de custo de desenvolvimento é feita para cada um. A lista de Backlog do produto 


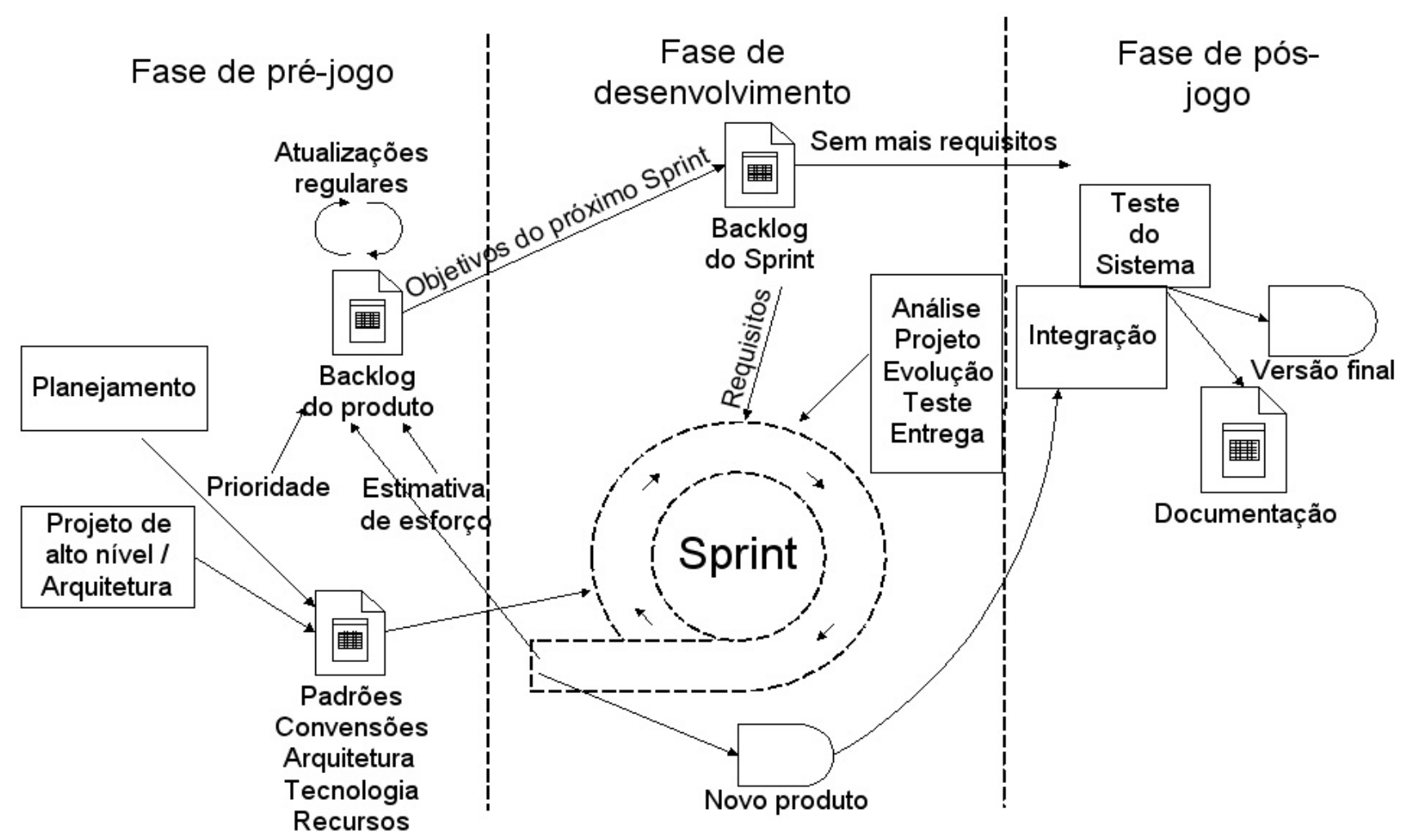

Figura 2.2: Ciclo de vida de Scrum (Abrahamsson et al., 2002)

é constantemente atualizada com novos requisitos, novo detalhamento de requisitos pré-existentes, novas prioridades, novas estimativas. Ainda na fase de planejamento é feita a definição da equipe, de ferramentas e de outros recursos. A avaliação e controle de riscos também são realizadas nessa etapa, que define também as necessidades de treinamento. Em todos os Sprints, o Backlog do produto é revisto pela equipe de desenvolvimento para planejar o próximo Sprint.

$\mathrm{Na}$ outra fase do pré-jogo, a fase de Arquitetura, um projeto de alto nível, incluindo a arquitetura, é concebido basendo-se no Backlog do produto. Esse projeto é revisto frente aos objetivos de implementação e decisões são tomadas basendo-se nessa revisão. Além disso, são realizados planos preliminares sobre o conteúdo das versões a serem produzidas.

Terminada a fase de pré-jogo, inicia-se o desenvolvimento das versões. Nessa fase, chamada de Desenvolvimento ou Fase de jogo, inicia-se a parte ágil de Scrum. Também conhecida como caixa-preta, essa fase é caracterizada por diferentes aspectos técnicos e ambientais, que podem ser alterados durante o processo e são observados e controlados através de várias práticas durante o Sprint.

Por fim, a fase do Pós-jogo concentra-se no encerramento do projeto. Essa fase inicia-se quando acredita-se que não existam mais requisitos a serem desenvolvidos. O sistema é preparado para ser entregue e são realizadas as tarefas de integração, testes do sistema e documentação.

A metodologia Scrum sugere a existência de equipes multidisciplinares e auto-organizáveis. Para isso, os indivíduos que compõem as equipes não possuem funções fixas. Todos os membros 
devem ter uma visão global do projeto e a equipe deve ser capaz de auto-organizar-se para atingir os objetivos pretendidos (Figueiredo e Sanches, 2005).

Aliado a isso, Scrum define alguns papéis e práticas que garantem o controle e a visibilidade do projeto, sem deixar de lado a liberdade dos desenvolvedores. Os papéis e práticas ajudam a identificar o que será desenvolvido e quais serão os responsáveis por quais atividades. Isso auxilia no controle e planejamento das iterações e no controle do andamento do projeto.

Em resumo, a metodologia Scrum pode ser definida como sendo iterativa, incremental e adaptativa e focada no gerenciamento e controle de projetos. Um aspecto importante dessa metodologia é a estabilidade dos requisitos durante uma iteração. Isso significa que novos requisitos não são incluídos em uma iteração em andamento. Nesses casos, eles são registrados e adicionados em futuras iterações.

\subsection{Metodologia Feature Driven Development}

A metodologia Feature Driven Development (FDD) foi criada por Jeff De Luca e Peter Code e obteve o reconhecimento de seu nome em 1997 (Khramtchenko, 2004). FDD é uma metodologia ágil voltada à entregas freqüentes de versões do software. Para isso, utiliza-se de um processo de desenvolvimento incremental e enfatiza mecanismos de controle e divulgação de informações sobre o projeto (Feature-driven Development Web Site, 2006).

O que diferencia FDD da maioria das metodologias ágeis é o fato de ser altamente escalável. FDD pode ser aplicada a projetos com equipes numerosas, podendo chegar a centenas de indivíduos. Para suportar a escalabilidade, a metodologia enfatiza a criação inicial de um modelo global do projeto e de uma lista de funcionalidades.

FDD consiste de cinco processos sequenciais, durante os quais o sistema é projetado e construído. Os processos que compõem a parte iterativa de FDD são: Projetar por funcionalidade e Construir por funcionalidade. São esses processos que apóiam o desenvolvimento ágil, pois proporcionam uma adaptação rápida às alterações tardias dos requisitos e das necessidades de negócio. O ciclo de vida de FDD é apresentado na Figura 2.3 (Abrahamsson et al., 2002).

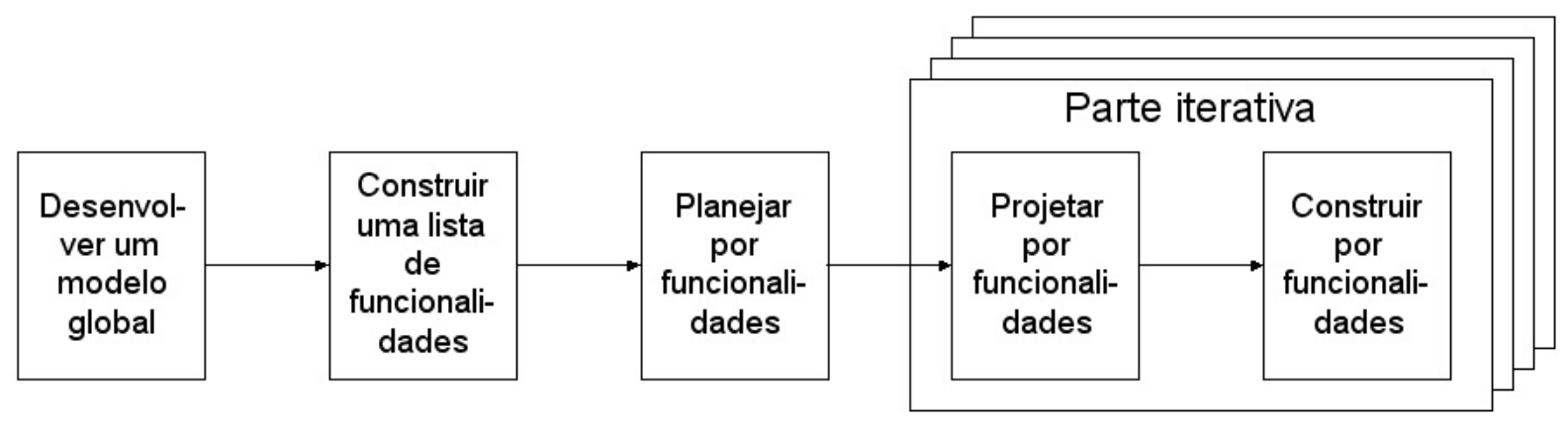

Figura 2.3: Ciclo de vida de Feature Driven Development (Abrahamsson et al., 2002) 
Um projeto FDD inicia-se com o Desenvolvimento de um modelo global. Nessa fase, os especialistas do domínio direcionam a atenção para o escopo, o contexto e os requisitos do sistema a ser desenvolvido. Alguns documentos podem ser produzidos, além da visão global do projeto, para auxiliar a elicitação dos requisitos.

A visão global pode ser dividida em pequenas áreas, separadas por domínio, que são analisadas por pequenas equipes, também divididas por domínio, que propõem um modelo para cada pequena área. Ao final dessa fase, um modelo global do projeto é produzido.

Os documentos produzidos nessa fase e o modelo global do projeto possibilitam o início da fase Construir uma lista de funcionalidades. As funcionalidades descobertas são agrupadas em pacotes de trabalho, que são implementados durante as iterações. A etapa de descoberta é um processo crítico. A qualidade de realização dessa etapa define a precisão na qual o progresso do processo será rastreado e o grau de manutenibilidade do código (Khramtchenko, 2004).

Após a etapa de descoberta das funcionalidades, inicia-se o planejamento. Nessa fase, chamada Planejar por funcionalidades, são criados planos de alto-nível, nos quais os pacotes de trabalho criados nas fases anteriores são priorizados e, em seguida, são associados a desenvolvedores individuais, que passam a ser chamados de proprietários da classe.

O proprietário da classe é o criador da funcionalidade. Em FDD, cada funcionalidade implementada tem um único criador. Isso significa que caso alguma funcionalidade precise sofrer alguma alteração, esta deve ter, necessariamente, a participação de seu criador. Acredita-se que essa prática identifica, de forma mais precisa, as consequências das alterações (Khramtchenko, 2004).

Ao final do planejamento, inicia-se a parte iterativa de FDD, composta pelas fases Projetar por funcionalidades e Construir por funcionalidades. A partir desse ponto, um pacote de trabalho é selecionado a cada iteração e o proprietário da classe escolhe os membros da equipe que irão desenvolvê-los. Em FDD, uma iteração pode variar de poucos dias a até duas semanas e em cada iteração podem existir várias equipes projetando e construindo suas funcionalidades concorrentemente.

O processo iterativo inclui atividades como: inspeção do projeto, codificação, testes unitários, integração e inspeção do código. Ao final das iterações, as funcionalidades produzidas são promovidas a Produto Principal, enquanto iniciam-se novas iterações com novos pacotes de trabalho selecionados. A parte iterativa de FDD é apresentada na Figura 2.4.

Em função do desenvolvimento por funcionalidades, é necessário que haja uma forte integração do sistema. O FDD sugere que haja sempre uma versão com qualidade de produção disponível. Para isso, mecanismos eficientes de gerência de configuração e de integração constante devem permitir que versões anteriores do software sejam recuperadas facilmente, possibilitando que uma versão funcional esteja sempre disponível. 


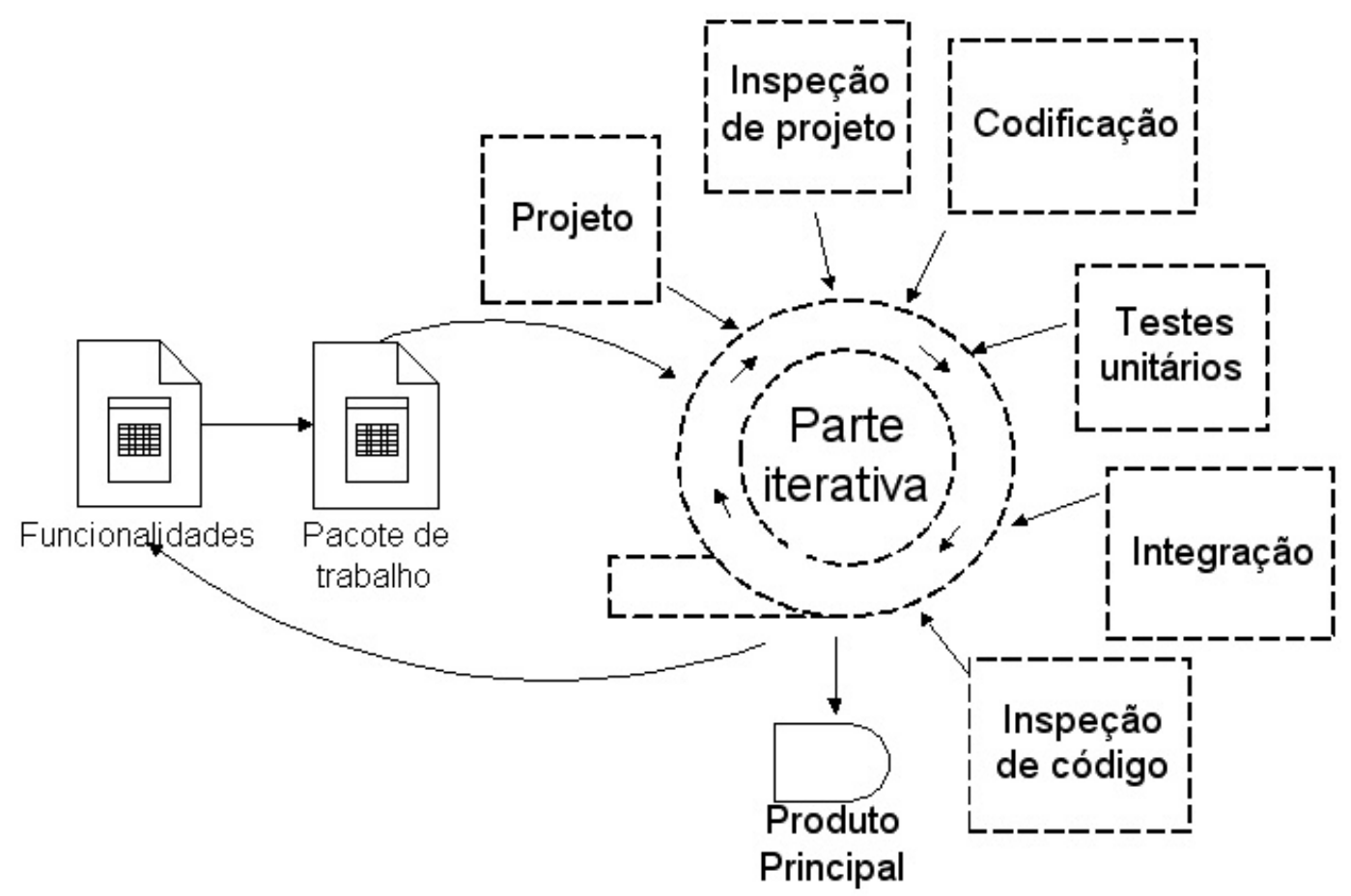

Figura 2.4: Parte iterativa de Feature Driven Development (Abrahamsson et al., 2002)

A última versão funcional serve como demonstração do estado do projeto. Para complementar esse indicador, a metodologia considera a utilização de técnicas que apresentem o progresso e planejamento do projeto, basendo-se nas funcionalidades produzidas.

\subsection{Metodologia Dynamic System Development Method}

A metodologia Dynamic System Development Method (DSDM) teve início em um consórcio, iniciado em janeiro de 1994, formado por dezesseis organizações. O objetivo do consórcio era criar um modelo independente para o desenvolvimento rápido de aplicações. Com os estudos realizados, chegou-se ao modelo de desenvolvimento chamado Dynamic System Development Method. Desde então, o modelo vem sendo desenvolvido e refinado, mas os conceitos básicos têm permanecido (Dynamic System Development Method Web Site, 2006a).

O modelo criado tem como objetivo principal as entregas rápidas de soluções de qualidade, dentro do prazo e orçamento previstos. As entregas rápidas e o trabalho em equipe compõem sua filosofia. Os autores da metodologia acreditam que o conhecimento do cliente em relação ao negócio, aliado ao conhecimento técnico da equipe de desenvolvimento e às entregas rápidas de versões de software, aumentam a satisfação do cliente e resultam no desenvolvimento de produtos de qualidade. O modelo segue o princípio de que nenhum sistema é construído perfeitamente na primeira tentativa (Dynamic System Development Method Web Site, 2006b). 
A idéia principal por traz de DSDM é que ao invés de definir um conjunto de funcionalidades e então ajustar tempo e recursos para desenvolvê-la, a metodologia define tempo e recurso disponíveis e então ajustam o conjunto de funcionalidades a serem desenvolvidas. A técnica sugerida para implementar essa idéia é denominada Timeboxing.

Para que o desenvolvimento siga o fluxo proposto pela metodologia, DSDM divide o ciclo de desenvolvimento em cinco fases: Estudo de viabilidade, Estudo do negócio, Iteração para um modelo funcional, Iteração para o projeto e construção e Implementação. O ciclo de vida de DSDM é apresentado na Figura 2.5.

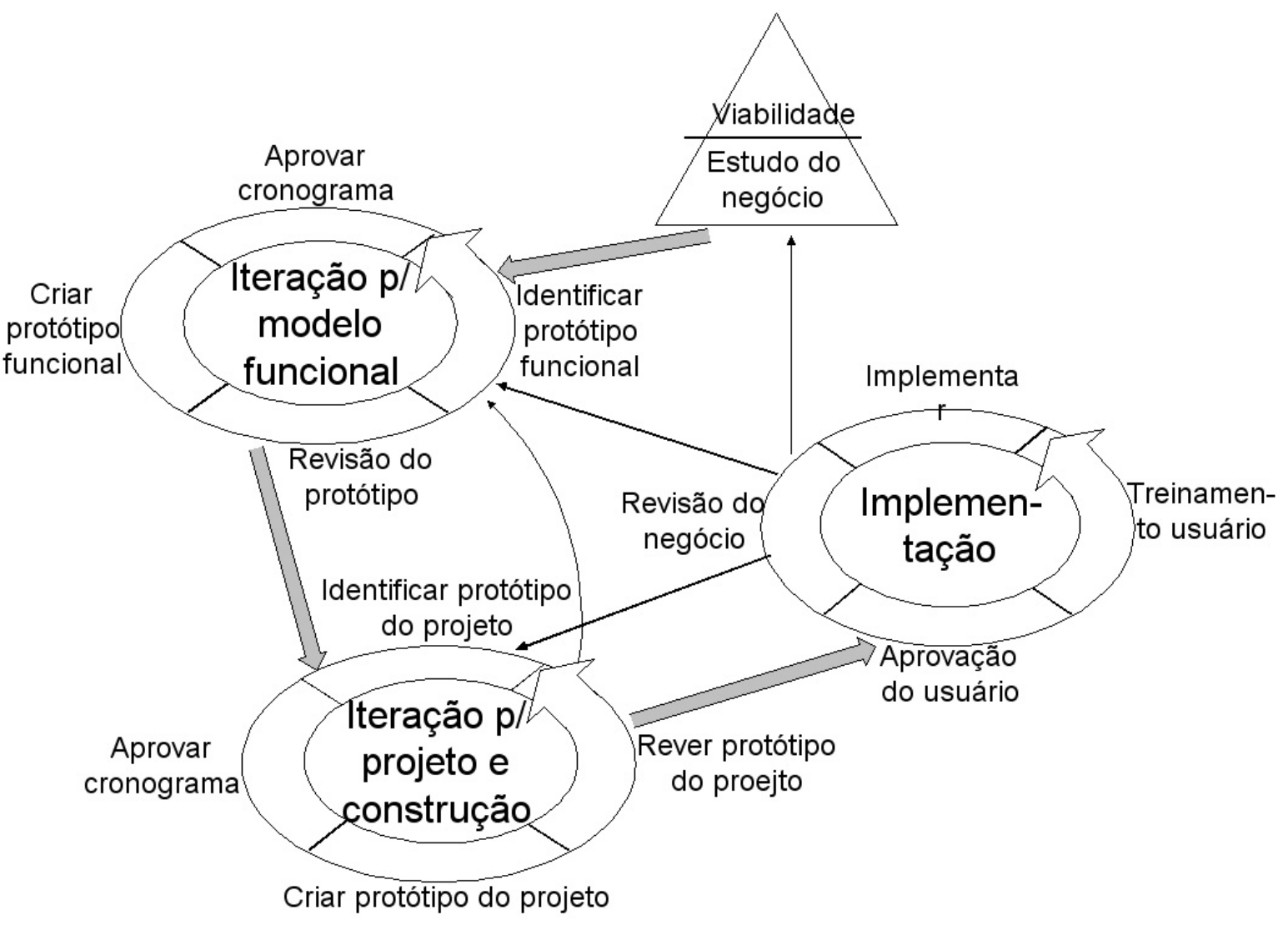

Figura 2.5: Ciclo de vida de Dynamic System Development Method (Abrahamsson et al., 2002)

Antes de iniciar um projeto utilizando essa metodologia, é importante realizar um Estudo de viabilidade, que é a fase inicial de DSDM. O estudo avalia se o tipo de projeto e, principalmente, se as pessoas envolvidas e as características organizacionais são adequadas ao uso da metodologia. Em paralelo, são realizadas análises técnicas e de riscos, podendo ser utilizados protótipos para validar requisitos técnicos. Essa fase dura poucas semanas e produz um relatório de viabilidade e um plano resumido de desenvolvimento.

O próximo passo é a realização de um Estudo do negócio. Essa fase analisa os aspectos tecnológicos e de negócio. Especialistas de domínio ajudam a definir as prioridades de desenvolvimento e as pessoas chave para o negócio, as quais podem auxiliar o esclarecimento de possíveis dúvidas sobre os requisitos de negócio. Nesse ponto, pode-se produzir alguns documentos como 
Diagrama de Entidades e Relacionamento, Modelo de Objetos, Arquitetura do Sistema, Plano de Prototipação e Plano para a Gerência de Configuração.

Após essa etapa, inicia-se a primeira fase iterativa e incremental de DSDM, a fase Iteração para o modelo funcional. Em todas as iterações é realizado um planejamento do conteúdo a ser desenvolvido e os resultados são analisados para a próxima iteração. Nesse passo são analisados códigos, são produzidos protótipos e são realizados testes continuamente. A experiência adquirida é utilizada para avaliar o modelo de análise, que junto com o protótipo, forma o modelo funcional, produzido nessa etapa.

Além do modelo funcional, essa fase produz uma lista priorizadas das funcionalidades que serão entregue ao final da iteração (a técnica de priorização das funcionalidades é conhecida como Moscow), um documento contendo informações referentes a revisões feitas sobre os protótipos, uma lista de requisitos não-funcionais e um documento descrevendo os riscos envolvidos no projeto.

Na próxima fase, chamada de Iteração para o projeto e construção, é onde o sistema é essencialmente construído. Ao final dessa fase tem-se uma versão funcional, com o conjunto de requisitos estipulados, testados e funcionando.

Por fim, o software passa do ambiente de desenvolvimento para o ambiente de produção. Nessa fase, denominada Implementação, é realizado um treinamento dos usuários e a versão do software é entregue. A fase de implementação produz ainda um manual do usuário e um relatório de revisão do projeto, que pode servir como orientação para as próximas iterações.

Além das cinco fases de desenvolvimento, DSDM descreve alguns princípios e atitudes que são esperadas dos envolvidos no processo de desenvolvimento e onze papéis que descrevem as funções existentes dentro do mesmo (Dynamic System Development Method Web Site, 2006b). Os princípios baseiam-se no trabalho em equipe, nas entregas freqüentes, na colaboração e cooperação dos envolvidos e nas alterações de requisitos.

Um dos princípios diz que todas as alterações, durante o desenvolvimento, devem ser reversíveis. Isso leva a necessidade de um controle de versões eficiente. Outro princípio aponta para a coragem dos usuários em tomar decisões, incentivada por técnicas sugeridas pela metodologia. Esse princípio possibilita a adaptação rápida a novos requisitos e, consequentemente, leva a um desenvolvimento rápido e eficiente.

Em resumo, DSDM visa o desenvolvimento de software de forma incremental e iterativa, onde a cada iteração uma nova versão do software é produzida. Aliado a isso, a metodologia foca o desenvolvimento no trabalho em equipe e em usuários motivados. Cada indivíduo dentro da equipe tem uma ou várias funções a desempenhar, o que faz com que a cooperação e a colaboração sejam essenciais para que um projeto obtenha sucesso (Dynamic System Development Method Web Site, 2006b). 


\subsection{Metodologia Adaptive Software Development}

Adaptive Software Development (ASD) é uma metodologia de desenvolvimento de software, criada por Jim Highsmith, que dá grande importância às pessoas, aos resultados e à máxima colaboração entre cliente e equipe de desenvolvimento. Para criar essa metodologia, Highsmith baseou-se na teoria Complex Adaptive System (CAS), que defende a idéia de que o desenvolvimento de software é semelhante ao mercado econômico. De acordo com a teoria CAS, a economia é caracterizada pela alta velocidade e alto grau de mudanças, e pela maior importância do aumento dos resultados sobre a otimização (Highsmith, 1999; Dirk Riehle, 2006).

Semelhantemente a economia, a ASD é uma metodologia direcionada para o desenvolvimento rápido e com alto grau de mudanças, e caracteriza-se por dar maior importância aos resultados sobre processos. Além disso, a ASD prioriza o entendimento sobre a documentação, a colaboração sobre o controle e a adaptação sobre a otimização (Highsmith, 2000; Jim Highsmith, 2006).

Essa metodologia abandona o ciclo de vida estático Planejar-Projetar-Construir para dar lugar ao ciclo de vida Adaptive (um ciclo dinâmico), que compreende as fases Especulação-ColaboraçãoAprendizagem. O ciclo de vida Adaptive, apresentado na Figura 2.6, é um ciclo dedicado a aprendizagem contínua e direcionado a aceitar mudanças constantes, a executar reavaliações e a estimular intensa colaboração entre desenvolvedores, testadores e clientes.

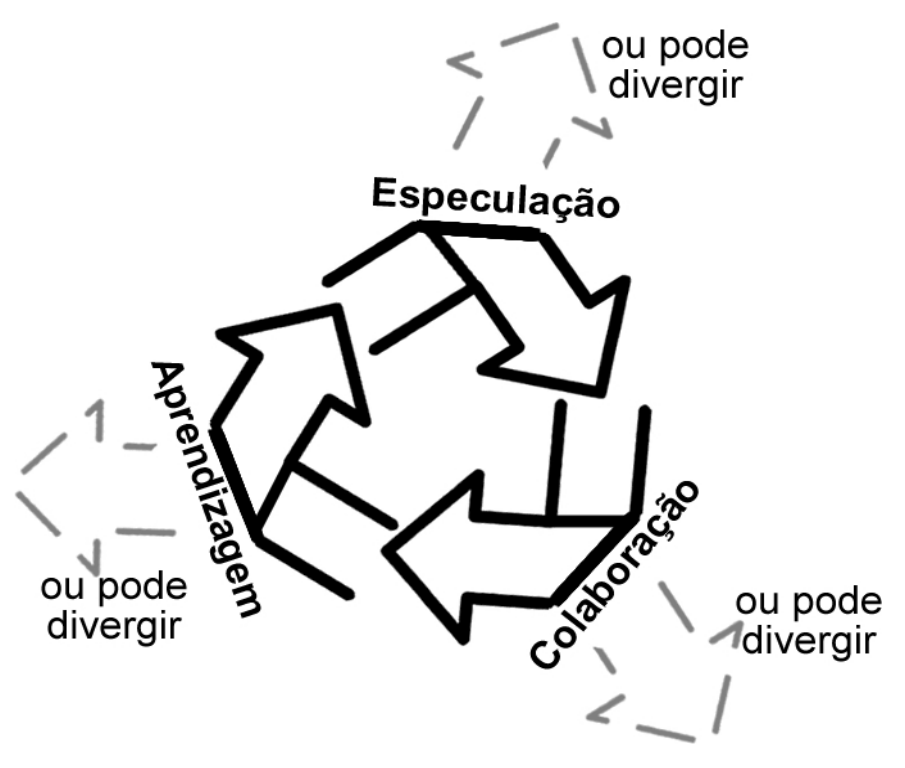

Figura 2.6: Ciclo de vida Adaptive (Highsmith, 2000)

Dentro do ciclo, a fase de Especulação reconhece a incerteza natural dos problemas e encoraja a exploração e experimentação; a fase de Colaboração reforça a necessidade do alto nível de troca de informações e ajuda a elucidar requisitos e reduzir ou solucionar problemas técnicos; a fase de Aprendizagem força a realização de atividades de reavaliação, possibilitando uma melhoria para a próxima iteração. 
O ciclo Adaptive tem seis características básicas: foco na missão, desenvolvimento baseado em componentes (resultados), iterações, timebox, análise de riscos e tolerância a mudanças. Essas características ajudam a direcionar todo o processo de desenvolvimento, incluindo o planejamento para cada iteração, os resultados esperados em cada iteração e a análise de riscos e previsão de mudanças para o próximo ciclo.

As três fases (Especulação-Colaboração-Aprendizagem) servem para proporcionar uma visão geral do ciclo de desenvolvimento. Cada fase pode ser dividida em porções menores, o que possibilita um melhor entendimento do ciclo e das atividades envolvidas em cada uma das fases. Na Figura 2.7 são apresentadas as fases do ciclo Adaptive e as atividades que as compõem.

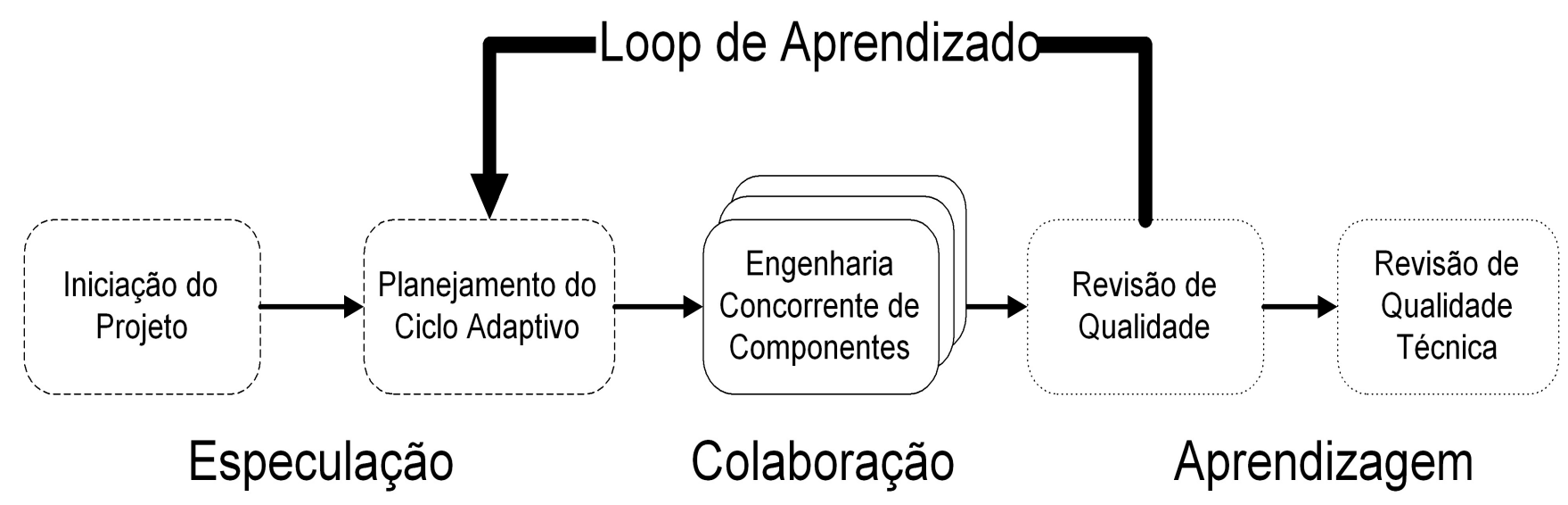

Figura 2.7: Atividades do ciclo de vida Adaptive (Highsmith, 2000)

A atividade de iniciação determina os objetivos e missões do projeto. Para isso, essa fase procura entender e documentar restrições, estabelecer a organização e os responsáveis pelo projeto, identificar e esboçar os requisitos, realizar uma estimativa inicial do escopo e tamanho do projeto e identificar os principais riscos. Feito isso, determina-se as funcionalidades que serão desenvolvidas durante o projeto. As funcionalidades definidas são baseadas nos resultados obtidos nas atividades anteriores.

O próximo passo é determinar o número total de ciclos do projeto e associar um timebox a cada um deles. O tamanho dos ciclos é determinado pelo cronograma geral e pelo grau de incerteza do projeto.

Cada ciclo é definido com um tema (ou objetivo) e possui marcos que ajudam a manter a visibilidade do projeto e a identificar defeitos e falhas.

Os passos finais dessa fase associam componentes aos ciclos, permitindo que ao final de cada ciclo sejam entregues produtos tangíveis. Além disso, define-se a lista de tarefas a serem realizadas. Nesse ponto, um componente definido pode vir a ser um objetivo de uma determinada tarefa. Atividades que não puderam ser definidas como componentes também são listadas nesse passo, completando assim a fase de Especulação. 
A fase Colaboração é composta pela etapa Engenharia Concorrente de Componentes. Essa etapa trata de assuntos que envolvem os relacionamentos existentes entre os membros da equipe.

As diferentes opiniões existentes devem ser gerenciadas da melhor forma possível. Em projetos de pequeno porte, especialmente onde os membros da equipe encontram-se próximos fisicamente, as diferenças de opiniões podem ser controladas informalmente. No entanto, em projetos de grande porte, é necessário um maior controle sobre esse aspecto. Para minimizar esses problemas, a fase Colaboração sugere a aplicação de algumas técnicas, como a programação em pares, a propriedade coletiva do código, entre outras.

A terceira fase, Aprendizagem, é composta pelas etapas Revisão de qualidade e Revisão de qualidade técnica. De uma forma geral, a aprendizagem é resultado da aplicação de técnicas de revisão de qualidade, que devem ser aplicadas ao final de cada ciclo de desenvolvimento. Existem quatro categorias básicas que devem ser observadas: a qualidade do produto na visão do usuário final; a qualidade do produto na visão técnica; a performance da equipe responsável pelas entregas e as práticas que a equipe utiliza; o estado do projeto.

Obter esse tipo de retorno é fundamental para o sucesso do projeto. É importante destacar que nessa etapa de desenvolvimento, a revisão é feita para possibilitar a aprendizagem para o próximo ciclo, não para descobrir falhas. Falhas são descobertas com a realização de revisões de código, revisões de casos de teste, entre outros, durante o ciclo.

Em resumo, Adaptive Software Development é uma metodologia adaptativa, que prioriza a resposta rápida à mudanças, a entrega de versões, a colaboração e a aprendizagem. Acredita-se que essas características possibilitam o desenvolvimento de software de forma ágil, controlada e com qualidade.

\subsection{Metodologia Crystal}

Crystal é uma família de processos aplicáveis a diferentes tipos de projetos. A idéia de ter múltiplos processos origina-se do fato de existir projetos que exigem diferentes níveis de controle. Projetos pequenos e não críticos podem ser desenvolvidos utilizando-se os processos menos rigorosos de Crystal, enquanto que projetos grandes e mais críticos demandam a utilização de processos mais rigorosos.

Cockburn, em seu livro entitulado Agile Software Development (Cockburn, 2002), compara a família de processos Crystal com um cristal própriamente dito. A base para a comparação está no fato de que um cristal, sob a influência da luz, pode mudar de cor conforme a intensidade. A metodologia Crystal funciona semelhantemente, pois pode adequar-se a criticalidade e tamanho de um projeto, caso esses aspectos variem. Se um projeto aumenta de tamanho ou de nível crítico, mais processos Crystal podem ser adicionados a ele, e vice-versa.

Cada membro da família de processos é marcado com uma cor. Crystal sugere que seja escolhida uma cor apropriada da metodologia para um determinado projeto, de acordo com o nível de 
criticalidade e o tamanho da equipe. Os quatro níveis de criticalidade definidas na metodologia são:

1. Conforto (C)

2. Arbitrário (A)

3. Imprescindível (I)

4. Vital (V)

Uma falha em um projeto do primeiro nível (nível C) pode gerar um desconforto, mas não traz consequências graves. Uma falha em um projeto do quarto nível (nível V) pode ser vital. Desse modo, pode-se dizer que para projetos que exigem menos rigor podem ser aplicados os primeiros níveis e para projetos mais rigorosos, aplica-se os últimos níveis.

Os níveis de criticalidade e os tamanhos de projeto são representados por categorias de projeto, apresentadas na Figura 2.8. Como exemplo, na Figura 2.8, a categoria A6 representa uma equipe de no máximo 6 pessoas que desenvolve um projeto com o nível de criticalidade A (Arbitrário).

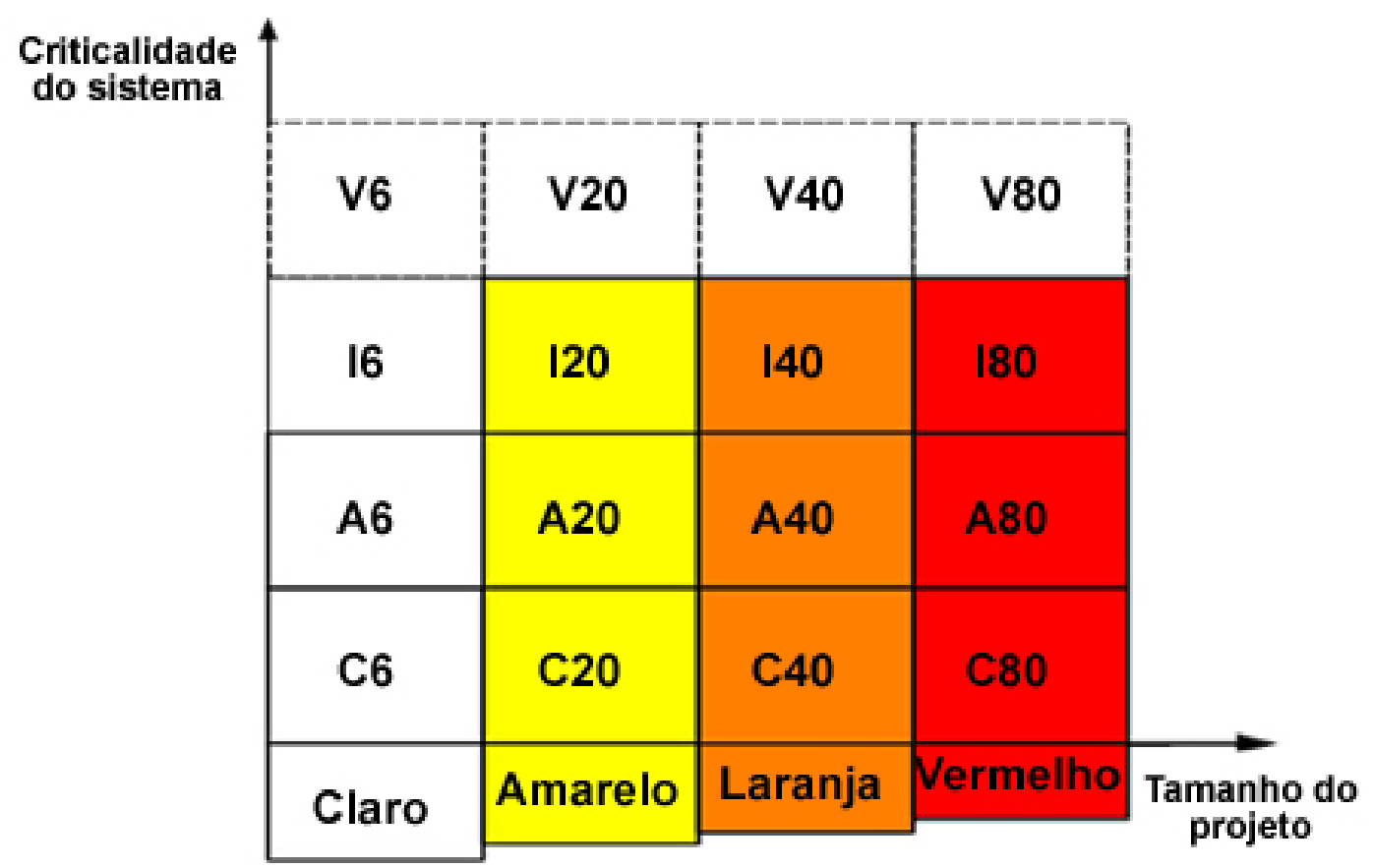

Figura 2.8: Categorias de projeto da metodologia Crystal (Abrahamsson et al., 2002).

Os processos da família Crystal seguem os princípios do desenvolvimento ágil. Eles priorizam a entrega incremental, medem o progresso do projeto através das versões do software, sugerem a existência de testes de regressão de funcionalidades automatizados, direcionam o ambiente de desenvolvimento para a cooperação, sugerem a realização de workshops $^{2}$ para o refinamento de produtos e da metodologia utilizada (realizados no início e no meio de cada incremento).

\footnotetext{
${ }^{2}$ Reuniões regulares realizadas com os envolvidos no projeto. Os envolvidos podem ser clientes, pessoas integrantes da equipe de desenvolvimento, facilitadores.
} 
Um exemplo de um incremento de um projeto que utiliza essa metodologia é apresentado na Figura 2.9. O exemplo considera um projeto com uma equipe formada por mais de 40 membros.

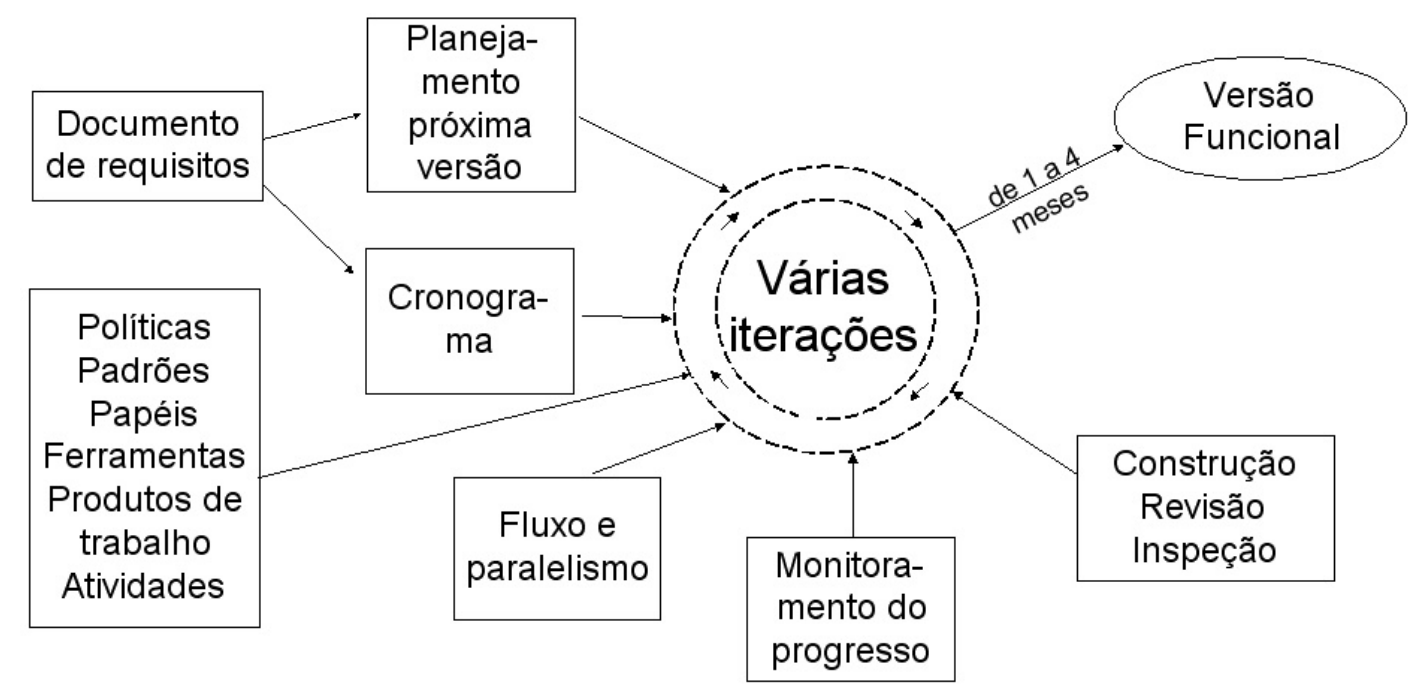

Figura 2.9: Um incremento de Crystal para equipes com mais de quarenta membros (Keith Everette, 2006).

Para auxiliar o desenvolvimento ágil, Crystal sugere a padronização de alguns itens, como as notações, as formatações, as convenções de projeto, as interfaces do usuário, entre outros. A produção de alguns produtos de trabalho também é ressaltada. Alguns exemplos desses produtos são: sequências de versões, modelos comuns de objetos, manual de usuário, casos de teste e migração do código. Segundo Abrahamsson, em (Abrahamsson et al., 2002), a produção do documento de requisitos é necessária em projetos com o nível de criticalidade mais elevado. Em outros casos, uma anotação informal dos requisitos é suficiente.

A metodologia sugere ainda a utilização de ferramentas que auxiliem no controle de versões, na comunicação, na medição do andamento do projeto, na realização de testes e na medição da performance.

Para suportar sua filosofica, a metodologia define um conjunto de práticas que auxiliam no desenvolvimento, porém, permite a utilização de práticas sugeridas por outras metodologias.

Algumas práticas sugeridas por Crystal para aumentar o controle e monitoramento do andamento do projeto são: Staging (define quais requisitos serão desenvolvidos no próximo incremento), Monitoramento do progresso (monitora o progresso do projeto), Revisão e Inspeção (verifica se os requisitos foram desenvolvidos satisfatoriamente), Fluxo e Paralelismo (garante que atividades realizadas durante o ciclo possam ocorrer em paralelo), Holistic Diversity Strategy (permite a criação de estratégias para que grandes equipes tornem-se equipes multifuncionais), Técnica para Refinamento da Metodologia (permite a aprendizagem referente a um incremento, possibilitando um refinamento do processo para o próximo incremento), Parecer do usuário (usuários examinam o que está sendo produzido para garantir que os requisitos foram desenvolvidos corretamente), 
Workshops de Reflexão (workshops realizados antes e depois de cada incremento, com o intuito de identificar possíveis problemas e soluções), entre outras.

Além das práticas, Crystal define diversos papéis que podem ser assumidos pelos membros da equipe. Pode-se citar o patrocinador, o projetista-programador sênior, o projetista-programador e o usuário. Esses quatro papéis podem ser divididos em diversos outros papéis que podem variar de acordo com o projeto. Por exemplo, o projetista-programador pode ser dividido em projetista das classes de negócio, programador, documentador do software e testador unitário. Outros papéis importantes que podem ser atribuídos a alguns dos quatro já citados são: coordenador, especialista do negócio e analista de requisitos.

Em resumo, a família de processos Crystal pode ser classificada como uma metodologia ágil que possui um ciclo de desenvolvimento incremental, altamente adaptável, podendo adequar-se a diversos tipos e tamanhos de projetos, e altamente escalável, podendo trabalhar com equipes grandes ou pequenas.

\subsection{Produzindo documentação de forma ágil}

Todo processo de desenvolvimento de software precisa, em algum momento, produzir documentos que auxiliem no controle, gerência ou construção do software. A documentação é bastante recomendada para permitir que o processo seja controlado e gerenciado de forma efetiva. No entanto, a falta de controle sobre sua produção pode tornar o processo oneroso. (Forward, 2002; Ambler, 2002).

Uma pesquisa realizada sobre a produção e o uso de documentação durante o processo de desenvolvimennto revelou informações importantes.

Sobre a produção de documentos, a pesquisa constatou que os documentos produzidos raramente são atualizados como deveriam, com exceção dos documentos referentes a testes e qualidade. Além disso, a pesquisa revelou que os engenheiros de software (ES) só mantém os documentos atualizados quando esses estão amarrados, de alguma forma, aos processos utilizados durante o desenvolvimento e que eles utilizam e confiam nos documentos que descrevem recursos referentes a projeto e arquitetura do sistema (Elrad et al., 2003).

Sobre a utilização de documentos, os dados obtidos mostraram que apenas $6 \%$ dos entrevistados perdem tempo considerável lendo documentação e $50 \%$ perdem tempo considerável consultando o código fonte. Esses dados ressaltam a importância da boa estruturação, padronização e documentação dos códigos-fonte.

A pesquisa mostrou ainda que a documentação, mesmo desatualizada, tem grande importância no desenvolvimento e que os ES preferem a criação e utilização de documentação simples e poderosas e tendem a ignorar documentações complexas e custosas (custosas referem-se ao tempo necessário para criar e atualizar a documentação). 
Por fim, a pesquisa concluiu que os ES procuram encontrar um caminho para expressar informações em um menor espaço e de forma que permita uma fácil atualização, além de atualizarem somente certos tipos de documentação, os que entendem ser os mais úteis para o desenvolvimento.

Os dados apresentados na pesquisa reforçam a idéia de que a comunicação é essencial para o desenvolvimento e que a documentação pode ter uma importância secundária frente mecanismos de comunicação eficientes.

De acordo com o artigo “Agile Documentation” (Agile Modeling Web Site, 2006), a importância da documentação é secundária frente a importância da comunicação. Os autores do artigo acreditam que deve-se produzir apenas os documentos suficientes para o andamento do projeto e que uma documentação abrangente não garante o sucesso do projeto, pelo contrário, pode aumentar as chances dele falhar. Outro aspecto destacado pelos autores é que antes de criar um documento é preciso analisar se seus benefícios são maiores do que os custos para sua criação e manutenção.

Para a realização de um processo de documentação ágil deve-se considerar quatro razões básicas para a criação de um documento (Agile Modeling Web Site, 2006):

1. Quando os envolvidos no projeto desejam que ele seja criado: A criação de um documento é fundamentalmente uma decisão de negócio.

2. Para definir o modelo contratado. Esses modelos definem a interação do sistema com outros sistemas, ou com sistemas externos. Interações as vezes são bi-direcionais.

3. Para auxiliar na documentação com grupos externos. Esses documentos são geralmente combinados com reuniões periódicas, teleconferências, emails, ferramentas colaborativas, etc.

4. Para processos de auditoria. Nessas situações é importante criar apenas os documentos suficiente para mostrar o trabalho realizado.

Considerando-se essas razões, acredita-se que os documentos que devem ser produzidos em um projeto ágil referem-se a contratos, decisões de projeto, visões de negócio, operações, requisitos e documentos de apoio ao desenvolvimento, ao sistema e ao usuário (Agile Modeling Web Site, 2006): .

Além disso, uma documentação ágil pode ser caracterizada por seis aspectos principais (Agile Modeling Web Site, 2006):

1. Os documentos são produzidos para maximizar o investimento dos envolvidos no projeto

2. Os documentos ágeis são "enxutos" e suficientes

3. Os documentos são coesos e satisfazem o simples propósito definido pelo projeto. Sempre que a criação do documento for duvidosa deve-se parar e repensar sua criação. 
4. Os documentos ágeis descrevem coisas importantes a serem sabidas

5. Os documentos ágeis têm um destinatário específico e facilitam o esforço de trabalho do mesmo.

6. Os documentos ágeis são suficientemente corretos, consistentes e detalhados.

Somando-se a esses aspectos, um processo de documentação ágil precisa possuir estratégias para identificar qual o momento de atualizar os documentos. Sugere-se que os contratos sejam atualizados antes do início do desenvolvimento e que os documentos referentes as partes do sistema (documentos de operações, manual de usuários) devem estar atualizados e prontos para publicação antes ou junto com o próprio sistema. Outra sugestão é que todo documento produzido deve ser atualizado quando o "consumidor" do documento começa a reduzir significativamente sua produtividade por causa da desatualização (Agile Modeling Web Site, 2006).

Outro ponto importante sobre o processo de documentação ágil é saber como aumentar a documentação que é produzida. Uma estratégia para realizar essa tarefa deve verificar quem são os potenciais "consumidores", identificar o que eles desejam e negociar qual o mínimo de informações que eles necessitam. Além disso, é preciso manter nos documentos apenas o suficiente e da forma mais simples possível. A utilização de ferramentas e a produção de conteúdos e modelos simples ajudam nessa tarefa (Agile Modeling Web Site, 2006).

Concluindo, um bom processo de documentação deve sempre priorizar a "comunicação" frente a "documentação". Quando não for possível satisfazer as necessidades através de mecanismos de comunicação, deve-se produzir documentação. No entanto, a documentação deve ser produzida em local adequado (ex: no código fonte, notas em diagramas, etc) e sua criação deve ser adiada o máximo possível. Sempre que possível, os documentos criados devem ser publicados, aumentando o poder da comunicação e reduzindo a necessidade de documentação.

\subsection{Considerações Finais}

Neste capítulo foram abordados os conceitos envolvidos com as metodologias ágeis de desenvolvimento. Os estudos realizados permitiram identificar algumas características presentes nas metodologias ágeis estudadas. Tais características possibilitaram a realização de uma análise que destacou semelhanças e diferenças existentes entre elas.

Os resultados da análise foram úteis para identificar algumas características que são importantes em uma metodologia ágil e, com isso, serviram como base para a criação do Modelo de Referência Ágil. As características, os resultados da análise e o modelo de referência estão apresentados no Capítulo 5. 


\section{Gerência e planejamento de projetos}

\subsection{Considerações Iniciais}

A gestão de projetos é, atualmente, alvo de importantes discussões na área de engenharia de software. Existe um consenso, entre os pesquisadores da área, de que a gestão eficiente de projetos é imperativa na busca pela qualidade de resultados (de Castro Magalhães et al., 2005; Darci, 2003). Dessa forma, realizou-se um estudo sobre as técnicas de auxílio a gestão e planejamento de projetos e alguns assuntos estudados são apresentados neste capítulo.

O capítulo está organizado da seguinte forma. Na Seção 3.2 são apresentadas algumas das técnicas estudadas que acredita-se que podem ser úteis para planejar e gerenciar projetos ágeis e na Seção 3.3 são apresentadas algumas considerações finais sobre este capítulo.

\subsection{Técnicas de auxílio à gestão de projetos}

Com o intuito de padronizar a gestão de projetos, o PMI (Project Management Institute) criou um guia, denominado de PMBOK (Projetc Management Body of knowledge), que objetiva "identificar o subconjunto do conjunto de conhecimentos em gerenciamento de projetos que é amplamente reconhecido como boa prática" (Project Management Institute, 2004). Em outras palavras, o PMBOK visa servir como guia para a gestão de projetos, fornecendo uma visão geral de práticas que, reconhecidamente, trazem bons resultados.

Dentre as diversas técnicas sugeridas pelo guia, destaca-se a Estrutura Analítica de Projetos (EAP). Uma EAP, do Inglês Work Breakdown Structure (WBS), subdivide o trabalho do projeto 
em partes menores e mais facilmente gerenciáveis. O trabalho planejado é dividido em níveis, cada vez mais detalhados, que possibilitam agendá-lo, estimá-lo, monitorá-lo e controlá-lo, além de possibilitar a visualização das entregas do projeto (Kerzner, 2006; Project Management Institute, 2004; Sliger, 2006). Um exemplo de uma EAP é apresentado na Figura 3.1

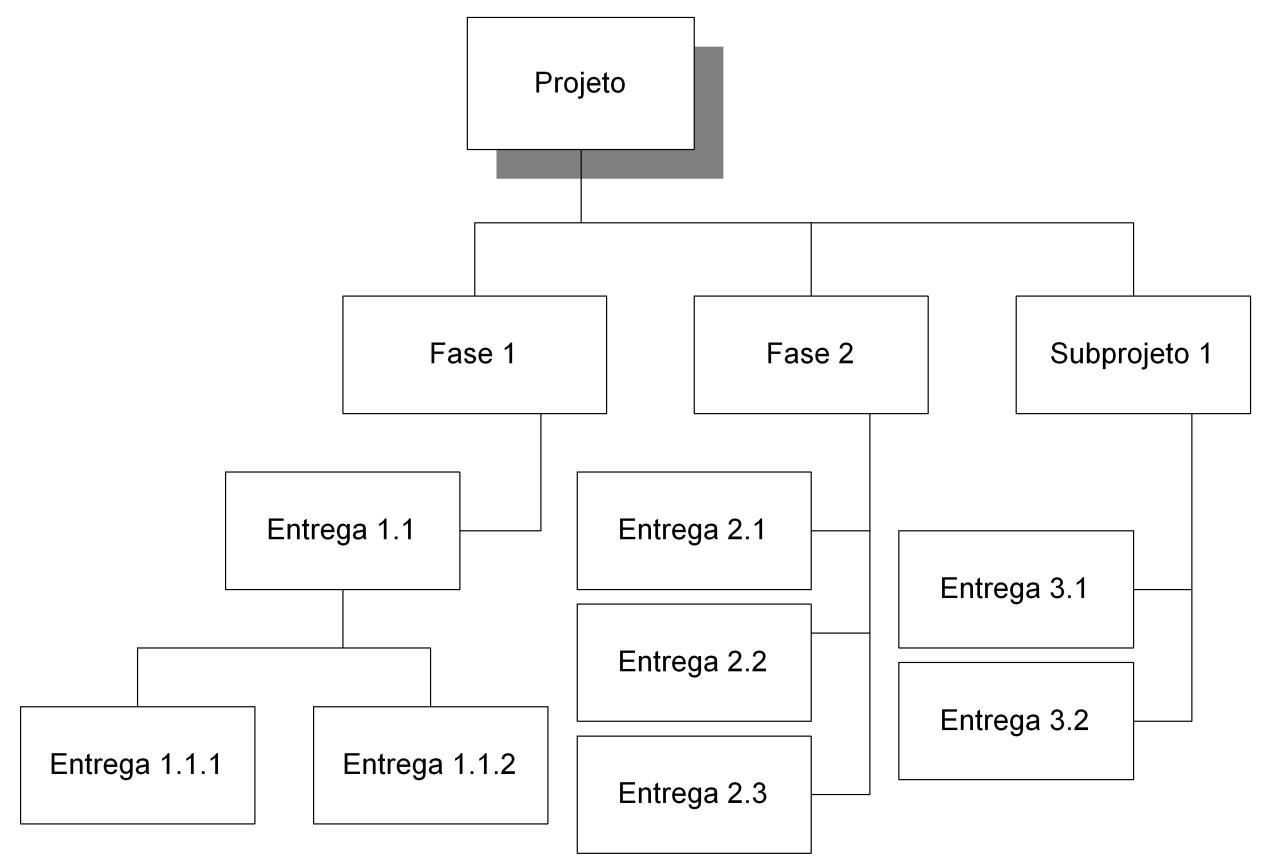

Figura 3.1: Exemplo de uma EAP para um projeto (Project Management Institute, 2004)

Algumas outras técnicas sugeridas pelo PMBOK que merecem destaque referem-se a representação de sequenciamento de atividades. O Método de Diagrama de Precedência (MDP) é um exemplo dessas técnicas. O MDP é um método de construção de um diagrama de rede que usa caixas ou retângulos, chamados de nós, para representar atividades e os conecta por setas que mostram as dependências (Project Management Institute, 2004). Um exemplo de uma MDP é apresentada na Figura 3.2

Outro método bastante utilizado para representar o sequenciamento de atividades é o Método de Diagrama de Setas (MDS). O MDS é um método de construção de um diagrama de rede do cronograma do projeto que usa setas para representar atividades e as conecta nos nós para mostrar suas dependências (Project Management Institute, 2004). Um exemplo de uma MDS é apresentado na Figura 3.3

Essas e outras técnicas fazem o PMBOK ser um guia amplamente reconhecido pelos gerentes de projeto. No entanto, acredita-se que o PMBOK é mais adequado a projetos de grande porte, pois o gerenciamento desses tipos de projetos são geralmente mais complexos e burocráticos. Para outros tipos de projetos, a gestão informal pode ser mais adequada (Kerzner, 2006; de Castro Magalhães et al., 2005).

A gestão informal é uma forma de gerenciamento menos burocrática. Ela reduz a necessidade de documentação e substitui diretrizes formais por listas de verificação menos detalhadas e mais 


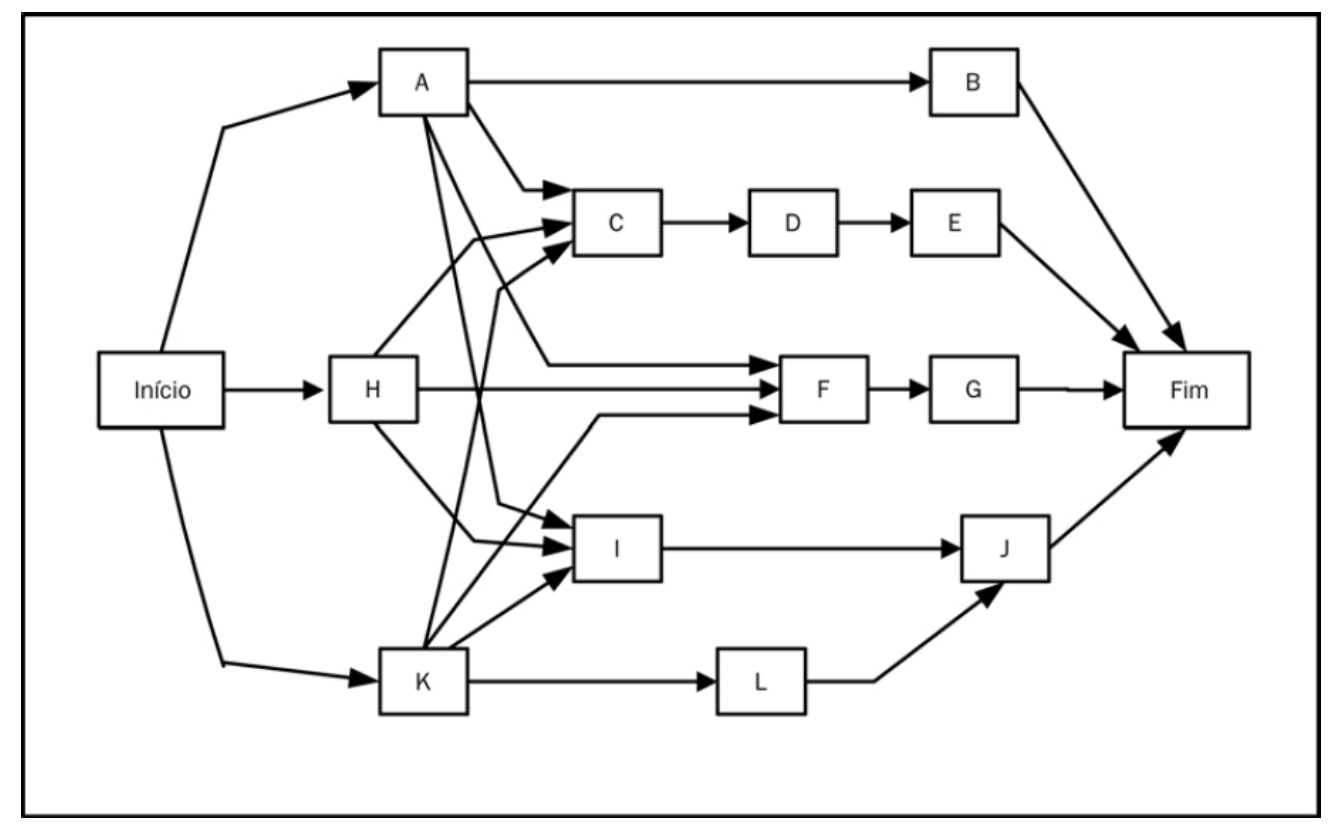

Figura 3.2: Exemplo de um MDP que representa o sequenciamento de atividades (Project Management Institute, 2004)

genéricas. Kerzner, em (Kerzner, 2006), aponta quatro elementos chave para a implementação da gestão informal de projetos: confiança, comunicação, cooperação e trabalho em equipe.

Para Kerzner, a confiança leva os gerentes a acreditarem que os encarregados cumprem suas tarefas de forma adequada, reduzindo a necessidade de documentação; a comunicação, que pode ocorrer vertical ou lateralmente, evita a emissão de relatórios e reuniões longas, os dois grandes obstáculos da gestão informal; a cooperação está relacionada com a atitude dos envolvidos no projeto, é geralmente voluntária e acontece em benefício de todos os envolvidos; o trabalho em equipe permite a troca de idéias, o alto índice de inovações e criatividade, o aumento da confiança e a lealdade entre os membros da equipe.

As características da gestão informal fazem acreditar que esse tipo de gerenciamento pode ser adequado às metodologias ágeis. No entanto, surgiram alguns modelos de gerenciamento diretamente direcionados pelo paradigma ágil.

Um exemplo desses modelos é o Extreme Project Mangement (XPM), que surgiu com o intuito de orientar a gerência e o planejamento de projetos ágeis, através de facilitações à mudanças rápidas e de um planejamento orientado pelos resultados (Catrine Jacobsen, 2001; Charles Ludwig, 2003). Focado, principalmente, na metodologia XP, o XPM guia a gestão de projetos através de um processo de gerenciamento criativo e voltado para os resultados. Segundo Catrine, em (Catrine Jacobsen, 2001; Boehm e Turner, 2005), “O XPM abrange o planejamento e o replanejamento diários. Todas as alterações referentes a contexto, externas e internas (risco, escopo, objetivos, etc), são identificadas e avaliadas diariamente.”.

Outra abordagem para o gerenciamento de projetos ágeis é a Agile Project Management (APM), que caracteriza-se por uma superposição de ordem, pela auto-organização, pela inteligência cole- 


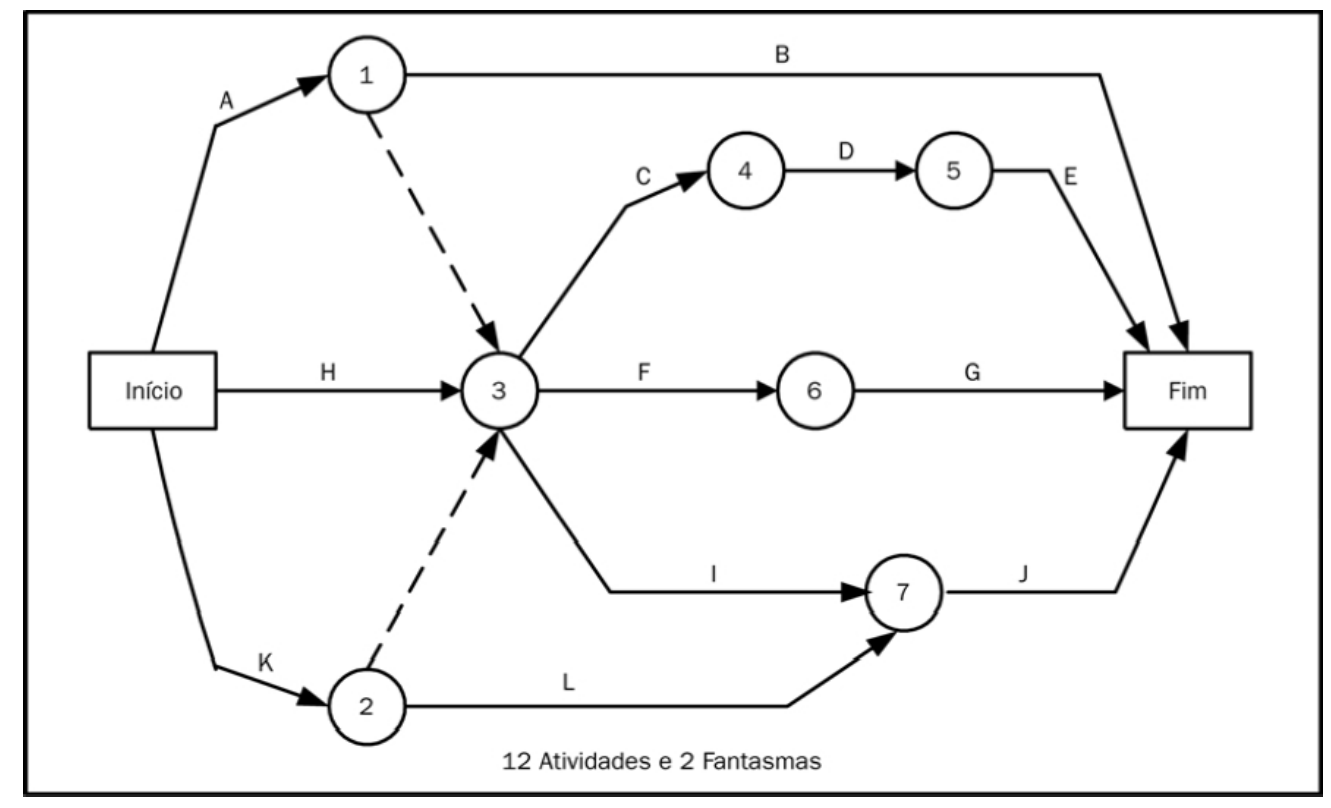

Figura 3.3: Exemplo de um MDS que representa o sequenciamento de atividades (Project Management Institute, 2004)

tiva e pela habilidade notável de adaptar-se a ambientes dinâmicos e complexos (de Castro Magalhães et al., 2005).

Os criadores da APM destacam as habilidades de liderança. Eles acreditam que a liderança deve combinar visão de negócio, habilidades de comunicação, gerência flexível e compreensão técnica com a habilidade para planejar, coordenar e executar.

Como nas metodologias ágeis os clientes definem as prioridades e as equipes auto-organizamse para atingir os objetivos definidos pelos clientes, os gerentes ficam mais livres para agirem como líderes. O principal papel do gerente, nessa abordagem, é direcionar o desenvolvimento, facilitar a colaboração e o trabalho em equipe, definir regras simples, certificar-se de que as regras estão sendo cumpridas e aplicar apenas o controle suficiente para manter a ordem, sem interferir muito na liberdade e criatividade da equipe.

\subsection{Considerações Finais}

Neste capítulo foram abordadas algumas propostas e técnicas utilizadas atualmente para o gerenciamento de projetos. Apesar do PMBOK ser caracterizado por um gerenciamento mais burocrático, as técnicas apresentadas não adicionam muita burocracia ao processo e podem auxiliar no planejamento do projeto.

O conhecimento adquirido com o estudo das metodologias ágeis e das técnicas de gerenciamento serviu como base para a criação de um modelo de referência para o desenvolvimento ágil de software. O modelo criado aborda as características das metodologias ágeis através de proces- 
sos de desenvolvimento e de diagramas que auxiliam no planejamento de projetos. O modelo de referência está apresentado no Capítulo 5. 


$\overline{7}$

O norma ISO/IEC 15504

\subsection{Considerações Iniciais}

A norma ou modelo ISO/IEC 15504 contém um guia para a avaliação de processos de software. Com a avaliação de um processo, pretende-se determinar forças e fraquezas e, com isso, possibilitar um processo de melhoria.

Através das cinco partes que o compõem, o modelo pretende orientar um processo de avaliação completo, inclusive orientando a apresentação de resultados obtidos.

Este capítulo tem o objetivo de descrever o processo completo de avaliação ou determinação da capacidade de processos, conforme especificado na ISO/IEC 15504. Na Seção 4.2 são descritos os objetivos do modelo. Na Seção 4.3 são descritas as cinco partes que compõem o modelo e na Seção 4.4 são apresentadas algumas considerações sobre este capítulo.

\subsection{Introdução ao modelo de referência ISO/IEC 15504}

A busca por qualidade de software cresce a cada dia. Segundo a norma de qualidade ISO/IEC 9126, a qualidade de software pode definida como "A totalidade de características de um produto de software que lhe confere a capacidade de satisfazer necessidades explícitas e implícitas".

Empresas do setor buscam, cada vez mais, formas de garantir que seus produtos de software sejam produzidos com qualidade. Para isso, procuram adequar seus processos de desenvolvimento a modelos de referência reconhecidos, visando uma melhora nos processos e nos produtos de software. 
Para auxiliar a melhoria dos processos de desenvolvimento, a International Organization for Standardization (ISO) e a International Electrotechnical Comission (IEC), orgãos normalizadores com importância internacionalmente reconhecida no setor de software, uniram-se através do projeto denominado Software Process Improvement and Capability dEterminations (SPICE) e criaram o modelo de referência para avaliação de processos chamado ISO/IEC 15504 (ou norma ISO/IEC 15504).

A norma tem por objetivo avaliar processos de software, visando a melhoria contínua e a determinação da capacidade de processos. Para alcançar os objetivos do primeiro enfoque, melhorar continuamente um processo, é preciso caracterizá-lo. Isso é feito com a especificação de quais processos devem ser avaliados e com a determinação da capacidade de cada um deles. Tais informações possibilitam identificar forças e fraquezas do processo, permitindo um direcionamento para a melhoria. O outro enfoque, determinar a capacidade dos processos, permite avaliar um processo frente a um nível de capacidade desejado, a fim de identificar riscos envolvidos no empreendimento de um projeto (ISO/IEC, 2003a).

A norma divide-se em cinco partes que orientam o processo de avaliação. As cinco partes da norma são descritas na Seção 4.3.

\subsection{As cinco partes do modelo de referência ISO/IEC 15504}

O modelo de referência ISO/IEC 15504 é composto por cinco partes que orientam todo o processo de avaliação. As cinco partes são apresentadas na Figura 4.1.

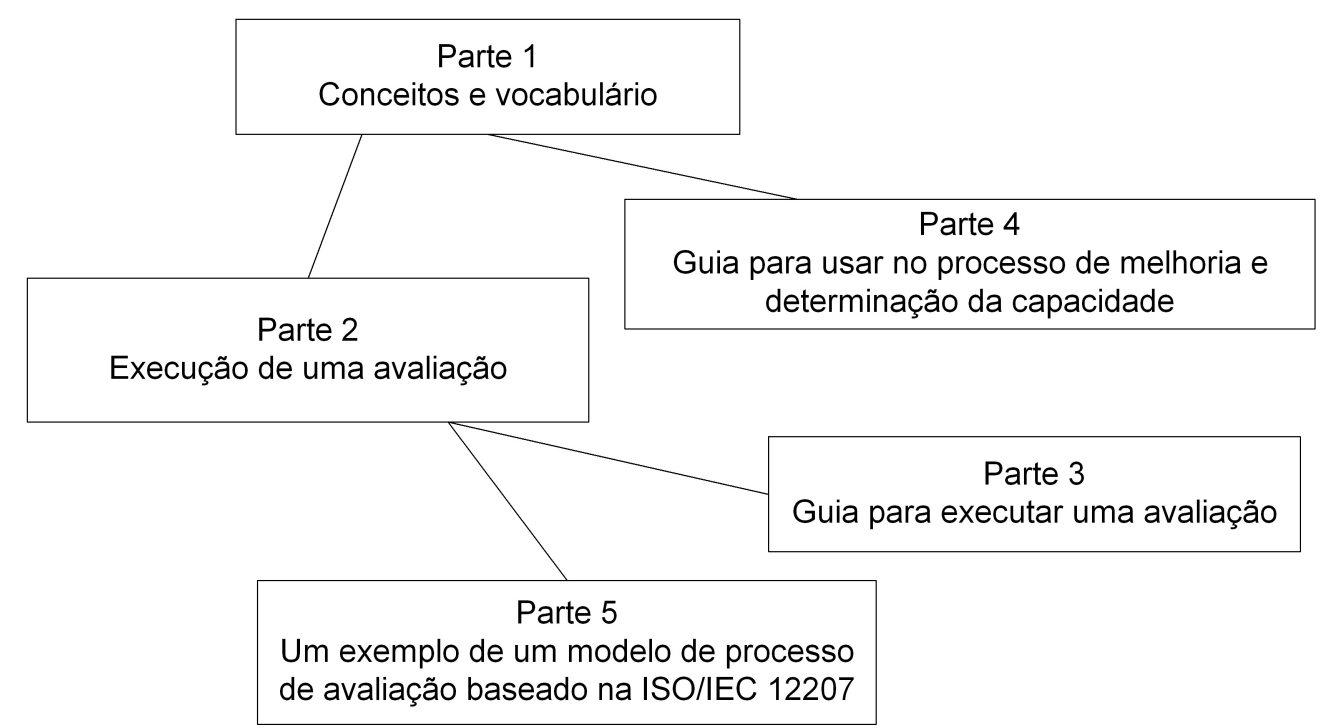

Figura 4.1: Partes que compõem a norma ISO/IEC 15504

A Parte 1 (Conceitos e vocabulário) é o ponto de entrada do modelo. Nela estão descritos os termos e definições utilizados nas outras partes. Além disso, descreve como as partes integram-se e fornece orientação para selecioná-las e usá-las. 
$\mathrm{Na}$ Parte 2 (Execução de uma avaliação) são especificados os requisitos para avaliação de processos. Os requisitos aumentam as chances dos resultados serem objetivos, imparciais, consistentes, repetíveis e representativos.

Além disso, nessa parte é definida uma estrutura de medidas para avaliação da capacidade do processo. A estrutura de medidas é composta por nove atributos de processo, agrupados em seis níveis de capacidade, que definem uma escala ordinal de capacidade. A escala indica o nível de capacidade de um processo e é aplicável aos processos a serem avaliados. A estrutura de medidas é apresentada na Figura 4.2.

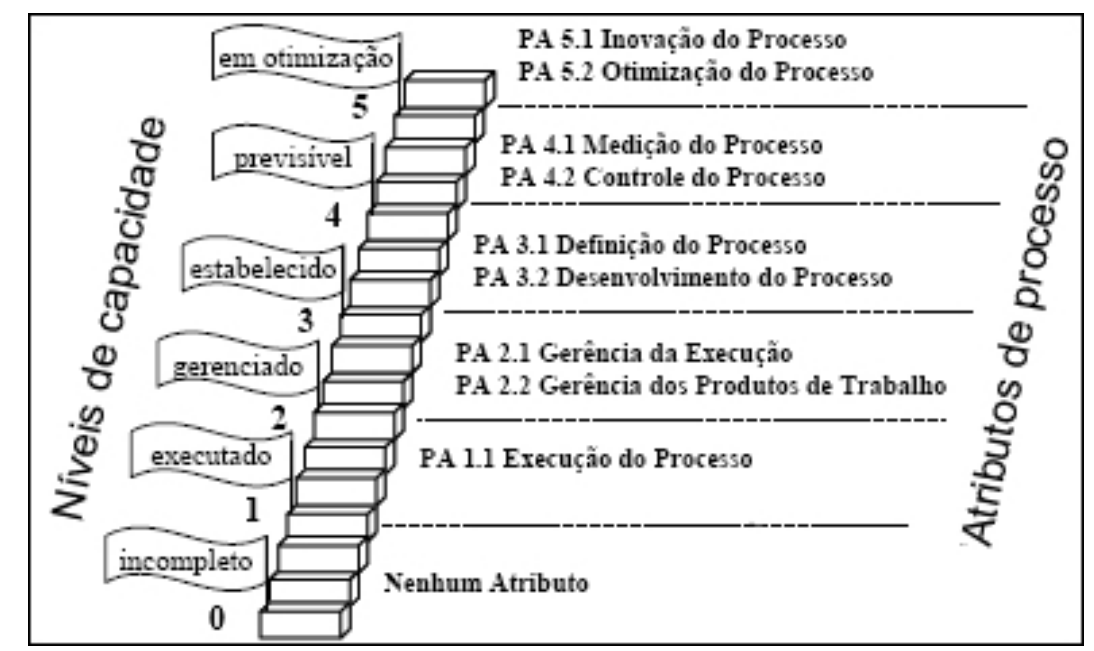

Figura 4.2: Níveis de capacidade e respectivos atributos de processo

Os níveis de capacidade podem variar de 0 a 5. Um nível de capacidade determina a situação no qual o processo se encaixa. Em outras palavras, um nível de capacidade define o grau de aderência do processo avaliado ao processo que está servindo de referência para a avaliação. Na Figura 4.3 são apresentados os níveis de capacidade definidos pela norma ISO/IEC 15504 e as respectivas situações que representam.

Para o entendimento da capacidade do processo, tanto no contexto de melhoria como no contexto de determinação da capacidade, algumas informações referentes ao processo avaliado são coletadas. Essas informações permitem determinar a extensão com que o processo atinge seus objetivos.

Para atingir os objetivos de uma avaliação, a ISO/IEC 15504 baseia-se em um modelo denominado Modelo de Avaliação de Processo. Esse modelo, bi-dimensional, é formado pela dimensão de processos e pela dimensão da capacidade.

A dimensão de processos é fornecida por um ou mais modelos de referência de processo, externos a norma. Esses modelos definem um conjunto de processos devidamente caracterizados por propósitos e saídas de processo. A dimensão da capacidade é formada pela estrutura de medidas, já descrita anteriormente e apresentada na Figura 4.2. 


\begin{tabular}{|l|l|} 
Niveis de capacidade & \multicolumn{1}{|c|}{ Situações } \\
\hline Nivel 0 - Incompleto & $\begin{array}{l}\text { Existe pouca ou nenhuma evidência } \\
\text { da realizaçấo sistemática de qualquer atributo } \\
\text { definido }\end{array}$ \\
\hline Nivel 1 - Executado & $\begin{array}{l}\text { O processo implementado alcança os resultados do } \\
\text { processo }\end{array}$ \\
\hline Nivel 2 - Gerenciado & $\begin{array}{l}\text { Processo Executado + Processo é implementado de uma } \\
\text { maneira gerenciada e seus produtos de trabalho sẩo } \\
\text { apropriadamente estabelecidos, controlados e mantidos }\end{array}$ \\
\hline Nivel 3 - Estabelecido & $\begin{array}{l}\text { Processo Gerenciado + Processo implementado usando um } \\
\text { processo definido capaz de atender as saídas do processo }\end{array}$ \\
\hline Nivel 4 - Previsivel & $\begin{array}{l}\text { Processo Estabelecido + Processo opera dentro de limites } \\
\text { definidos para realizaçẩo das saídas do processo }\end{array}$ \\
\hline Nivel 5 - Em otimizaçẫo & $\begin{array}{l}\text { Processo Previsivel + Processo é alterado e adaptado } \\
\text { dinamicamente para atingir efetivamente os objetivos de } \\
\text { negócio relevantes (atuais e projetados) }\end{array}$ \\
\hline
\end{tabular}

Figura 4.3: Níveis de capacidade e respectivos significados

A estrutura do Modelo de Avaliação de Processos e seu aspecto bi-dimensional é apresentado na Figura 4.4.

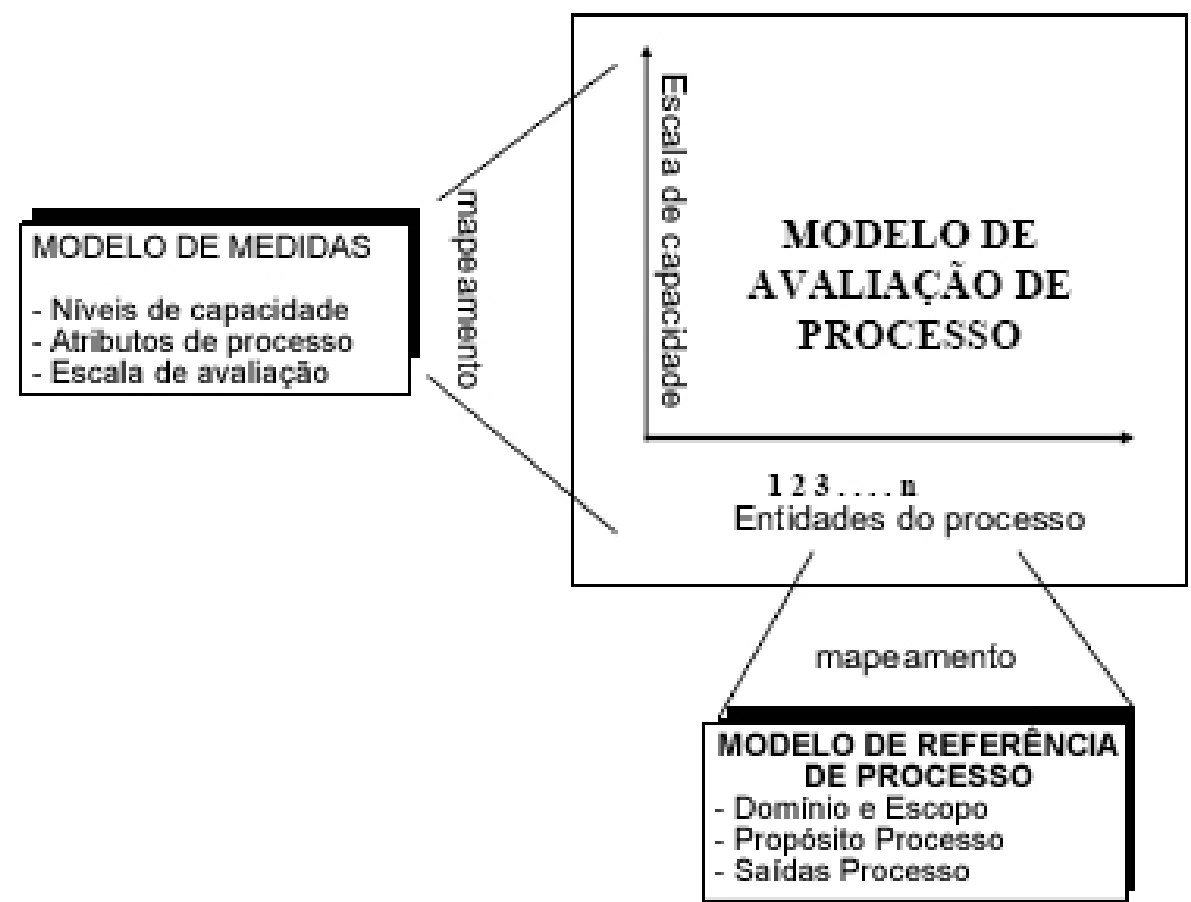

Figura 4.4: Dimensões do modelo de avaliação de processo 
De um modo geral, o Modelo de Avaliação de Processo relaciona-se com um ou mais modelos de referência e é a base para o estabelecimento da capacidade do processo e para a coleta de evidências que justificam os níveis de capacidade estabelecidos.

Para determinar a capacidade de um processo é preciso coletar evidências que auxiliem nessa tarefa. A coleta de evidências deve ser feita de forma confiável e repetível e deve atender as especificações da norma ISO/IEC 15504.

Para que a coleta siga tais especificações, é preciso que o Modelo de Avaliação de Processos atenda a alguns requisitos, tanto na dimensão da capacidade como na dimensão de processos. Os requisitos ajudam a estabelecer um mecanismo formal e verificável que representa os resultados de uma avaliação como um conjunto de atributos de processo pontuados. Tais pontuações são atribuídas de forma independente, para cada processo selecionado do modelo de referência.

As pontuações dos atributos de processo são atribuídas de acordo com as evidências de realização dos mesmos. As pontuações são especificadas no modelo de medidas e, juntamente com os atributos de processo, determinam o nível de capacidade do processo. A Figura 4.5 apresenta as pontuações sugeridas pela norma ISO/IEC 15504.

\begin{tabular}{|l|c|}
\multicolumn{1}{|c|}{ Pontuação } & Significado \\
\hline "N" - Nẫo realizado & $\begin{array}{c}0 \% \text { a } 15 \% \text { - existe um pouco ou } \\
\text { nenhuma evidência da realizaçẫo }\end{array}$ \\
\hline "P": Parcialmente realizado. & $\begin{array}{c}>15 \% \text { a } 50 \% \text { - existe evidência } \\
\text { de uma abordagem sistemática } \\
\text { sólida para a realizaçẫo do }\end{array}$ \\
\hline "L": Largamente realizado. & $\begin{array}{c}>50 \% \text { a } 85 \% \text { - existe evidência } \\
\text { de uma abordagem sistemática } \\
\text { sólida para a realização }\end{array}$ \\
\hline "F": Totalmente realizado. & $\begin{array}{c}>5 \% \% \text { a } 100 \% \text { - existe uma } \\
\text { evidência de um abordagm sólida } \\
\text { e completa para a realizaçẫo }\end{array}$ \\
\hline
\end{tabular}

Figura 4.5: Pontuações sugeridas para os atributos de processo e seus respectivos significados

Um nível " $\mathrm{X}$ " de capacidade é atribuído a um processo quando, para o processo avaliado, todos os atributos de processo dos níveis anteriores a " $\mathrm{X}$ " recebem a pontuação " $F$ " e todos os atributos de processo do nível "X" recebem as pontuações "L" ou "F". As pontuações dos atributos de processo e os respectivos níveis de capacidade que representam são apresentadas na Figura 4.6.

Em resumo, o Modelo de Medidas e o Modelo de Referência de Processo formam o Modelo de Avaliação de Processos, que serve como base para todo o processo de avaliação. Um forte relacionamento entre esses três elementos (Modelo de Medidas, Modelo de Referência de Processo e Modelo de Avaliação de Processo) pode ser observado. Na Figura 4.7 é apresentada a estrutura do processo de avaliação proposto pela norma ISO/IEC 15504. Nela é possível observar os relacionamentos existentes entre os elementos do processo, além de algumas atividades essenciais para a realização efetiva de uma avaliação. 


\begin{tabular}{|c|c|c|}
\hline $\begin{array}{c}\text { Escala } \\
1 \\
\end{array}$ & $\begin{array}{l}\text { Atributos do processo } \\
\text { Execuçăo }\end{array}$ & $\begin{array}{r}\text { Pontuação } \\
\text { L ou F }\end{array}$ \\
\hline 2 & $\begin{array}{l}\text { Execuçäo } \\
\text { Gerencia da Execução } \\
\text { Gerência dos Produtos }\end{array}$ & $\begin{array}{l}\quad F \\
L \text { ou } F \\
\text { L ou } F\end{array}$ \\
\hline 3 & $\begin{array}{c}\text { Execução } \\
\text { Gerencia da Execução } \\
\text { Gerência dos Produtos } \\
\text { Definição do Processo } \\
\text { Desenvolvimento do Processo }\end{array}$ & $\begin{array}{c}F \\
F \\
F \\
\text { Lou } F \\
\text { Lou } F\end{array}$ \\
\hline 4 & $\begin{array}{c}\text { Execução } \\
\text { Gerencia da Execução } \\
\text { Gerềncia dos Produtos } \\
\text { Definiçäo do Processo } \\
\text { Desenvolvimento do Processo } \\
\text { Medição do Processo } \\
\text { Controle do Processo }\end{array}$ & $\begin{array}{l}F \\
F \\
F \\
F \\
F \\
\text { L ou } F \\
\text { L ou } F\end{array}$ \\
\hline 5 & $\begin{array}{c}\text { Execuçäo } \\
\text { Gerencia da Execução } \\
\text { Gerência dos Produtos } \\
\text { Definiçăo } \\
\text { Recursos } \\
\text { Medição do Processo } \\
\text { Controle do Processo } \\
\text { Inovação do Processo } \\
\text { Otimizaçäo do Processo }\end{array}$ & $\begin{array}{l}F \\
F \\
F \\
F \\
F \\
F \\
F \\
\text { L ou } F \\
\text { L ou } F\end{array}$ \\
\hline
\end{tabular}

Figura 4.6: Pontuações dos atributos de processo e respectivos níveis de capacidade

Uma das atividades da avaliação é o planejamento. A criação e documentação de um plano para a avaliação é fundamental. O plano deve conter as entradas e atividades que devem ser realizadas durante a avaliação; os recursos e prazos requeridos para a realização das atividades; a definição dos envolvidos e suas responsabilidades no processo; os critérios de verificação de realização dos requisitos e as descrições das saídas da avaliação.

Além disso, o plano deve garantir a pertinência da coleta e validação dos dados aos objetivos da avaliação. Ao realizar tais atividades, é preciso demonstrar explicitamente quais técnicas e estratégias foram utilizadas. Os resultados obtidos com a validação servem como base para a pontuação dos atributos de processo e, com isso, subsidiam a caracterização do processo em relação a sua capacidade.

De um modo geral, a Parte 2 da norma ISO/IEC 15504 abrange todo o processo de avaliação. Ela define os elementos necessários para a realização de uma avaliação e descreve as atividades que devem ser realizadas para a condução da mesma. Desta forma, pode-se dizer que as outras partes da norma servem para auxiliar e/ou guiar o processo de avaliação descrito na Parte 2. 


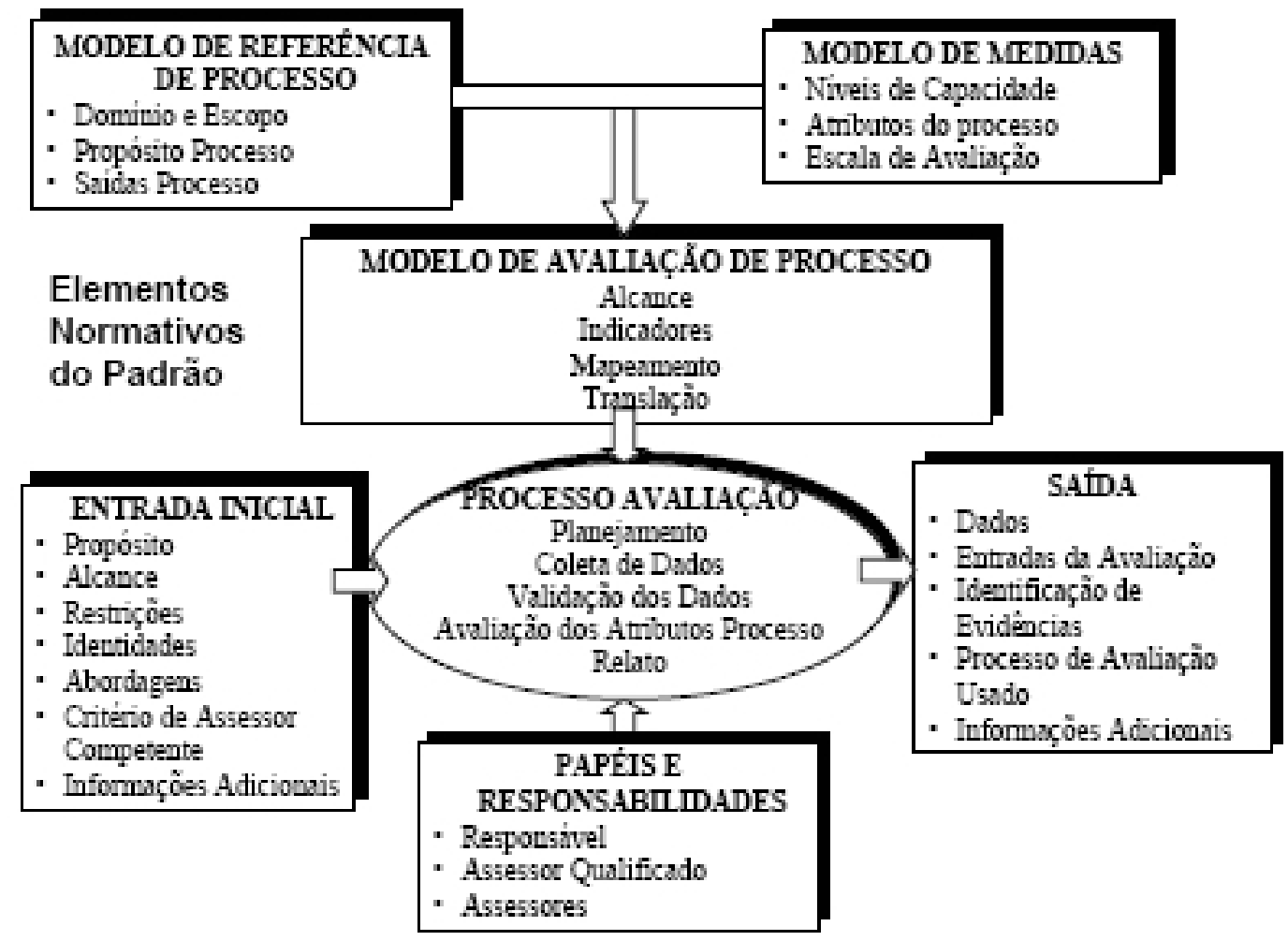

Figura 4.7: Estrutura do processo de avaliação

A Parte 3 (Guia para executar uma Avaliação) fornece orientação no atendimento dos requisitos mínimos para realizar uma avaliação, conforme especificada na Parte 2. Uma visão geral da avaliação do processo é fornecida, além de orientação para o processo. Tais orientações são relacionadas a ferramentas de apoio, a competência da equipe envolvida e a alguns fatores que contribuem para o sucesso do processo. Comprometimento, motivação, confidencialidade das fontes de informação são exemplos de fatores positivos (ISO/IEC, 2003b). Um exemplo de processo de avaliação documentado pode ser encontrado no Anexo A da Parte 3 da norma.

A Parte 4 (Guia para usar no processo de melhoria e determinação da capacidade) orienta como utilizar a avaliação de processo em um programa de melhoria ou determinação da capacidade do processo. A Parte 4 ajuda a entender os resultados obtidos e, com isso, direciona os responsáveis para uma possível melhoria dos processos que apresentam fraquezas (ISO/IEC, 2003c).

A Parte 5 define um Modelo de Avaliação de Processo, compatível com a Parte 2. O modelo definido utiliza na dimensão de processos o modelo de referência ISO/IEC 12207 Amd 1 e Amd 2 e na dimensão de capacidade a estrutura de medidas definida na Parte 2 (ISO/IEC, 2003d). 


\subsection{Considerações finais}

Este capítulo apresentou o processo de avaliação especificado pela norma ISO/IEC 15504. De uma forma geral, a norma orienta a avaliação de um processo, possibilitando a determinação de sua capacidade e a orientação para um processo de melhoria.

Conforme descrito, a norma ISO/IEC 15504 possibilita que a partir de um modelo de referência de processos seja possível determinar a capacidade de um processo. Isso significa dizer que um processo de avaliação pode determinar o grau de aderência de um processo a um modelo de processo.

Essas considerações levam a crer que uma avaliação de processo que baseia-se na norma ISO/IEC 15504 e que utiliza como modelo de referência um modelo que respeite as características definidas pelas metodologias ágeis de desenvolvimento, pode determinar o quanto ágil é o processo avaliado. Isso pode ser o mesmo que dizer que um processo de desenvolvimento é ou não um processo ágil.

Baseando-se nos estudos realizados, no Capítulo 5 é apresentada uma proposta de um modelo de referência para o desenvolvimento ágil de software. Presumi-se que o modelo proposto possa ser utilizado em uma avaliação de processo, com o intuito de determinar se o processo avaliado é um processo de desenvolvimento ágil. 


\section{Uma proposta de um modelo de referência para o desenvolvimento ágil de software}

\subsection{Considerações Iniciais}

Um modelo de referência de processo serve para orientar a implantação de um processo em um organização, com o intuito de torná-lo repetível e possível de ser medido. Nesse contexto, o modelo de referência apresentado neste capítulo tem o objetivo de orientar a implantação de um processo de desenvolvimento de software, a fim de torná-lo ágil.

Na Seção 5.2 são apresentadas as características encontradas nas metodologias ágeis de desenvolvimento estudadas. Na Seção 5.3 são apresentados os requisitos para um modelo de referência de processo. Na Seção 5.4 é apresentada uma proposta de um modelo de referência de processo para o desenvolvimento ágil de software. Por fim, na Seção 5.5 são apresentadas algumas considerações finais sobre este capítulo.

\subsection{Categorização das metodologias ágeis}

As metodologias ágeis existentes atualmente realizam, de diferentes formas, atividades para desenvolver software com qualidade e de forma ágil. Nesse sentido, realizou-se um estudo com al- 
gumas das metodologias ágeis mais conhecidas atualmente e pertencentes a Agile Alliance ${ }^{1}$ (Agile

Alliance Web site, 2007).

As seis metodologias ágeis apresentadas no Capítulo 2 são descritas em função de valores, práticas e papéis que ditam o comportamento das pessoas envolvidas no desenvolvimento e as diretrizes para a correta realização do processo de desenvolvimento sugerido por elas. Uma análise sobre as características, processos, ciclos de vida propostos por essas metodologias permitiu observar semelhanças e diferenças.

Com relação aos processos e ciclos de vida, identificou-se alguns aspectos comuns, dentre os quais:

- Planejamento inicial do projeto

- Entregas de versões

- Desenvolvimento iterativo

- Testes de software

- Integração contínua

O estudo proporcionou ainda a identificação de 37 características. Na Figura 5.1 são apresentadas as características encontradas, o mapeamento para os processos da ISO/IEC $12207^{2}$ e para o modelo de referência ágil e as respectivas metodologias que as possuem.

Na Figura 5.1, a coluna "Proc. Modelo Ágil" indica o processo do modelo de referência ágil que tem relação com a característica. A coluna "Proc. ISO/IEC 12207" indica o nome do processo, no modelo de referência de processos ISO/IEC 12207, que descreve atividades que assemelham-se com a característica. As colunas "Características" e as colunas com os nomes das metodologias (“XP”, "Scrum”, "FDD”, “DSDM", “ASD” e "Crystal”) representam as características encontradas e as metodologias analisadas, respectivamente.

As colunas referentes as metodologias são preenchidas com "X" quando elas possuem a característica relacionada, com "N" quando não possuem a característica relacionada e não são preenchidas quando nenhuma referência à característica foi encontrada na metodologia.

Uma breve análise sobre os dados obtidos permite observar que $27 \%$ das características são encontradas nas 6 metodologias estudadas e 37,8\% são encontradas em pelo menos 4 delas. Esses números confirmam o alto grau de semelhança existente entre essas metodologias.

\footnotetext{
${ }^{1}$ uma organização não lucrativa que promove o desenvolvimento ágil (Agile Alliance Web site, 2007)

${ }^{2} \mathrm{~A}$ norma ISO/IEC 12207 é um modelo de referência de processos de desenvolvimento de software. Ela divide o ciclo de vida do desenvolvimento do software em cinco grupos de processos (Fundamentais, Apoio, Organizacionais e Adaptação), que são subdivididos em dezenove macro processos de desenvolvimento. Os processos descritos na ISO/IEC 12207 englobam todo o ciclo de desenvolvimento do software e podem servir como referência para a implantação de um processo de desenvolvimento em uma empresa (ISO/IEC, 1999)
} 


\begin{tabular}{|c|c|c|c|c|c|c|c|c|}
\hline Proc. Modelo Ágil & Proc. ISOAEC 12207 & Características & $\mathbf{X P}$ & Scrum & FDD & DSDM & ASD & Crystal \\
\hline \multirow{6}{*}{$\begin{array}{l}\text { DES.02 Produção de } \\
\text { estórias }\end{array}$} & Codificacao & Refactoring & $x$ & & & & & \\
\hline & Codificacao & Programação em pares & $\mathbf{X}$ & & & & $\mathbf{X}$ & \\
\hline & Codificacao & Posse coletiva do código & $x$ & & $\mathbf{N}$ & & & \\
\hline & Testes & Testes automatizados & $\mathbf{X}$ & & & & & $\mathbf{X}$ \\
\hline & Testes & Testes unitários & $\mathbf{X}$ & $\mathbf{X}$ & $\mathbf{X}$ & $\mathbf{X}$ & $\mathbf{X}$ & $\mathrm{X}$ \\
\hline & Testes & Testes funcionais & $\mathbf{X}$ & $\mathrm{X}$ & $\mathbf{X}$ & $\mathbf{X}$ & $\mathbf{X}$ & $\mathrm{X}$ \\
\hline \multirow[t]{2}{*}{$\begin{array}{l}\text { OPE.01 Colocar } \\
\text { versão em produção }\end{array}$} & Instalacao & Entrega de versões & $\mathbf{x}$ & $x$ & $\mathbf{x}$ & $\mathbf{x}$ & $\mathrm{x}$ & $x$ \\
\hline & Instalacao & $\begin{array}{l}\text { Processo de colocação de } \\
\text { versões em produção }\end{array}$ & $\mathbf{x}$ & $\mathbf{x}$ & $\mathbf{x}$ & $\mathrm{x}$ & $\mathbf{x}$ & \\
\hline OPE.03 Encerramento & $\begin{array}{l}\text { Instalacao e } \\
\text { Treinamento }\end{array}$ & $\begin{array}{l}\text { Processo de finalização } \\
\text { (treinamento e implantação) }\end{array}$ & $\mathbf{x}$ & $\mathbf{x}$ & $\mathbf{x}$ & $\mathbf{x}$ & & \\
\hline $\begin{array}{l}\text { DES.04 Integração } \\
\text { contínua }\end{array}$ & Integraçẫo & Testes de integração & $x$ & $\mathbf{x}$ & $\mathbf{x}$ & $\mathrm{X}$ & $\mathbf{x}$ & $x$ \\
\hline $\begin{array}{l}\text { Projeto arquitetural do } \\
\text { software e do sistema }\end{array}$ & Projeto & $\begin{array}{l}\text { Construir visão global do } \\
\text { projeto }\end{array}$ & $\mathrm{x}$ & $\mathrm{x}$ & $\mathrm{x}$ & $\mathrm{x}$ & $\mathrm{x}$ & \\
\hline \multirow[t]{2}{*}{$\begin{array}{l}\text { INI.01 Definição e } \\
\text { evolução das estórias } \\
\text { e requisitos }\end{array}$} & Requisitos & $\begin{array}{l}\text { Troca de informações } \\
\text { intensa entre cliente e } \\
\text { deservolvedor }\end{array}$ & $\mathbf{x}$ & $\mathrm{x}$ & $\mathbf{x}$ & $\mathbf{x}$ & $\mathbf{x}$ & $\mathrm{x}$ \\
\hline & Requisitos & $\begin{array}{l}\text { Identificação de novos } \\
\text { requisitos }\end{array}$ & $\mathbf{x}$ & $\mathbf{x}$ & $\mathbf{x}$ & $\mathbf{X}$ & $\mathbf{x}$ & $\mathbf{x}$ \\
\hline $\begin{array}{l}\text { AP0.02 Preparação / } \\
\text { Evolução da } \\
\text { documentação }\end{array}$ & Documentaçã̃o & $\begin{array}{l}\text { Preparação/Evolução da } \\
\text { documentação }\end{array}$ & & $x$ & $\mathbf{x}$ & $\mathrm{X}$ & & $\mathrm{x}$ \\
\hline \multirow[t]{2}{*}{$\begin{array}{l}\text { AP0.01 Controle de } \\
\text { Versões }\end{array}$} & $\begin{array}{l}\text { Gerência de } \\
\text { Configuraçẫo }\end{array}$ & Controle de versões & & & $\mathbf{x}$ & $\mathbf{x}$ & & $\mathbf{x}$ \\
\hline & $\begin{array}{l}\text { Gerência de } \\
\text { Configuraçẫo }\end{array}$ & Gerência de Configuração & & & $\mathbf{x}$ & $\mathbf{x}$ & & $\mathbf{x}$ \\
\hline \multirow{2}{*}{$\begin{array}{l}\text { AP0.02 Revisão e } \\
\text { garantia de qualidade }\end{array}$} & Garantia de & Revisão técnica & & & $\mathbf{X}$ & $\mathrm{X}$ & $\mathbf{X}$ & $\mathrm{X}$ \\
\hline & $\begin{array}{l}\text { qualidade, } \\
\text { verificaçẫo, validaçẫo }\end{array}$ & Revisão de qualidade & & & $\mathbf{x}$ & $\mathbf{x}$ & $\mathbf{x}$ & $\mathrm{x}$ \\
\hline \multirow[t]{2}{*}{$\begin{array}{l}\text { INI.05 Planejamento } \\
\text { global do projeto }\end{array}$} & $\begin{array}{l}\text { Gerência i } \\
\text { Planejamento }\end{array}$ & $\begin{array}{l}\text { Planejamento do projeto } \\
\text { global }\end{array}$ & $\mathbf{x}$ & $\mathbf{x}$ & $\mathbf{x}$ & $x$ & $\mathbf{x}$ & $\mathbf{x}$ \\
\hline & \begin{tabular}{|l|} 
Gerência I \\
Planejamento
\end{tabular} & $\begin{array}{l}\text { Processo de inicialização do } \\
\text { projeto }\end{array}$ & $\mathbf{x}$ & $\mathbf{x}$ & $\mathbf{x}$ & $\mathbf{x}$ & $\mathbf{x}$ & $\mathbf{x}$ \\
\hline \multirow[t]{4}{*}{$\begin{array}{l}\text { DES.01 Planejamento } \\
\text { das iterações }\end{array}$} & $\begin{array}{l}\text { Gerêncial } \\
\text { Planejamento }\end{array}$ & Planejamento das iterações & $\mathbf{x}$ & $\mathrm{x}$ & $\mathbf{x}$ & $\mathrm{x}$ & $\mathbf{x}$ & \\
\hline & \begin{tabular}{|l|} 
Gerêncial \\
Planejamento
\end{tabular} & $\begin{array}{l}\text { Estimativa de custo das } \\
\text { funcionalidades }\end{array}$ & $\mathbf{x}$ & $\mathbf{x}$ & & & & \\
\hline & \begin{tabular}{|l|} 
Gerêncial \\
Planejamento
\end{tabular} & $\begin{array}{l}\text { Priorização das } \\
\text { funcionalidades }\end{array}$ & $\mathbf{x}$ & $\mathbf{x}$ & $\mathbf{x}$ & $\mathrm{x}$ & $\mathbf{x}$ & \\
\hline & $\begin{array}{l}\text { Gerência ! } \\
\text { Planejamento }\end{array}$ & $\begin{array}{l}\text { Ciclos de desermolvimento } \\
\text { curtos }\end{array}$ & $\mathbf{x}$ & $\mathbf{x}$ & $\mathbf{x}$ & $\mathbf{x}$ & $x$ & $\mathrm{x}$ \\
\hline $\begin{array}{l}\text { INI.03 Preparação do } \\
\text { ambiente de } \\
\text { deservolvimento }\end{array}$ & Infra-estrutura & $\begin{array}{l}\text { Definição de condições } \\
\text { mínimas para o projeto } \\
\text { (infra-estrutura, equipe, } \\
\text { ferramentas) }\end{array}$ & & $x$ & $\mathrm{x}$ & $x$ & $x$ & $x$ \\
\hline
\end{tabular}




\begin{tabular}{|c|c|c|c|c|c|c|c|c|}
\hline Proc. Modelo Ágil & Proc. ISO/EC 12207 & Características & $\mathbf{X P}$ & Scrum & FDD & DSDM & ASD & Crystal \\
\hline \multirow{5}{*}{$\begin{array}{l}\text { DES.05 Refinamento } \\
\text { de produtos e } \\
\text { processos }\end{array}$} & Revisẫo conjunta & Reuniőes regulares & $\mathbf{X}$ & $\mathbf{X}$ & & $\mathbf{X}$ & & \\
\hline & Revisẫo conjunta & $\begin{array}{l}\text { Revisão de pessoas-e- } \\
\text { processos }\end{array}$ & & & & & $\mathrm{x}$ & $\mathrm{x}$ \\
\hline & Revisẫo conjunta & $\begin{array}{l}\text { Revisão do estado do } \\
\text { projeto }\end{array}$ & & $\mathbf{x}$ & $\mathrm{x}$ & & $\mathrm{x}$ & $\mathbf{x}$ \\
\hline & Melhoria & $\begin{array}{l}\text { Aprendizagem para a } \\
\text { próxima iteração }\end{array}$ & & $x$ & & $x$ & $x$ & $\mathrm{x}$ \\
\hline & Melhoria & $\begin{array}{l}\text { Workshops para } \\
\text { refinamento do produto e da } \\
\text { metodologia }\end{array}$ & & $\mathbf{x}$ & $\mathrm{x}$ & $x$ & $x$ & $\mathbf{x}$ \\
\hline $\begin{array}{l}\text { DES.03 Tratamento de } \\
\text { riscos }\end{array}$ & Identificaçẫo Riscos & Identificação de riscos & $\mathbf{x}$ & $\mathbf{x}$ & & $\mathbf{x}$ & $\mathbf{x}$ & \\
\hline \multirow{5}{*}{$\begin{array}{l}\text { INI.02 Recrutamento e } \\
\text { treinamento de } \\
\text { pessoal }\end{array}$} & Recursos humanos & $\begin{array}{l}\text { Equipes altamente } \\
\text { escaláveis }\end{array}$ & & & $\mathrm{x}$ & & $\mathrm{x}$ & $\mathrm{X}$ \\
\hline & Recursos humanos & Equipes multidisciplinares & $\mathbf{X}$ & $\mathbf{X}$ & & $\bar{X}$ & & $\mathbf{x}$ \\
\hline & Recursos humanos & Equipes auto-organizáveis & $\mathbf{X}$ & $\mathbf{x}$ & & & & \\
\hline & Recursos humanos & $\begin{array}{l}\text { Equipe de deservolvimento } \\
\text { sempre possui visão global } \\
\text { do projeto }\end{array}$ & $\mathbf{X}$ & $\mathbf{x}$ & $\mathbf{x}$ & & & \\
\hline & Recursos humanos & Trabalho em equipe & $\mathbf{X}$ & $\mathbf{X}$ & $\mathbf{x}$ & $\mathbf{X}$ & $\mathbf{X}$ & $\mathbf{X}$ \\
\hline Năo mapeado & Năo mapeado & Dimulgação dos resultados & $\mathbf{x}$ & & $\mathrm{x}$ & $x$ & & \\
\hline OPE.02 Manutenção & Năo mapeado & Năo mapeado & & & & & & \\
\hline
\end{tabular}

Figura 5.1: Categorização das metodologias ágeis de desenvolvimento.

Além disso, 13,5\% são encontradas, no máximo, em 2 metodologias e 16,2\% são encontradas em exatamente 3 delas. Somando-se esses percentuais chega-se ao índice de 29,7\% de características que estão presentes em, no máximo, 3 metodologias. O baixo percentual indica o baixo índice de diferenças existentes entre as metodologias. Esse fato reforça a idéia de que as metodologias ágeis existentes atualmente são bastante semelhantes.

O alto grau de semelhança aumenta as chances de criação de um modelo de referência ágil que não contrarie as premissas das metodologias ágeis existentes atualmente e que respeite o manifesto ágil.

Dessa forma, o modelo de referência ágil foi dividido em quatro grupos de processos que, por sua vez, foram subdivididos em dezesseis processos. A divisão em quatro grupos de processos e em dezesseis processos foi baseada nas características semelhantes dos ciclos de vida utilizados pelas metodologias estudadas e visaram a concepção de um ciclo de vida próprio para o modelo. Além de influenciarem a divisão, os estudos e análises realizados também influenciaram a elaboração dos processos.

\subsection{Requisitos para um modelo de referência de processo}

Um modelo de referência de processos serve como guia para a implantação de processos. Para que um processo seja considerado um modelo de referência, ele deve conter uma declaração do domínio do modelo, uma descrição dos processos que o compõe e uma descrição do relacionamento entre os processos definidos por ele (ISO/IEC, 2003e). 
O elemento fundamental dentro do modelo é a descrição dos processos. A descrição deve incorporar uma declaração do propósito do processo, a qual descreve em alto nível os objetivos da execução do processo, e o conjunto de saídas que demonstram sucesso na realização do propósito do processo. Uma declaração de saída pode descrever a produção de um artefato, uma significante alteração de estado e/ou o atendimento das restrições especificadas (requisitos, objetivos, etc).

Na Seção 5.4 é apresentado um modelo de referência que objetiva orientar a implantação de processos de desenvolvimento ágeis.

\subsection{Um modelo de referência para o desenvolvimento ágil de software}

Esta seção descreve uma proposta de um modelo de referência para o desenvolvimento ágil de software. O modelo apresentado é direcionado a desenvolvedores de software e gerentes de projetos de software que desejam aplicar técnicas que tornem o processo de desenvolvimento ágil.

\subsubsection{Declaração do domínio}

O modelo de referência ágil de software fornece um conjunto de processos, atividades e tarefas que orienta o processo de desenvolvimento de software para que possa ser realizado de forma ágil. O modelo pode ser utilizado para o construção de software, independentemente do ambiente de operação do mesmo.

\subsubsection{Processos do modelo de referência}

O modelo de referência é composto por 16 processos, distribuídos dentro de quatro grupos de processos - Processos de Inicialização (INI), Processos de Desenvolvimento Iterativo (DES), Processos de Operação (OPE) e Processos de Apoio (APO) - que abrangem todo o ciclo de desenvolvimento.

O Grupo de Processos de Inicialização é responsável por iniciar o projeto e preparar o ambiente para o início das iterações. Os processos desse grupo são responsáveis por iniciar as negociações do projeto com o cliente e, em paralelo, iniciar atividades para recrutar e organizar as equipes que integrarão o projeto e preparar o ambiente de desenvolvimento, inclusive realizando testes com possíveis arquiteturas. Um planejamento global para o projeto também deve ser realizado, considerando-se as estórias ${ }^{3}$ definidas até o momento.

Passada a fase de inicialização, inicia-se a fase de desenvolvimento. O Grupo de Processos de Desenvolvimento Iterativo é responsável pelo desenvolvimento do software e pelo refinamento

\footnotetext{
${ }^{3}$ Funcionalidades identificadas pelos clientes que devem ser produzidas pelo projeto.
} 
dos produtos e processos. Os processos desse grupo formam o ciclo iterativo do modelo, uma das característica fortemente aplicadas pelas metodologias ágeis.

O ciclo inicia-se com o planejamento das iterações. Após planejar a iteração, iniciam-se atividades para a produção das estórias e testes automatizados e para o tratamento dos riscos. Após serem produzidas, as estórias são integradas e, ao final de cada iteração, os produtos e os processos passam por atividades de refinamento, visando uma melhoria para a próxima iteração. Os processos do ciclo de desenvolvimento podem ocorrer diversas vezes dentro do projeto, possibilitando a construção de diversas versões do software.

Após a construção de uma primeira versão, inicia-se a fase que trata da operação do software. O Grupo de Processos de Operação abrange as atividades referentes a instalação de versões, manutenção e encerramento do projeto. Dentro do processo de encerramento está previsto a realização de atividades para produzir e/ou atualizar os documentos necessários ao projeto e a entrega de um produto final.

Por fim, e não menos importante, está o Grupo de Apoio. Os processos que compõem esse grupo ajudam a assegurar a qualidade dos produtos intermediários e finais, garantem a padronização dos processos e produtos e auxiliam no controle de versões de software. Esses processos auxiliam no desenvolvimento do projeto durante todo o projeto.

Na Figura 5.2 são apresentados os grupos de processo que compõem o modelo de referência ágil e as interações entre eles.

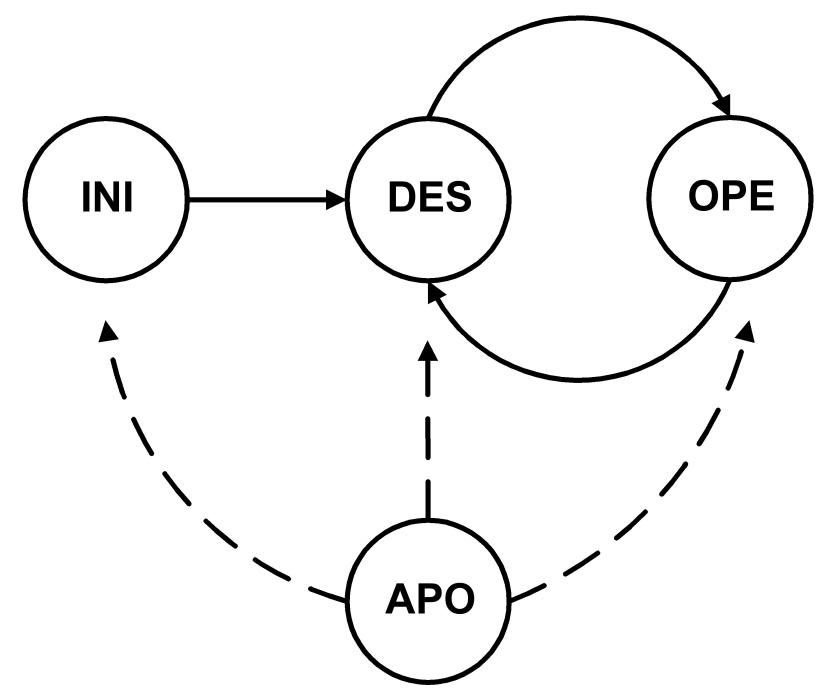

Figura 5.2: Grupos de processos do modelo de referência ágil e as interações entre eles.

Como já citado, o modelo de referência é composto por 16 processos. Na Figura 5.3 estão apresentados os 16 processos, e seus respectivos grupos, que compõem o modelo de referência ágil.

Os processos são detalhados em propósito, práticas básicas, resultados e produtos de trabalho de entrada e saída. O propósito descreve os objetivos do processo, os resultados descrevem os 


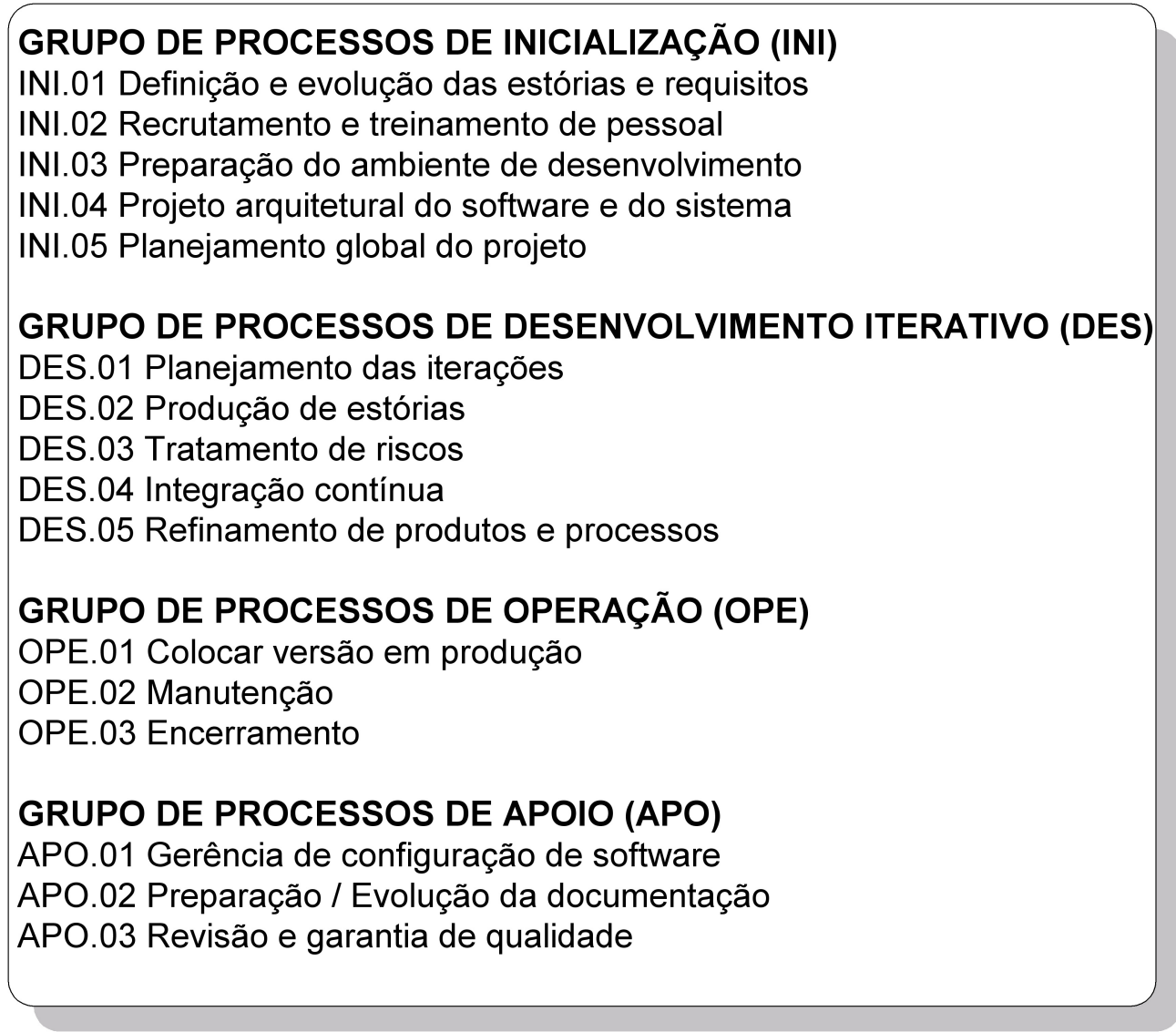

Figura 5.3: Grupos de processos do modelo de referência ágil e seus respectivos processos.

resultados esperados com a correta realização do processo, as práticas básicas descrevem as atividades que devem ser realizadas para alcançar os resultados e os propósitos do processo e os produtos de trabalho descrevem os artefatos que são consumidos (produtos de trabalho de entrada) e produzidos (produtos de trabalho de saída) pelo processo.

Essa forma de detalhamento foi baseada no template para um modelo de avaliação de processos, da norma ISO/IEC 15504 (ISO/IEC, 2003d). O template ainda apresenta, para cada prática básica, uma ou mais referências para os resultados que a prática produz. O template é apresentado na Figura 5.4.

Os processos do Modelo de Referência Ágil, e o respectivo grupo ao qual pertencem, são apresentados a seguir.

\subsubsection{Grupo de Processos de Inicialização (INI)}

\section{INI.01 Definição e evolução das estórias e requisitos}

Propósito: O propósito deste processo é identificar, de forma ágil, as necessidades do software a ser desenvolvido. 


\begin{tabular}{|l|l|}
\hline ID & Código que identifica o processo \\
\hline Propósito & Descreve os objetivos do processo \\
\hline Resultados & $\begin{array}{l}\text { Descreve os resultados esperados na realizaçấo } \\
\text { efetiva do processo }\end{array}$ \\
\hline Práticas básicas & $\begin{array}{l}\text { Descreve atividades a serem realizadas para } \\
\text { atingir os resultados e o propósito do processo. } \\
\text { [Resultado(s): referência para os resultados] }\end{array}$ \\
\hline
\end{tabular}

\begin{tabular}{|l|l|}
\hline \multicolumn{2}{|c|}{ Produtos de trabalho } \\
\hline \multicolumn{1}{|c|}{ Entrada } & \multicolumn{1}{c|}{ Saída } \\
\hline $\begin{array}{l}\text { Lista de produtos de trabalho que } \\
\text { sâo consumidos pelo processo }\end{array}$ & $\begin{array}{l}\text { Lista de produtos de trabalho que } \\
\text { sâo produzidos pelo processo }\end{array}$ \\
\hline
\end{tabular}

Figura 5.4: Template para um modelo de avaliação de processos (ISO/IEC, 2003d).

Práticas básicas: Para que os resultados esperados sejam atingidos, algumas práticas básicas devem ser realizadas. As práticas básicas necessárias a este processo são:

INI.01.PB01. Estabelecer mecanismos de comunicação. Definir quais mecanismos de comunicação serão utilizados para monitorar as necessidades e o nível de satisfação do cliente. Os mecanismos escolhidos devem permitir uma comunicação direta e eficiente entre cliente e desenvolvedor. [Resultado: 1]

Nota 1: Exemplos de mecanismos que podem facilitar essa tarefa são os workshops e as reuniões regulares com a participação de clientes e desenvolvedores.

INI.01.PB02. Obter estórias e requisitos não-funcionais. Auxiliar o cliente a definir as estórias e os requisitos não-funcionais que farão parte do projeto. Um especialista do domínio deve integrar a equipe de desenvolvimento e permanecer no mesmo local de trabalho da mesma (Cockburn, 2002). [Resultado: 2]

Nota 1: O especialista do domínio é responsável por esclarecer eventuais dúvidas sobre os requisitos e sobre as interfaces de usuário e por direcionar o desenvolvimento. A proximidade entre especialista e desenvolvedor possibilita um feedback visual e funcional rápido, aumentando as chances de maximizar a qualidade de fatores de qualidade, como a usabilidade, a corretitude e a facilidade de adaptar-se a novas situações (extendibilidade).

INI.01.PB03. Avaliar as requisições de evolução de requisitos e incorporá-las ao projeto. Avaliar o impacto das evoluções, aprová-las quando for conveniente e atualizar a lista de estórias e requisitos não-funcionais. [Resultado: 2] 
INI.01.PB04. Divulgar. Realizar a divulgação dos requisitos através de mecanismos de comunicação eficientes. A divulgação dos requisitos aumenta o entendimento dos desenvolvedores sobre as necessidades do cliente e pode aumentar a produtividade da equipe (Highsmith, 2002).[Resultado: 3]

INI.01.PB05. Produzir a lista de estórias e de requisitos não-funcionais. Produzir um documento que contenha a especificação das estórias e dos requisitos não-funcionais de forma clara, concisa, consistente e não ambígua. [Resultado: 4]

Nota 2: A Lista de Estórias e de Requisitos Não-funcionais deve ser definida e priorizada pelo cliente (Highsmith, 2002). As estórias devem ser descritas de forma resumida, sem muito detalhes, pois o detalhamento é obtido antes do início da implementação. Na Figura 5.5 é apresentado um exemplo de uma Lista de Estórias e de Requisitos Não-funcionais já priorizada.

Lista de Estórias e Requisitos Não-funcionais
Visão geral do sistema
O Sistema de Apoio a Escrita (SAPES) tem como objetivo principal auxiliar a
pesquisa bibliográfica. Os usuários deste sistema são, principalmente, pesquisadores que,
durante sua pesquisa podem ler publicações e armazená-las ...
Lista de estórias
A. Preparação e manutenção dos itens bibliográficos.
$\quad$ (Prioridade 1) A.1. - O sistema deve permitir a inserção, alteração e
(Prioridade 2) A.2. - O sistema deve gerar automaticamente a forma de
exclusão de itens bibliográficos, mantendo uma bibliografia
citação, seguindo o padrão ABNT (Associação Brasileira de Normas Técnicas), quando o
pesquisador inserir um item bibliográfico na bibliografia.
B. Consultas gerais e Emissão de Relatórios.
(Prioridade 2) B.1. - O sistema deve permitir consulta a itens bibliográficos
C.1. - O sistema deve ter capacidade para recuperar dados perdidos da
C.2. - O sistema deve fornecer facilidades para a realização de backups
seguinte itens de informação: autor, assunto, editora, periódico, local e ano de publicação.
(Prioridade 2) B.2. - O sistema deve fornecer recursos para a criação e
impressão de fichas técnicas a partir das informações que o sistema possui sobre os itens
bibliográficos. $\quad$
Requisitos não-funcionais
Co. Confiabilidade
dos arquivos do sistema.

Figura 5.5: Exemplo de uma Lista de Estórias e de Requisitos Não-funcionais já priorizada.

INI.01.PB06. Produzir o modelo de negócios do sistema. Produzir um modelo de negócios que represente como as estórias descritas na Lista de Estórias e de Requisitos Não-funcionais serão produzidas e sob quais regras funcionarão. [Resultado: 5] 
Resultados: Para que este processo possa ser considerado um processo implementado, deve haver indícios da realização de algumas atividades e/ou a produção de alguns artefatos. Tais atividades e artefatos referem-se a(o):

1. Existência de mecanismos de comunicação eficientes entre cliente e desenvolvedor;

2. Existência de mecanismos que identifiquem as necessidades do cliente e incorporemnas ao projeto;

3. Existência de um mecanismo para divulgação dos requisitos e/ou das alterações de requisitos;

4. Produção da lista de estórias e de requisitos não-funcionais;

5. Produção de um modelo de negócios do sistema;

Produtos de trabalho: Os processos produzem ou consomem produtos de trabalho. Os produtos de trabalho necessários a este processo são:

\begin{tabular}{||l|l||}
\hline Produtos de trabalho de entrada & Produtos de trabalho de saída \\
\hline - Requisição de evolução & - Lista de estórias e de requisitos não- \\
& funcionais \\
& - Modelo de negócios do sistema \\
\hline
\end{tabular}

\section{INI.02 Recrutamento e treinamento de pessoal}

Propósito: O propósito deste processo é fornecer indivíduos com habilidades e conhecimentos suficientes para realizar efetivamente as tarefas referentes ao projeto.

Práticas básicas: Para que os resultados esperados sejam atingidos, algumas práticas básicas devem ser realizadas. As práticas básicas necessárias a este processo são: 
INI.02.PB01. Identificar habilidades e competências necessárias ao projeto. Identificar quais características são desejadas em um indivíduo que irá compor a equipe de desenvolvimento do projeto. As características são obtidas baseando-se nas particularidades do projeto. [Resultado: 1]

Nota 1: Algumas características que devem ser incluídas são: habilidades técnicas, habilidades de trabalho em equipe, facilidade de adaptação a novas realidades, facilidade de realizar diversas funções dentro do projeto. Essas características compõem um perfil adequado para um indivíduo que irá trabalhar em um projeto ágil (Cockburn e Highsmith, 2001).

INI.02.PB02. Recrutar indivíduos qualificados. Realizar atividades de recrutamento que identifiquem indivíduos com as habilidades e competências desejadas. [Resultados: 2, 3]

INI.02.PB03. Definir uma estratégia para treinar os indivíduos recrutados. Produzir um plano para capacitar os indivíduos a agirem conforme necessidades do projeto e de acordo com a filosofia ágil implantada. [Resultados: 2, 3]

Nota 1: O plano para capacitar os indivíduos deve almejar a excelência técnica de todos. A excelência técnica é um dos fatores que maximiza as possibilidades das metodologias ágeis adaptarem-se a novas situações. A facilidade de adaptar-se a novas situações (Extendibilidade) é um fator de qualidade que deve ser considerado em um processo de garantia de qualidade (Mnkandla e Dwolatzky, 2006).

INI.02.PB04. Treinar indivíduos. Prover indivíduos capacitados a agirem conforme necessidades do projeto e de acordo com a filosofia ágil implantada. [Resultados: 2 , $3,4]$

Resultados: Para que este processo possa ser considerado um processo implementado, deve haver indícios da realização de algumas atividades e/ou a produção de alguns artefatos. Tais atividades e artefatos referem-se a(o):

1. Definição das habilidades e competências desejadas nos indivíduos envolvidos no projeto.

2. Existência de indivíduos capazes de seguir a filosofia ágil implantada.

3. Existência de indivíduos capazes de realizar diversas funções dentro do projeto.

Produtos de trabalho: Os processos produzem ou consomem produtos de trabalho. Os produtos de trabalho referentes a este processo são: 


\begin{tabular}{||l|l||}
\hline Produtos de trabalho de entrada & Produtos de trabalho de saída \\
\hline - Descrição do projeto & - Plano de treinamento \\
& - Indivíduos capacitados e treinados \\
\hline
\end{tabular}

\section{INI.03 Preparação do ambiente de desenvolvimento}

Propósito: O propósito deste processo é manter um ambiente de desenvolvimento estável e confiável para a realização dos processos.

Práticas básicas: Para que os resultados esperados sejam atingidos, algumas práticas básicas devem ser realizadas. As práticas básicas necessárias a este processo são:

INI.03.PB01. Identificar as necessidades referentes ao ambiente de desenvolvimento. [Resultado: 1]

Nota 1: Os requisitos para o ambiente de desenvolvimento devem incluir necessidades referentes a hardware, software, métodos, ferramentas, técnicas, padrões, facilidades de desenvolvimento, operação e manutenção.

INI.03.PB02. Adquirir elementos necessários ao ambiente e disponibilizá-los. Adquirir os elementos necessários, prepará-los e disponibilizá-los para utilização. [Resultado: 2]

INI.03.PB03. Realizar testes no ambiente de desenvolvimento. Garantir que a a tecnologia e arquitetura escolhidas para o projeto funcionam satisfatóriamente no ambiente de desenvolvimento e, possivelmente, em ambiente operacional. [Resultado: 3, 4]

INI.03.PB04. Fornecer auxílio aos usuários do ambiente de desenvolvimento. Prover auxílio, aos usuários do ambiente, na utilização e na manutenção dos elementos disponibilizados. [Resultado: 5]

INI.03.PB05. Manter e prover melhorias ao ambiente de desenvolvimento. Manter o ambiente de desenvolvimento em bom funcionamento, corrigir problemas e prover melhorias. [Resultado: 4]

Resultados: Para que este processo possa ser considerado um processo implementado, deve haver indícios da realização de algumas atividades e/ou a produção de alguns artefatos. Tais atividades e artefatos referem-se a(o):

1. Identificação e especificação dos requisitos necessários ao ambiente de desenvolvimento para a realização dos outros processos;

2. Aquisição dos elementos necessários ao ambiente de desenvolvimento. 
3. Realização de testes, no ambiente de desenvolvimento, com a tecnologia e arquitetura escolhidas para o projeto.

4. Existência de um ambiente de desenvolvimento estável e confiável.

5. Existência de indivíduos aptos a utilizarem o ambiente de desenvolvimento de forma efetiva.

Produtos de trabalho: Os processos produzem ou consomem produtos de trabalho. Os produtos de trabalho referentes a este processo são:

\begin{tabular}{||l|l||}
\hline Produtos de trabalho de entrada & Produtos de trabalho de saída \\
\hline - Descrição do processo & - Ambiente de desenvolvimento \\
\hline
\end{tabular}

\section{INI.04 Projeto arquitetural do software e do sistema}

Propósito: O propósito deste processo é fornecer um projeto arquitetural para o software e para o sistema, que represente os requisitos especificados e que descreva como os elementos do software e do sistema se integram em um sistema final completo.

Práticas básicas: Para que os resultados esperados sejam atingidos, algumas práticas básicas devem ser realizadas. As práticas básicas necessárias a este processo são:

INI.04.PB01. Definir a arquitetura do sistema. Interpretar os requisitos do sistema e definir uma arquitetura que identifique elementos de hardware, software e manuais de operação, inclusive a base de dados. [Resultado: 1]

Nota 1: A arquitetura do sistema deve ser projetada para operar independentemente de plataforma. Essa decisão auxilia a garantir a compatibilidade e portabilidade do sistema. A compatibilidade e portabilidade são fatores de qualidade que devem ser considerados em um processo de garantia de qualidade (Mnkandla e Dwolatzky, 2006).

INI.04.PB02. Especificar interfaces. Especificar interfaces internas e externas entre os elementos do software e do sistema. [Resultado: 3]

Nota 1: Uma boa especificação das interfaces entre os elementos do software e do sistema aumenta a manutenibilidade. A manutenibilidade é um fator de qualidade que deve ser considerado em um processo de garantia de qualidade (Mnkandla e Dwolatzky, 2006).

INI.04.PB03. Definir projeto de banco de dados. Definir a estrutura do banco de dados. [Resultado: 4] 
INI.04.PB04. Definir a arquitetura do software. Interpretar os requisitos do software e definir uma arquitetura que descreva a estrutura geral do software e de seus elementos e as interações existentes entre eles. [Resultado: 2]

Nota 1: Um bom projeto arquitetural do software pode aumentar a reusabilidade de seus componentes. A reusabilidade é um fator de qualidade que deve ser considerado em um processo de garantia de qualidade (Mnkandla e Dwolatzky, 2006).

INI.04.PB05. Verificar consistência com os requisitos. O cliente deve auxiliar os desenvolvedores a garantir a consistência do projeto arquitetural do software e do sistema com os requisitos do software e do sistema. A proximidade do cliente à equipe de desenvolvimento minimiza inconsistências com os requisitos, já que o feedback do cliente pode ser obtido rapidamente (Cockburn e Highsmith, 2001). [Resultado: 5] INI.04.PB06. Divulgar resultados às partes envolvidas. Divulgar às partes envolvidas o projeto arquitetural do sistema, o projeto arquitetural do software e as interfaces especificadas. A divulgação deve ser realizada através de mecanismos de comunicação eficientes. Um exemplo de um mecanismo de divulgação eficiente é a impressão do projeto arquitetural do sistema e do software em um banner e a disponibilização do banner em local visível e de fácil acesso aos desenvolvedores. [Resultado: 6]

Resultados: Para que este processo possa ser considerado um processo implementado, deve haver indícios da realização de algumas atividades e/ou a produção de alguns artefatos. Tais atividades e artefatos referem-se a(o):

1. Existência de um projeto arquitetural do sistema;

2. Existência de um projeto arquitetural do software;

3. Definição de interfaces internas e externas de cada elemento do sistema e do software;

4. Definição do projeto de banco de dados

5. Existência de um mecanismo que permita ao cliente e aos desenvolvedores verificar a consistência do projeto com os requisitos do software e do sistema;

6. Existência de um mecanismo de divulgação do projeto arquitetural do sistema e do software e de seus relacionamentos.

Produtos de trabalho: Os processos produzem ou consomem produtos de trabalho. Os produtos de trabalho referentes a este processo são: 


\begin{tabular}{||l|l||}
\hline Produtos de trabalho de entrada & Produtos de trabalho de saída \\
\hline - Modelo de negócios de sistema & - Projeto arquitetural do sistema \\
- Lista de estórias e de requisitos não- & - Projeto arquitetural do software \\
funcionais & \\
& - Projeto de banco de dados \\
\hline
\end{tabular}

\section{INI.05 Planejamento global do projeto}

Propósito: $\mathrm{O}$ propósito deste processo é planejar atividades e realizar estimativas iniciais referentes ao processo de desenvolvimento.

Práticas básicas: Para que os resultados esperados sejam atingidos, algumas práticas básicas devem ser realizadas. As práticas básicas necessárias a este processo são:

INI.05.PB01. Definir o escopo do software. Produzir uma declaração inicial, clara e não abígua do escopo do software. O escopo deve conter uma declaração explícita de dados quantitativos (ex.: número de usuários simultâneos, tempo de respostas), restrições e/ou limitações de qualquer espécie, estórias e versões, lista de tarefas, e deve estar preparado para sofrer modificações (Crocker, 2003). [Resultado: 1]

INI.05.PB02. Realizar estimativas. Estimar, superficialmente, os recursos, custos e atividades necessários para o desenvolvimento do projeto. As estimativas, nesse ponto do projeto, devem ser feitas de forma superficial, pois ainda não se conhece as estórias com detalhes. As estimativas devem ser melhoradas no planejamento das iterações. [Resultado: 2]

INI.05.PB03. Estabelecer um cronograma de utilização dos recursos. Definir quais recursos serão alocados para o projeto e quando serão utilizados e liberados. [Resultado: 3]

INI.05.PB04. Definir uma estratégia para a integração contínua das estórias. Uma estratégia para a integração contínua deve definir o local (hardware, software e ferramentas) de integração e as atividades que devem ser realizadas para realizar a integração. [Resultado: 4]

INI.05.PB05. Estabelecer um mecanismo de monitoramento do feedback do cliente. Estabelecer mecanismos que auxiliem na captação do feedback do cliente, identificando pontos positivos e negativos dos produtos intermediários e finais. A realização de workshops ao final das iterações auxiliam nessa tarefa. [Resultado: 1]

Nota 1: O feedback do cliente é importante para maximizar a corretitude e a usabilidade do sistema e, com isso, aumentar a satisfação do próprio cliente. 
INI.05.PB06. Estabelecer um plano global para o projeto. Produzir um plano global para o projeto que descreva os objetivos do projeto, as principais estórias e as possíveis versões do software, a estrutura inicial das equipes e suas responsabilidades, os especialistas do domínio (pessoa relacionada ao cliente) que farão parte da equipe de desenvolvimento, as reuniões regulares, o tempo de duração de cada iteração, o cronograma de utilização dos recursos, as estimativas, a estratégia de integração contínua, os mecanismos de monitoramento do feedback. Um template para um plano global do projeto é apresentado na Figura 5.6. [Resultado: 5]

Nota 1: As equipes devem possuir papéis e responsabilidades bem definidos. Os membros de uma equipe podem acumular funções e responsabilidades durante um projeto ou iteração.

Nota 2: Em uma equipe devem existir, no mínimo, três funções: Responsável pelo priorização das estórias (pessoa responsável por determinar a prioridade das estórias e divulgar aos interessados), Especialista do Domínio (pessoa com conhecimento aprofundado do domínio do problema) e Gerente de Projeto (pessoa que gerencia o projeto, auxilia a equipe em momentos de caos, resolve problemas políticos e externos ao desenvolvimento).

Resultados: Para que este processo possa ser considerado um processo implementado, deve haver indícios da realização de algumas atividades e/ou a produção de alguns artefatos. Tais atividades e artefatos referem-se a(o):

1. Existência de uma declaração inicial do escopo do software;

2. Existência de estimativas superficiais para o desenvolvimento do projeto;

3. Existência de um cronograma de utilização dos recursos;

4. Existência de uma estratégia para a integração contínua;

5. Estabelecimento de mecanismos de monitoramento do feedback do cliente;

6. Existência de um plano global para o projeto;

Produtos de trabalho: Os processos produzem ou consomem produtos de trabalho. Os produtos de trabalho referentes a este processo são:

\begin{tabular}{||l|l||}
\hline Produtos de trabalho de entrada & Produtos de trabalho de saída \\
\hline - Lista de estórias e de requisitos não- & - Plano global do projeto \\
funcionais & \\
- Modelo de negócios do sistema & \\
\hline
\end{tabular}




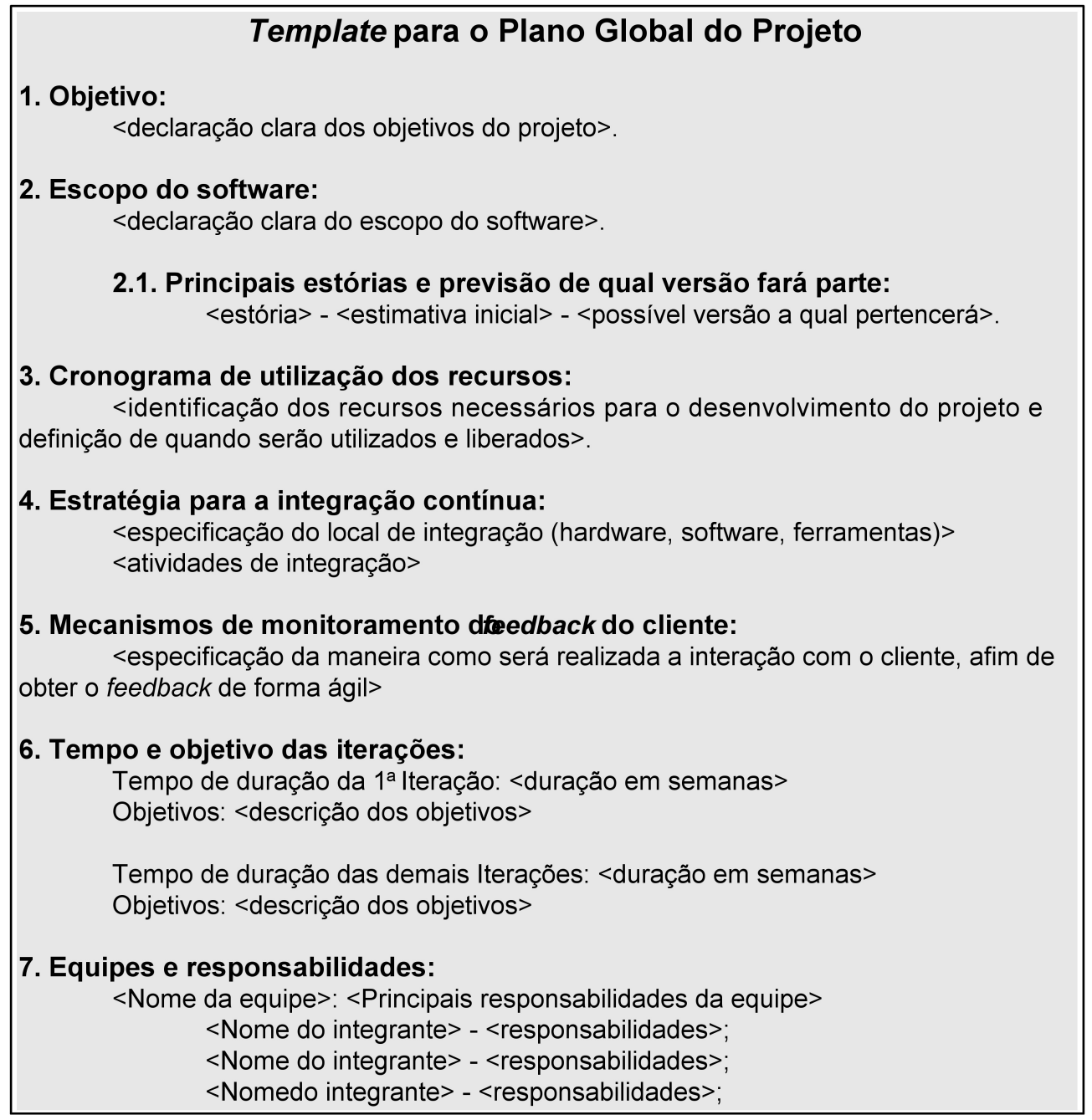

Figura 5.6: Template para a elaboração de um Plano Global para um projeto ágil.

\subsubsection{Grupo de Processos de Desenvolvimento Iterativo (DES)}

\section{DES.01 Planejamento das iterações}

Propósito: O propósito deste processo é priorizar, detalhar e estimar (nesse ponto é feita uma estimativa melhorada) as estórias e definir quais delas farão parte da próxima iteração.

Práticas básicas: Para que os resultados esperados sejam atingidos, algumas práticas básicas devem ser realizadas. As práticas básicas necessárias a este processo são:

DES.01.PB01. Priorizar estórias. Priorizar as estórias definidas pelo cliente. O próprio cliente é o responsável por definir e priorizar as estórias. [Resultado: 1]

DES.01.PB02. Detalhar e estimar estórias. Detalhar cada estória e estimar os esforços necessários para produzí-las. As estimativas são realizadas pela equipe de desenvolvimento. [Resultado: 1] 
DES.01.PB03. Definir estórias para a próxima iteração. Definir quais estórias serão desenvolvidas na próxima iteração. O cliente é o responsável por definir quais estórias devem ser desenvolvidas na próxima iteração. [Resultado: 2]

DES.01.PB04. Criar casos de teste de integração e definir os resultados esperados. Criar ou adaptar casos de teste, e os respectivos resultados esperados, para integrar as estórias a serem desenvolvidas na próxima iteração. A criação de casos de teste de integração, nesse ponto do processo, possibilita que as estórias sejam integradas assim que forem implementadas, adicionando agilidade ao processo de desenvolvimento (Schwaber e Beedle, 2004). [Resultado: 1]

DES.01.PB05. Estabelecer mecanismos para detectar novas estórias e incluí-las ao projeto. As novas estórias podem ser desenvolvidas durante a iteração corrente, se forem originadas de uma estória pertencente a iteração, ou podem ser adicionadas na lista de estórias a serem desenvolvidas nas próximas iterações. [Resultado: 3, 1]

Nota 1: A qualidade de realização dessa tarefa garante a gerência do escopo do projeto e da iteração, e possibilita ao cliente obter feedback freqüente dos custos do projeto (Mnkandla e Dwolatzky, 2006).

DES.01.PB06. Criar um plano para a iteração. Criar um plano para a iteração que contenha os objetivos da iteração, as estórias a serem desenvolvidas, as estimativas de cada estória, os casos de teste de integração, as equipes e suas responsabilidades. $\mathrm{O}$ plano para a iteração deve ser concebido em conjunto com o cliente. Na Figura 5.7 é apresentado um template para um Plano para a Iteração. [Resultado: 4]

Resultados: Para que este processo possa ser considerado um processo implementado, deve haver indícios da realização de algumas atividades e/ou a produção de alguns artefatos. Tais atividades e artefatos referem-se $\mathrm{a}(\mathrm{o})$ :

1. Existência de uma lista de estórias priorizadas e estimadas pelo cliente.

2. Existência de uma lista contendo as estórias que serão desenvolvidas na próxima iteração.

3. Existência de casos de teste de integração, para as estórias a serem desenvolvidas durante a iteração.

4. Existência de uma estratégia para detectar novas estórias e adicioná-las ao projeto ou a iteração.

5. Existência de um plano para a próxima iteração.

Produtos de trabalho: Os processos produzem ou consomem produtos de trabalho. Os produtos de trabalho referentes a este processo são: 


\section{Template para o Plano para a Iteração}

1. Declaração: Esta iteração compõem a versão <número da versão> do software.

2. Objetivos:

<declaração clara dos objetivos da iteração>

3. Estórias a serem desenvolvidas:

<estória> - <estimativa>;

$<$ estória $>$ - <estimativa $>$.

$<$ estória $>$ - <estimativa>.

4. Equipes e responsabilidades durante a iteração:

$<$ Nome da equipe>: <Principais responsabilidades da equipe> $<$ Nome do integrante $>$ - <responsabilidades na iteração $>$

$<$ Nome do integrante $>$ - <responsabilidades na iteração>;

$<$ Nomedo integrante $>$ - <responsabilidades na iteração>;

\section{Lista de estórias adicionadas a iteração}

<estória> - <estimativa>;

$<$ estória $>$ - <estimativa>

$<$ estória $>$ - <estimativa>

Figura 5.7: Template para a elaboração de um Plano para a Iteração.

\begin{tabular}{||l|l||}
\hline Produtos de trabalho de entrada & Produtos de trabalho de saída \\
\hline - Projeto arquitetural do sistema & - Plano para a iteração \\
- Projeto arquitetural do software & - Casos de teste de integração \\
- Modelo de negócios do sistema & \\
- Lista de estórias e de requisitos não- & \\
funcionais & \\
- Plano global do projeto & \\
\hline
\end{tabular}

\section{DES.02 Produção de estórias}

Propósito: O propósito deste processo é codificar e documentar estórias através da utilização de técnicas de implementação que produzam códigos mais eficientes, mais simples e com menos erros.

Práticas básicas: Para que os resultados esperados sejam atingidos, algumas práticas básicas devem ser realizadas. As práticas básicas necessárias a este processo são:

DES.02.PB01. Criar casos de teste de unidade e resultados esperados. Criar ou adaptar casos de testes unitários, e respectivos resultados esperados, para as estórias a serem produzidas. Os casos de teste devem ser criados antes do início da codificação das estórias. Essa prática permite que as estórias implementadas possam ser validadas assim que a implementação for concluída. [Resultado: 1] 
DES.02.PB02. Produzir código de software que implemente as estórias. Os códigos devem ser produzidos com o auxílio de ferramentas de desenvolvimento. O código deve ser padronizado, documentado, simples e devem implementar os requisitos minimamente, ou seja, somente o que o cliente quer, sem nenhum recurso adicional (Williams, 2003). [Resultado: 2, 5]

Nota 1: A produção de código simples e de requisitos mínimos, aliada à comunicação intensa com o cliente, à resposta rápida às alterações de requisitos e à criação de casos de teste antes da codificação, aumenta as chances do sistema ser construído de forma correta. A corretitude é um fator de qualidade que deve ser considerado em um processo de garantia de qualidade (Mnkandla e Dwolatzky, 2006).

Nota 2: A padronização e documentação do código aumentam a manutenibilidade, a reusabilidade e a eficiência. A manutenibilidade, a reusabilidade e a eficiência são fatores de qualidade que devem ser considerados em um processo de garantia de qualidade (Mnkandla e Dwolatzky, 2006). Na Figura 5.8 é apresentado um exemplo de um checklist que orienta a criação de um código-fonte padronizado e documentado.

Nota 3: Uma prática denominada refactoring é bastante útil para a produção de códio padronizado e documentado. A prática, aplicada por diversas metodologias ágeis, encoraja os desenvolvedores a alterarem o código para torná-lo mais claro e eficiente (Highsmith e Cockburn, 2001; Boehm, 2002).

DES.02.PB03. Realizar testes unitários. Executar os casos de teste pré-definidos. Os testes unitários devem ser realizados de forma automatizada ou semi-automatizada (Highsmith, 2002). [Resultado: 3]

Nota 1: A execução dos testes unitários ajuda na validação e verificação do software. As atividades de validação e verificação devem ser consideradas em um processo de garantia de qualidade (Mnkandla e Dwolatzky, 2006).

DES.02.PB04. Armazenar os resultados dos testes unitários realizados. Os resultados dos testes podem ser utilizados para serem comparados a resultados de testes posteriores. [Resultado: 4]

Resultados: Para que este processo possa ser considerado um processo implementado, deve haver indícios da realização de algumas atividades e/ou a produção de alguns artefatos. Tais atividades e artefatos referem-se a(o):

1. Existência de casos de teste unitário para validar as estórias; 


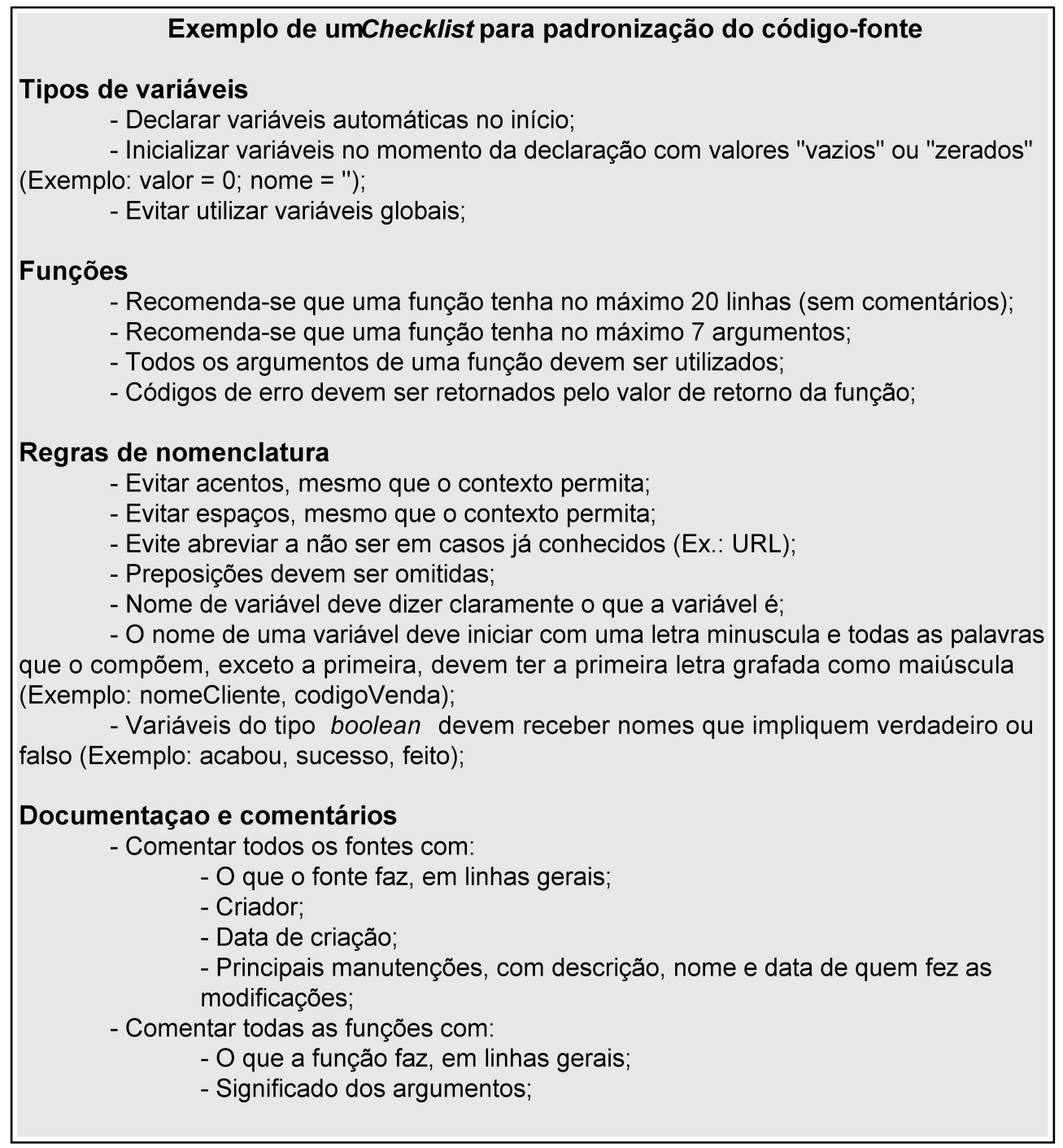

Figura 5.8: Exemplo de um checklist para a padronização e documentação do código-fonte (Microsoft, 2007).

2. Existência de estórias implementadas satisfatóriamente;

3. Realização de testes unitários;

4. Registro dos resultados dos testes realizados;

5. Existência de código de software padronizado e documentado;

Produtos de trabalho: Os processos produzem ou consomem produtos de trabalho. Os produtos de trabalho referentes a este processo são:

\begin{tabular}{||l|l||}
\hline Produtos de trabalho de entrada & Produtos de trabalho de saída \\
\hline - Lista de estórias e de requisitos não- & - Casos de teste unitário \\
funcionais & \\
- Modelo de negócios do sistema & - Estória implementada \\
- Projeto arquitetural do sistema & - Resultados dos testes unitários \\
\hline
\end{tabular}


- Projeto arquitetural do software

- Projeto de banco de dados

- Plano para a iteração

- Ferramentas de desenvolvimento

- Padrões de codificação

\section{DES.03 Tratamento de riscos}

Propósito: O propósito deste processo é identificar, analisar, tratar e monitorar os riscos do projeto de forma contínua e iterativa.

Práticas básicas: Para que os resultados esperados sejam atingidos, algumas práticas básicas devem ser realizadas. As práticas básicas necessárias a este processo são:

DES.03.PB01. Identificar riscos. Identificar os riscos do projeto durante a realização das iterações. Os riscos devem ser identificados iterativamente e devem ser registrados em locais visíveis (quadro, lousa, ferramenta) e de fácil acesso aos desenvolvedores. Após identificados, os riscos devem ser colocados na pauta da reunião do dia, para serem analisados (Highsmith, 2000). [Resultado: 1]

Nota 1: Exemplos de riscos que podem ser identificados são: custos, cronogramas, recursos, etc.

DES.03.PB02. Analisar riscos. Analisar os riscos qualitativamente, produzindo uma lista priorizada, indicando quais poderão ser eliminados e quais serão monitorados. Os resultados da análise podem influenciar o trabalho planejado para a iteração corrente. [Resultado: 1]

Nota 1: O resultado da análise deve ser mantido em local visível e de fácil acesso aos desenvolvedores. Lousas e quadros podem ser utilizados para esse fim (Highsmith, 2000).

DES.03.PB04. Definir/realizar ações para gerenciar os riscos. Definir/realizar atividades para gerenciar o risco, eliminar o risco ou reduzir seu impacto. Essa tarefa é realizada por todos os membros da equipe e as decisões tomadas devem estar em locais visíveis e de fácil acesso aos desenvolvedores. Lousas e quadros podem ser utilizados para esse fim. [Resultado: 2]

Nota 1: As reuniões regulares, as métricas de performance, os workshops ao final de cada iteração, entre outras práticas, auxiliam o gerenciamento dos riscos. 
Resultados: Para que este processo possa ser considerado um processo implementado, deve haver indícios da realização de algumas atividades e/ou a produção de alguns artefatos. Tais atividades e artefatos referem-se a(o):

1. Existência de atividades que identifiquem, analisem e priorizem os riscos;

2. Realização de ações para a eliminação e/ou gerenciamento do risco.

Produtos de trabalho: Os processos produzem ou consomem produtos de trabalho. Os produtos de trabalho referentes a este processo são:

\begin{tabular}{||l|l||}
\hline Produtos de trabalho de entrada & Produtos de trabalho de saída \\
\hline - Plano para a iteração & - Lista de riscos identificados \\
& - Atividades para o gerenciamento de riscos \\
\hline
\end{tabular}

\section{DES.04 Integração contínua}

Propósito: O propósito deste processo é combinar as unidades do software e do sistema (itens de software, de hardware, outros sistemas) produzindo itens integrados, consistentes com o projeto e que demonstrem que as estórias e os requisitos não-funcionais estão satisfatoriamente implantados em uma plataforma operacional completa.

Práticas básicas: Para que os resultados esperados sejam atingidos, algumas práticas básicas devem ser realizadas. As práticas básicas necessárias a este processo são:

DES.04.PB01. Executar os procedimentos de integração. Integrar as unidades de software produzidas em uma plataforma operacional, de acordo com a estratégia de integração definida no planejamento global do projeto. [Resultado: 1,2]

DES.04.PB02. Realizar testes de integração. Executar os casos de teste de integração, definidos no planejamento das iterações, com cada item integrado, de acordo com a estratégia de integração definida. [Resultado: 1,2]

Nota 1: A realização dos testes de integração ajudam a validação e verificação do software. As atividades de validação e verificação devem ser consideradas em um processo de garantia de qualidade (Mnkandla e Dwolatzky, 2006).

DES.04.PB03. Armazenar os resultados dos testes de integração. [Resultado: 3]

Resultados: Para que este processo possa ser considerado um processo implementado, deve haver indícios da realização de algumas atividades e/ou a produção de alguns artefatos. Tais atividades e artefatos referem-se a(o): 
1. Execução de procedimentos de integração;

2. Existência de uma versão do software com qualidade de produção;

3. Registro dos resultados dos testes de integração realizados.

Produtos de trabalho: Os processos produzem ou consomem produtos de trabalho. Os produtos de trabalho referentes a este processo são:

\begin{tabular}{||l|l||}
\hline Produtos de trabalho de entrada & Produtos de trabalho de saída \\
\hline - Casos de teste de integração & - Versão integrada da estória \\
- Plano global do projeto & - Resultados dos testes de integração \\
- Estória implementada & \\
\hline
\end{tabular}

\section{DES.05 Refinamento de produtos e processos}

Propósito: O propósito deste processo é refinar (melhorar) continuamente a qualidade dos processos e produtos a cada iteração.

Práticas básicas: Para que os resultados esperados sejam atingidos, algumas práticas básicas devem ser realizadas. As práticas básicas necessárias a este processo são:

DES.05.PB01. Identificar falhas ou problemas durante o desenvolvimento. Identificar falhas ou problemas que ocorrem nos processos ou nos produtos de trabalho produzidos durante o desenvolvimento. A realização de workshops ao final de cada iteração auxilia nessa tarefa. [Resultado: 1]

DES.05.PB02 Armazenar falhas ou problemas encontrados pelo cliente ou desenvolvedores. As falhas e problemas encontrados são armazenadas para posterior consulta. [Resultado: 3]

DES.05.PB03. Definir atividades de refinamento (melhoria). Definir atividades para refinar (melhorar) os produtos e os processos na próxima iteração. Os produtos e processos devem ser refinados a cada iteração, proporcionando uma melhora na qualidade dos produtos intermediários e, consequentemente, do produto final (Mnkandla e Dwolatzky, 2006). [Resultado: 2]

DES.05.PB04 Realizar atividades de refinamento (melhoria). Executar as atividades de refinamento (melhoria) pré-definidas. [Resultado: 4]

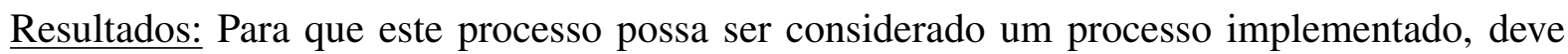
haver indícios da realização de algumas atividades e/ou a produção de alguns artefatos. Tais atividades e artefatos referem-se a(o):

1. Identificação de falhas ou problemas em um ciclo de desenvolvimento. 
2. Definição de atividades para refinar os produtos e melhorar o desempenho dos processos na próxima iteração.

3. Existência de registros de falhas ou problemas encontrados durante o ciclo de desenvolvimento.

4. Existência de atividades de refinamento das falhas ou problemas detectados.

Produtos de trabalho: Os processos produzem ou consomem produtos de trabalho. Os produtos de trabalho referentes a este processo são:

\begin{tabular}{||l|l||}
\hline Produtos de trabalho de entrada & Produtos de trabalho de saída \\
\hline - Plano global do projeto & - Falhas e problemas encontrados \\
- Plano da iteração & - Atividades de refinamento (melhoria) \\
- Descrição do processo & - Nova versão do produto e/ou do processo \\
- Produto de trabalho & \\
\hline
\end{tabular}

\subsubsection{Grupo de Processos de Operação (OPE) OPE.01 Colocar versão em produção}

Propósito: O propósito deste processo é colocar em produção uma versão do software que atende aos requisitos pretendidos.

Práticas básicas: Para que os resultados esperados sejam atingidos, algumas práticas básicas devem ser realizadas. As práticas básicas necessárias a este processo são:

OPE.01.PB01. Criar um guia de instalação que oriente a instalação de uma nova versão do software. [Resultado: 1]

OPE.01.PB02. Definir critérios de instalação. Definir critérios que ajudem a demonstrar que a instalação foi bem sucedida. [Resultado: 2]

OPE.01.PB03. Instalar a versão do software. Seguir os critérios e o guia de intalação definidos e colocar a versão do software em ambiente operacional. Uma instalação bem sucedida é percebida quando os critérios de instalação são alcançados. [Resultado: 3]

OPE.01.PB04. Armazenar os eventos e/ou resultados relevantes. [Resultado: 4]

OPE.01.PB05. Auxiliar o usuário na operação do software. Auxiliar os usuários a operarem a nova versão do software de forma satisfatória. [Resultado: 5]

Resultados: Para que este processo possa ser considerado um processo implementado, deve haver indícios da realização de algumas atividades e/ou a produção de alguns artefatos. Tais atividades e artefatos referem-se a(o): 
1. Existência de um guia para colocar versões de software em ambiente de operação;

2. Existência de critérios a serem utilizados para demonstrar que a versão posta em ambiente operacional está em conformidade com osrequisitos de instalação definidos;

3. Existência de uma versão de software instalada e operando no ambiente ao qual se destina;

4. Registro de eventos e/ou resultados relevantes ocorridos durante a instalação;

5. Existência de auxilio ao usuário na operação inicial da nova versão;

Produtos de trabalho: Os processos produzem ou consomem produtos de trabalho. Os produtos de trabalho referentes a este processo são:

\begin{tabular}{||l|l||}
\hline Produtos de trabalho de entrada & Produtos de trabalho de saída \\
\hline - Projeto arquitetural do sistema & - Guia de instalação \\
- Projeto arquitetural do software & - Relatório de incidentes \\
- Versão do software & - Plano de treinamento dos usuários \\
\hline
\end{tabular}

\section{OPE.02 Manutenção}

Propósito: O propósito deste processo é gerenciar modificações, na versão do software em ambiente de operação, referentes a correção de defeitos, a adaptações, ao desenvolvimento de novas estórias e a facilidades de realizar os outros propósitos (correção de defeitos, adaptações e desenvolvimento de novas estórias).

Práticas básicas: Para que os resultados esperados sejam atingidos, algumas práticas básicas devem ser realizadas. As práticas básicas necessárias a este processo são:

OPE.02.PB01. Estabelecer estratégia para gerenciar modificações. Produzir um plano para gerenciar correções, adaptações e/ou inclusão de novas estórias à versão de software em operação. [Resultado: 1]

Nota 1: Frequentemente, uma equipe é designada para realizar a manutenção do sistema. Essa prática permite manter uma equipe desenvolvendo novas estórias, enquanto outra realiza as correções necessárias. Para que essa prática adicione agilidade ao processo, é preciso que a equipe de manutenção seja definida no planejamento global do projeto.

OPE.02.PB02. Receber solicitações de modificação. Receber solicitações de modificação do cliente, através de um mecanismo de comunicação eficiente. [Resultado: 
OPE.02.PB03. Analisar impacto das solicitações. Determinar o impacto que as solicitações solicitadas podem causar na versão de software em operação. [Resultado: 2]

OPE.02.PB04. Avaliar as solicitações de modificação. Avaliar as solicitações e determinar se são viáveis, aprovando ou reprovando a solicitação. O resultado da avaliação deve ser armazenado para futuras consultas. [Resultado: 2]

OPE.02.PB05. Atualizar documentação. Atualizar os documentos que serão afetados com as modificações. [Resultado: 3]

OPE.02.PB06. Implementar e testar modificações. Implementar e testar as modificações, demonstrando que os requisitos e a integridade do sistema e do software não foram compremetidos. [Resultado: 4]

OPE.02.PB07. Atualizar o sistema em operação. Transportar a versão modificada do software para um ambiente operacional. A nova versão deve manter um grau de funcionamento que deve ser aprovado pelo cliente. A aprovação do cliente deve ser registrada. [Resultado: 5]

OPE.02.PB08. Divulgar modificações. Divulgar as modificações realizadas aos interessados. [Resultado: 6]

Resultados: Para que este processo possa ser considerado um processo implementado, deve haver indícios da realização de algumas atividades e/ou a produção de alguns artefatos. Tais atividades e artefatos referem-se a(o):

1. Existência de uma estratégia para gerenciar as modificações necessárias e/ou requeridas pelo usuário.

2. Existência de um mecanismo para receber solicitações, analisar o impacto das mesmas no projeto e aprovar ou reprovar as solicitações.

3. Existência de uma estratégia para atualizar os documentos afetados pelas modificações.

4. Existência de mecanismos que demonstrem que as estórias e requisitos implementados não foram comprometidos.

5. Existência de um sistema com grau de funcionamento aceitável em ambiente operacional.

6. Divulgação das modificações realizadas a todas as partes interessadas.

Produtos de trabalho: Os processos produzem ou consomem produtos de trabalho. Os produtos de trabalho referentes a este processo são: 


\begin{tabular}{||l|l||}
\hline Produtos de trabalho de entrada & Produtos de trabalho de saída \\
\hline - Requisição de evolução & - Versão modificada do software \\
- Versão do software & - Relatório de modificações \\
- Modelo de negócios do sistema & - Registro de aceitação \\
- Projeto arquitetural do software & - Plano de gerenciamento de manutenção \\
- Projeto arquitetural do sistema & \\
- Projeto de banco de dados & \\
\hline
\end{tabular}

\section{OPE.03 Encerramento}

Propósito: O propósito deste processo é entregar ao cliente uma versão final do sistema que satisfaça os requisitos desejados.

Práticas básicas: Para que os resultados esperados sejam atingidos, algumas práticas básicas devem ser realizadas. As práticas básicas necessárias a este processo são:

OPE.03.PB01. Produzir e/ou atualizar documentos. Produzir e/ou atualizar os documentos que devem ser produzidos ou mantidos pelo projeto. [Resultado: 1]

Nota 1: Os documentos que não são necessários, durante o desenvolvimento, aos desenvolvedores e clientes, mas que devem ser produzidos pelo projeto (de acordo com a lista de documentos a serem mantidos), são criados no processo de encerramento. Essa prática adiciona agilidade ao processo, pois evita que documentos sejam produzidos antes de serem necessários e, com isso, economiza-se tempo de produçao e atualização (Schwaber e Beedle, 2004).

OPE.03.PB02. Entregar versão completa do sistema ao cliente. Colocar a versão completa do sistema em operação e entregar para o cliente toda a documentação produzida. [Resultado: 1, 2]

OPE.03.PB03. Treinar usuários. Capacitar os usuários do sistema a utilizarem-no de forma adequada e eficiente. [Resultado: 3]

$\underline{\text { Resultados: }}$ Para que este processo possa ser considerado um processo implementado, deve haver indícios da realização de algumas atividades e/ou a produção de alguns artefatos. Tais atividades e artefatos referem-se a(o):

1. Produzir documentação completa e atualizada do sistema.

2. Existência de uma versão completa do software operando em local definido pelo cliente. 
3. Existência de usuários capacitados a utilizar o sistema desenvolvido.

Produtos de trabalho: Os processos produzem ou consomem produtos de trabalho. Os produtos de trabalho referentes a este processo são:

\begin{tabular}{||l|l||}
\hline Produtos de trabalho de entrada & Produtos de trabalho de saída \\
\hline - Lista de documentos a serem mantidos & - Versão completa do sistema \\
- Versão do software & \\
\hline
\end{tabular}

\subsubsection{Grupo de Processos de Apoio (APO)}

\section{APO.01 Gerência de configuração de software}

Propósito: O propósito deste processo é identificar os itens de software que devem possuir várias versões e gerenciar as versões desses itens. O processo deve armazenar um histórico das versões dos itens e permitir que as versões sejam recuperadas e/ou evoluídas, compondo, no segundo caso, uma nova versão.

Práticas básicas: Para que os resultados esperados sejam atingidos, algumas práticas básicas devem ser realizadas. As práticas básicas necessárias a este processo são:

APO.01.PB01. Estabelecer uma estratégia para a implantação de gerência de configuração. Produzir um plano de implantação de gerência de configuração que inclua a ferramenta de controle de versões, o esquema de identificação dos itens de configuração, atividades para relatar o estado dos itens de configuração e o cronograma de implantação da gerência de configuração (Koskela, 2003). Na Figura 5.9 é apresentado um template para um plano de implantação de gerência de configuração. [Resultado: $1,2,3,4,5]$

APO.01.PB02. Selecionar os itens de configuração. Selecionar os itens que devem ser identificados, armazenados, testados, utilizados, alterados, disponibilizados e/ou mantidos no repositório. O conjunto mínimo de itens de configuração exigidos em um projeto ágil é apresentado na Figura 5.10. [Resultado: 2]

APO.01.PB03. Estabelecer um esquema de identificação para os itens de configuração. Definir um esquema de identificação que descreva a maneira como cada item será denominado. O esquema deve permitir conhecer a evolução das versões de cada item. Na Figura 5.11 é apresentado um exemplo de um esquema de identificação com o conjunto mínimo de itens de configuração exigidos em um projeto ágil. [Resultado: 3]

APO.01.PB04. Controlar versões. Utilizar ferramentas para auxiliar no controle das versões dos itens de configuração. A ferramenta deve "bloquear" o acesso a um item 


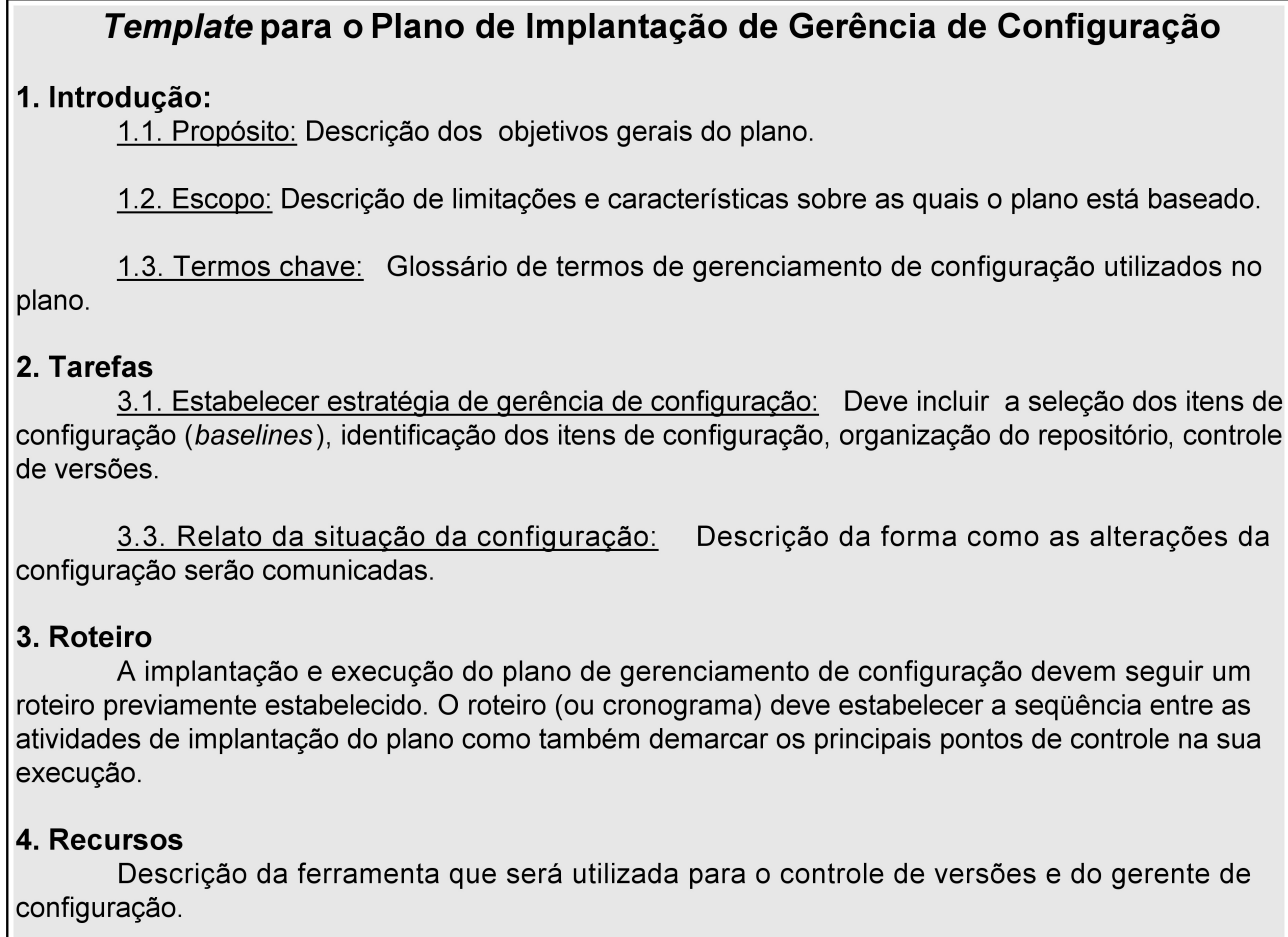
roteiro previamente estabelecido. O roteiro (ou cronograma) deve estabelecer a seqüência entre as atividades de implantação do plano como também demarcar os principais pontos de controle na sua execução.

4. Recursos configuração.

Descrição da ferramenta que será utilizada para o controle de versões e do gerente de

Figura 5.9: Template de um Plano de Implantação de Gerência de Configuração.

de configuração quando esse já estiver sendo acessado por algum usuário. Algumas ferramentas que podem ser utilizadas para esse fim são: Concurrent Versions System (CVS) (Bar e Fogel, 2003), Subversion (Collins-Sussman et al., 2004). [Resultado: 4] APO.01.PB05. Relatar situação dos itens de configuração. Relatar informações atualizadas sobre os itens de configuração. [Resultado: 5]

Resultados: Para que este processo possa ser considerado um processo implementado, deve haver indícios da realização de algumas atividades e/ou a produção de alguns artefatos. Tais atividades e artefatos referem-se $\mathrm{a}(\mathrm{o})$ :

1. Existência de um plano de implantação de gerência de configuração;

2. Existência de uma lista de itens de informação e/ou produtos de trabalho que devem ser colocados sob controle de configuração;

3. Existência de um esquema de identificação para os itens de configuração;

4. Existência de uma ferramenta para auxiliar o controle de versões dos itens de configuração;

5. Relato do estado dos itens de configuração.

Produtos de trabalho: Os processos produzem ou consomem produtos de trabalho. Os produtos de trabalho referentes a este processo são: 


\begin{tabular}{|c|c|}
\hline \multicolumn{2}{|c|}{ Conjunto mínimo de itens de configuração exigidos } \\
\hline $\begin{array}{l}\text { Processo INI.01 } \\
\text { - Lista de estórias e de requisitos não-funciona } \\
\text { - Modelo de negócios do sistema } \\
\text { Processo INI.04 } \\
\text { - Projeto arquitetural do sistema } \\
\text { - Projeto arquitetural do software } \\
\text { - Projeto de banco de dados } \\
\text { Processo INI.05 } \\
\text { - Plano global do projeto } \\
\text { Processo DES.01 } \\
\text { - Casos de teste de integração }\end{array}$ & $\begin{array}{l}\text { Processo DES.02 } \\
\text { S - Casos de teste unitário } \\
\text { - Resultados dos testes unitários } \\
\text { Processo DES. } 04 \\
\begin{array}{l}\text { - Versão integrada da estória } \\
\text { - Resultados dos testes de integração }\end{array} \\
\text { Processo DES. } 05 \\
\begin{array}{l}\text { - Nova versão do produto e/ou do processo } \\
\text { Processo OPE. } 02\end{array} \\
\text { - Versão modificada do software } \\
\text { Processo OPE. } 03 \\
\text { - Versão completa do sistema }\end{array}$ \\
\hline
\end{tabular}

Figura 5.10: Conjunto mínimo de itens de configuração em um projeto ágil e os respectivos processos que os produzem.

\begin{tabular}{|c|c|c|c|c|c|c|}
\hline Item de configuração & Projeto & Tipo & Nome & Versão & \multicolumn{2}{|c|}{ Nome completo } \\
\hline $\begin{array}{l}\text { Lista de estórias e de requisitos } \\
\text { nẫo-funcionais }\end{array}$ & AA & LE & & 1.1 & AALE & $\mathrm{v} 1.1$ \\
\hline Modelo de negócios do sistema & AA & $\mathrm{MN}$ & & 1.1 & AAMN & $\mathrm{v1.1}$ \\
\hline Projeto arquitetural do sistema & AA & $\mathrm{PA}$ & Sis & 1.1 & AAPASis & V1.1 \\
\hline Projeto arquitetural do software & AA & $\mathrm{PA}$ & Sw & 1.1 & AAPASw & $\mathrm{v1.1}$ \\
\hline Projeto de banco de dados & $\mathrm{AA}$ & $\mathrm{PB}$ & & 1.1 & AAPB & V1.1 \\
\hline Plano global do projeto & AA & $P G$ & & 1.1 & AAPG & $\mathrm{v} 1.1$ \\
\hline Casos de teste de integraçẫo & AA & CT & Int & 1.1 & AACTInt & $\mathrm{v1.1}$ \\
\hline Casos de teste unitário & AA & CT & Unit & 1.1 & AACTUnit & $\mathrm{v1.1}$ \\
\hline Resultados dos testes unitários & AA & RT & Unit & 1.1 & AARTUnit & $\mathrm{v} 1.1$ \\
\hline Versẫo integrada da estória & AA & $\mathrm{V} \mid$ & & 1.1 & AAVI & $\mathrm{v1.1}$ \\
\hline $\begin{array}{l}\text { Resultados dos testes de } \\
\text { integraçẫo }\end{array}$ & AA & RT & Int & 1.1 & AARTInt & $\mathrm{v1.1}$ \\
\hline $\begin{array}{l}\text { Nova versão do produto e/ou do } \\
\text { processo }\end{array}$ & AA & NV & & 1.2 & AANV & $\mathrm{v1.2}$ \\
\hline Versão modificada do software & $\mathrm{AA}$ & $\mathrm{VM}$ & & 1.2 & AAVM & $\mathrm{v} 1.2$ \\
\hline Versẫo completa do sistema & $\mathrm{AA}$ & $\mathrm{VC}$ & & 1.1 & AAVC & $\mathrm{v1.1}$ \\
\hline
\end{tabular}

Figura 5.11: Exemplo de um esquema de identificação com o conjunto mínimo de itens de configuração exigidos.

\begin{tabular}{||l|l||}
\hline Produtos de trabalho de entrada & Produtos de trabalho de saída \\
\hline - Ferramenta para o controle de versões & - Plano de implantação de gerência de confi- \\
& guração \\
- Lista de itens de informação & - Repositório de itens de configuração \\
\hline
\end{tabular}

\section{APO.02 Preparação / Evolução da documentação}

Propósito: O propósito deste processo é identificar quais informações, produzidas pelos processos, precisam ser registradas para aumentar a produtividade e a qualidade dos processos e registrar essas informações de forma simples e padronizada.

Práticas básicas: Para que os resultados esperados sejam atingidos, algumas práticas básicas devem ser realizadas. As práticas básicas necessárias a este processo são: 
APO.02.PB01: Identificar quais documentos precisam ser produzidos. Um novo documento deve ser produzido quando for percebido que sua ausência está provocando lentidão ao processo e quando não houver um mecanismo de comunicação que substitua, eficientemente, a necessidade de sua criação (Agile Modeling Web Site, 2006; Elrad et al., 2003). Essa atividade produz uma lista de documentos que devem ser produzidos. A Lista deve incluir informações de quando o documento deve ser produzido e/ou atualizado. Na Figura 5.12 é apresentada uma sugestão de um conjunto mínimo de documentos que deve ser produzido em um projeto ágil. [Resultado: 1]

\begin{tabular}{|c|c|}
\hline \multicolumn{2}{|c|}{ Conjunto mínimo de documentos a serem produzidos } \\
\hline $\begin{array}{l}\text { Processo INI.01 } \\
\text { - Lista de estórias e de requisitos não-funciona } \\
\text { - Modelo de negócios do sistema } \\
\text { Processo APO.01 } \\
\text { configuração im plantação de gerência de } \\
\text { Processo APO.02 } \\
\text { - Lista de documentos a serem mantidos } \\
\text { - Padrões para os documentos } \\
\text { Processo APO.03 } \\
\text { - Plano de qualidade } \\
\text { Processo INI.02 } \\
\text { - Plano de treinamento } \\
\text { Processo INI.04 } \\
\text { - Projeto arquitetural do sistema } \\
\text { - Projeto arquitetural do software } \\
\text { - Projeto de banco de dados }\end{array}$ & $\begin{array}{l}\text { Processo INI.05 } \\
\text { Is - Plano global do projeto } \\
\text { Processo DES.01 } \\
\text { - Casos de teste de integração } \\
\text { - Plano para a iteração } \\
\text { Processo DES.02 } \\
\text { - Casos de teste unitário } \\
\text { - Resultados dos testes unitários } \\
\text { Processo DES.04 } \\
\text { - Resultados dos testes de integração } \\
\text { Processo OPE.01 } \\
\text { - Guia de instalação } \\
\text { - Plano de treinamento dos usuários } \\
\text { - Relatório de incidentes } \\
\text { Processo OPE.02 } \\
\text { - Relatório de modificações } \\
\text { - Registro de aceitação } \\
\text { - Plano de gerenciamento de manutenção }\end{array}$ \\
\hline
\end{tabular}

Figura 5.12: Conjunto mínimo de documentos que devem ser produzidos em um projeto ágil e os respectivos processos que os produzem.

Nota 1: Exemplo: Uma lousa (um mecanismo de comunicação) pode ser utilizada para a apresentação das estórias adicionadas à iteração, suprindo a necessidade de criação de um documento que contenha tais estórias.

APO.02.PB02: Definir a linguagem e os padrões para os documentos. Definir a linguagem que deve ser utilizada e os padrões que devem ser seguidos na produção dos documentos. [Resultado: 3]

APO.02.PB03: Estabelecer a organização, manutenção e localização dos documentos. Produzir um esquema para organizar os documentos, facilitar a localização e definir um mecanismo para armazenar, manter e/ou eliminar os documentos obsoletos. [Resultado: 2,4$]$

APO.02.PB04: Produzir e manter documentos. Produzir e manter os documentos sempre padronizados e simples. [Resultado: 4] 
Nota 1: Os documentos devem ter o detalhamento suficiente para atingir seus objetivo, devem ser de fácil manutenção e devem estar devidamente identificados (Agile Modeling Web Site, 2006; Elrad et al., 2003).

APO.02.PB05: Divulgar a criação de documentos. Divulgar aos interessados que um novo documento foi produzido, informando qual o seu conteúdo. [Resultado: 5]

Resultados: Para que este processo possa ser considerado um processo implementado, deve haver indícios da realização de algumas atividades e/ou a produção de alguns artefatos. Tais atividades e artefatos referem-se a(o):

1. Existência de uma lista mínima de documentos que devem ser produzidos;

2. Estabelecimento da organização dos documentos;

3. Definição de linguagem e padrões a serem utilizados nos documentos;

4. Existência de atividades que produzam e mantenham os documentos;

5. Existência de atividades de divulgação.

Produtos de trabalho: Os processos produzem ou consomem produtos de trabalho. Os produtos de trabalho referentes a este processo são:

\begin{tabular}{||l|l||}
\hline Produtos de trabalho de entrada & Produtos de trabalho de saída \\
\hline - Requisitos do documento & - Padrões de documentação \\
& - Lista de documentos a serem mantidos \\
\hline
\end{tabular}

\section{APO.03 Revisão e garantia de qualidade}

Propósito: O propósito deste processo é assegurar que os produtos de software tenham qualidade (de acordo com os requisitos de qualidade especificados) e sejam produzidos de acordo com os planos estabelecidos.

Práticas básicas: Para que os resultados esperados sejam atingidos, algumas práticas básicas devem ser realizadas. As práticas básicas necessárias a este processo são:

APO.03.PB01. Definir um modelo de qualidade. Estabelecer um modelo de qualidade que contenha os fatores de qualidade que devem ser considerados e as métricas a serem utilizadas para avaliar os fatores estabelecidos. Os fatores de qualidade para as metodologias ágeis são apresentados na Figura 5.13 (Mnkandla e Dwolatzky, 2006). [Resultado: 1]

APO.03.PB02. Identificar as práticas de desenvolvimento que devem ser utilizadas para garantir a qualidade. Identificar quais práticas ágeis serão úteis para atingir os 


\section{Fatores de qualidade para as Metodologias Áge: $c_{:}$}

Portabilidade: Facilidade de instalar o software em diferentes plataformas de hardware e software.

Timelines: Entrega de versão do software antes ou exatamente quando o cliente precisa.

Integridade: Quanto o acesso ao software ou a dados, por pessoas não-autorizadas, pode ser controlado.

Verificabilidade e validação: Quanto fácil é testar o sistema.

Usabilidade: Facilidade com que as pessoas, de vários níveis de conhecimento, podem aprender e utilizar o software.

Manutenibilidade: Facilidade para modificar o software para corrigir defeitos ou reunir novos requisitos.

Custo-efetividade: Habilidade do sistema de ser completado com o orçamento previsto.
Corretitude: Habilidade do sistema de agir de acordo com a especificação definida

Robustez: Execução apropriada do sistema sobre casos não cobertos pela especificação. Esse fator complementa a corretitude.

Extendibilidade: Habilidade do sistema em adaptarse a novas especificações.

Reusabilidade: Software que é composto de elementos que podem ser utilizados para construir outras aplicações.

Compatibilidade: Software que é composto de elementos que podem, facilmente, combinar com outros elementos.

Eficiência: Quantidade de recursos de computação e de código exigida para que um programa execute sua função.

Figura 5.13: Fatores de qualidade para as metodologias de desenvolvimento ágil (Mnkandla e Dwolatzky, 2006).

fatores de qualidade definidos no modelo de qualidade, relacionando as práticas aos respectivos fatores. [Resultado: 2]

Nota 1: As práticas podem ser escolhidas dentre as diversas práticas ágeis sugeridas pelas diversas metodologias ágeis existentes atualmente. Por exemplo, a prática Sprint da metodologia Scrum pode ser útil para maximizar a qualidade do fator de qualidade denominado "Custo-efetividade", pois controla o escopo das iterações e, com isso, pode auxiliar no controle do orçamento (Mnkandla e Dwolatzky, 2006).

APO.03.PB03. Definir uma estratégia para garantir que as práticas estão sendo executadas corretamente. A estratégia deve descrever como a prática deve ser aplicada e como detectar problemas na forma com que a prática está sendo executada. [Resultado: 3]

APO.03.PB04. Produzir um plano de qualidade. Criar um plano que inclua o modelo de qualidade, as práticas ágeis a serem utilizadas e a estratégia para garantir a correta execução das práticas. Na Figura 5.14 é apresentado um template para um plano de qualidade. [Resultado: 4]

APO.03.PB04. Revisar a execução das práticas. Revisar a execução das práticas para garantir que estão sendo executadas corretamente. [Resultado: 5] 


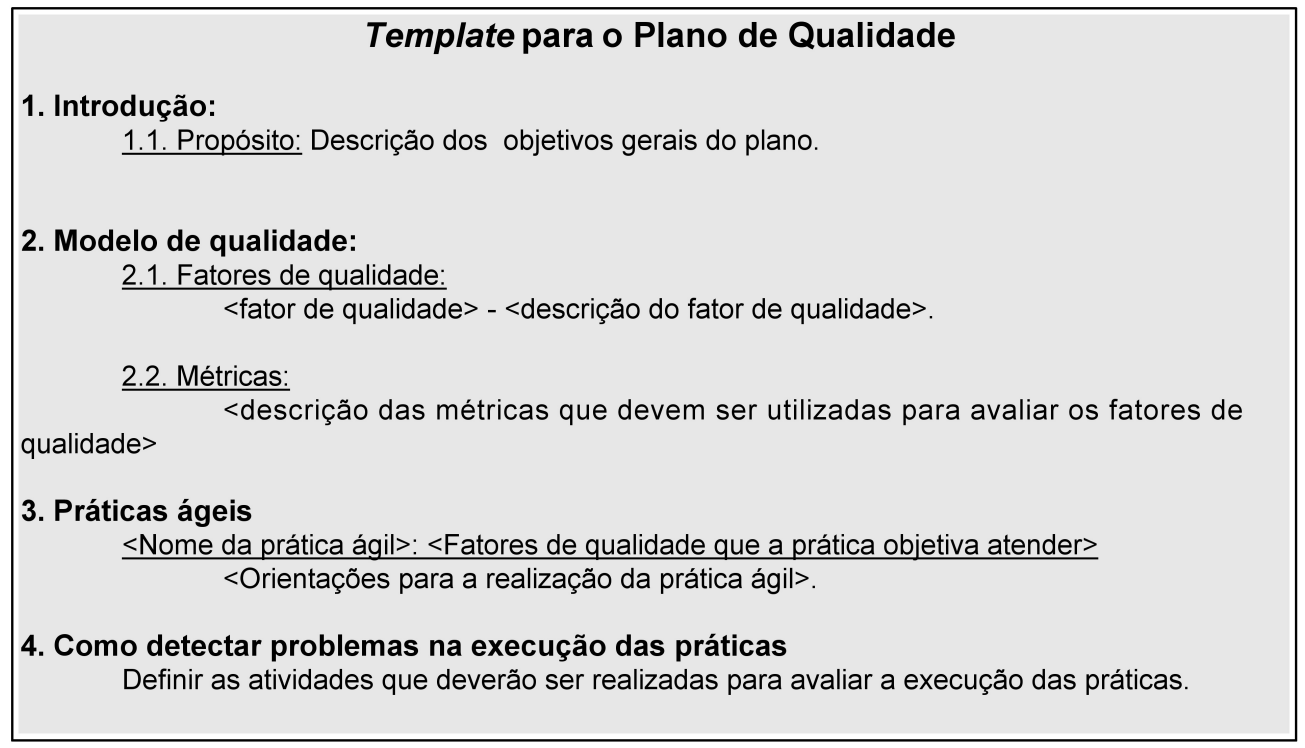

Figura 5.14: Template para o plano de qualidade.

APO.03.PB06. Definir ações de correção para as falhas encontradas na execução das práticas. Definir e priorizar ações a serem tomadas para solucionar problemas identificados durante a revisão. [Resultado: 6]

Resultados: Para que este processo possa ser considerado um processo implementado, deve haver indícios da realização de algumas atividades e/ou a produção de alguns artefatos. Tais atividades e artefatos referem-se $\mathrm{a}(\mathrm{o})$ :

1. Existência de um modelo de qualidade;

2. Existência de uma lista de práticas ágeis a serem utilizadas e os respectivos fatores de qualidade que objetivam atender;

3. Existência de uma estratégia para garantir a qualidade de execução das práticas;

4. Existência de um plano de qualidade;

5. Existência de atividades de revisão das práticas ágeis identificadas;

6. Existência de ações de melhoria.

Produtos de trabalho: Os processos produzem ou consomem produtos de trabalho. Os produtos de trabalho referentes a este processo são:

\begin{tabular}{||l|l||}
\hline Produtos de trabalho de entrada & Produtos de trabalho de saída \\
\hline - Fatores de qualidade & - Plano de qualidade \\
\hline
\end{tabular}




\subsubsection{Relacionamentos entre os processos}

Independentemente dos grupos, os processos relacionam-se e criam uma certa dependência entre eles. Essas dependências acabam por apontar a sequência na qual os processos devem ocorrer dentro de um projeto.

As depências podem ser representadas através de um dos diversos métodos aplicados para representar o sequenciamento de atividades. O Método de Diagrama de Precedência (MDP) tem esse objetivo e representa as atividades através de retângulos e as dependências através de setas (Project Management Institute, 2004). Na Figura 5.15 são apresentadas, utilizando-se uma representação adaptada do MDP, as dependências existentes entre os processos do modelo. Na figura, os processos são representados por retângulos de cantos arredondados e as depend encias são representadas através de setas contínuas. As setas tracejadas representam um relacionamento/dependência não obrigatória. Pode-se considerar como processos iniciais aqueles que não dependendem de nenhum outro (não é destino de nenhuma seta) e pode-se considerar como processos finais aqueles que não são pré-requisitos de nenhum outro (não é origem de nenhuma seta).

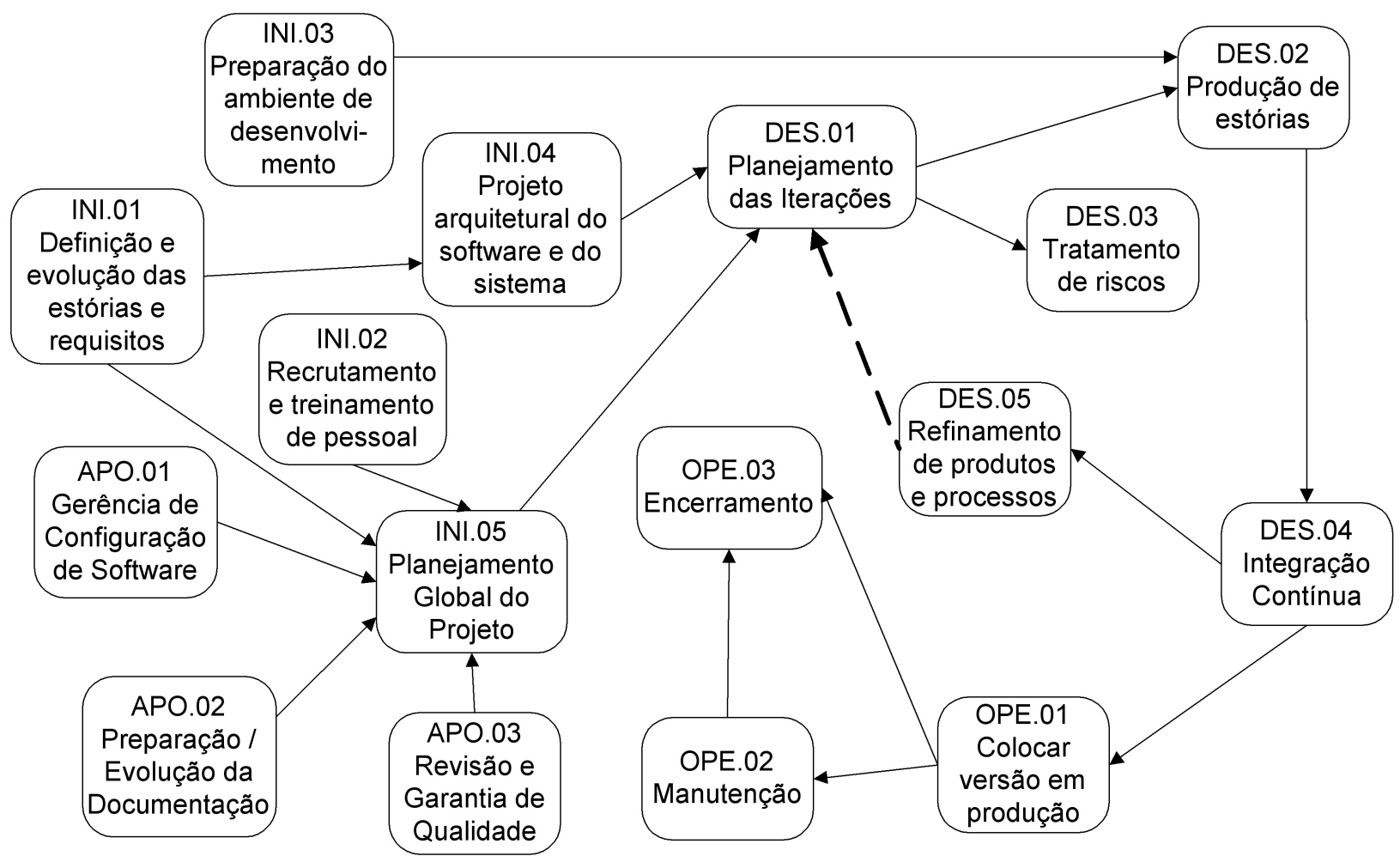

Figura 5.15: Representação das dependências existentes entre os processos do modelo.

A representação dos relacionamentos permite entender melhor o ciclo de vida proposto pelo modelo, inclusive permite visualizar o ciclo iterativo existente (o ciclo percorre os processos DES.01, DES.02, DES.04, DES.05 e volta ao DES.01).

Para complementar essa representação, criou-se uma EAP com o intuito de dividir o trabalho do projeto em partes menores e mais detalhadas (Project Management Institute, 2004). 
Uma EAP permite visualizar os produtos de trabalho que devem ser produzidos pelos processos. Na EAP criada para o modelo de referência são apresentados os processos, em segundo nível, e os produtos de trabalho (pacotes de trabalho), em terceiro nível. A EAP é apresentada na Figura 5.16.

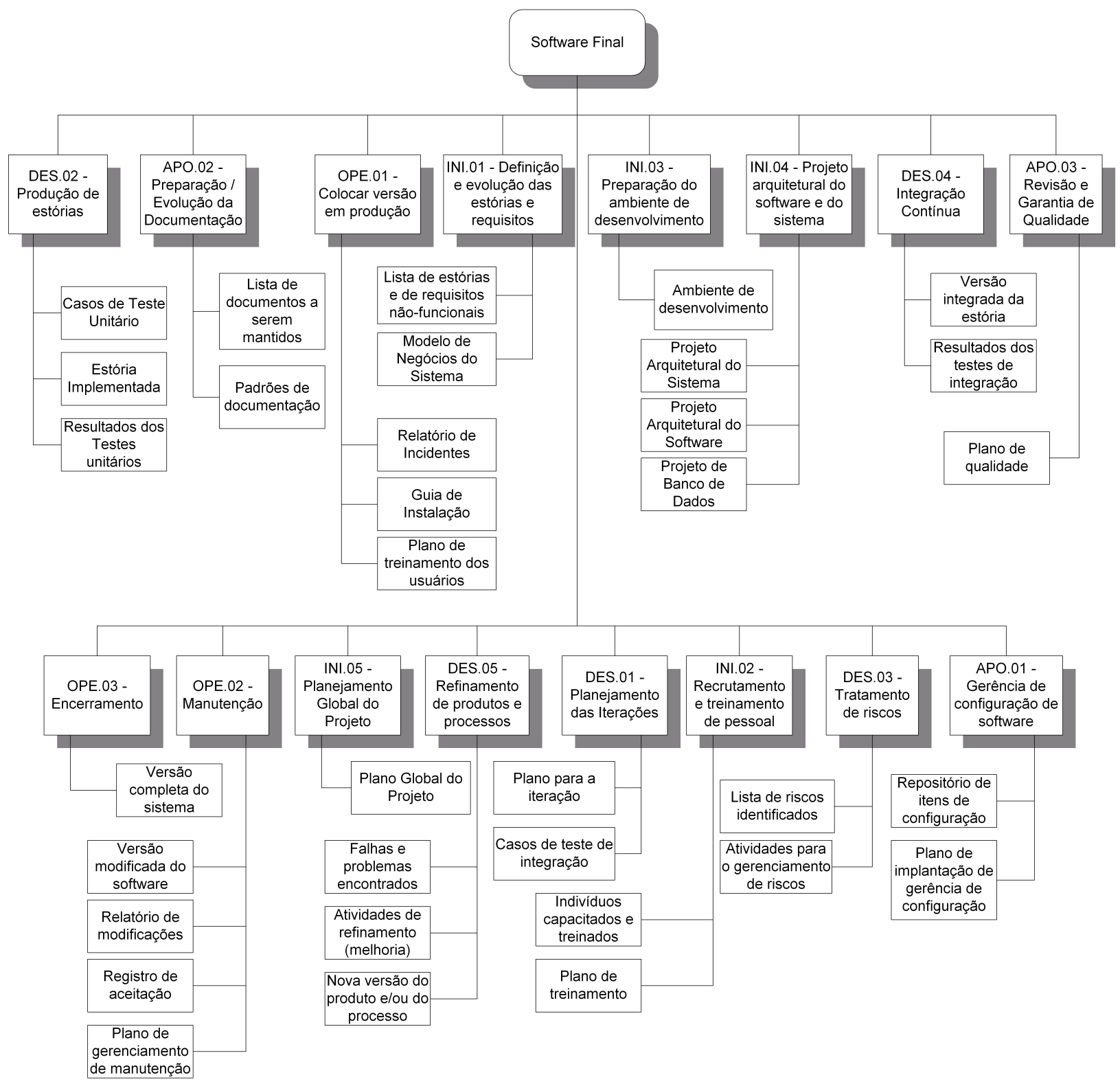

Figura 5.16: EAP criada para o modelo de referência ágil.

Uma EAP pode ser complementada com a definição das atividades necessárias para a produção dos produtos de trabalho. Para a EAP apresentada na Figura 5.16, foram identificadas as atividades necessária para produzir os produtos de trabalho especificados. As atividades são relacionadas aos respectivos produtos de trabalho que produzem e processo que pertencem e são identificadas por uma numeração. Na Tabela 5.17 são apresentadas as atividades. 
Tabela 5.17: Atividades necessárias para a produção dos produtos de trabalho

\begin{tabular}{|c|c|c|}
\hline $\begin{array}{l}\text { Processos do Modelo de } \\
\text { Referência Ágil }\end{array}$ & $\begin{array}{l}\text { Produtos de tra- } \\
\text { balho produzidos } \\
\text { pelo processo }\end{array}$ & $\begin{array}{l}\text { Atividades necessárias para pro- } \\
\text { duzir os produtos de trabalho }\end{array}$ \\
\hline \multirow{2}{*}{$\begin{array}{l}\text { INI.01 Definição e evolu- } \\
\text { ção das estórias e requisi- } \\
\text { tos }\end{array}$} & $\begin{array}{l}\text { Lista de estórias e re- } \\
\text { quisitos não funcio- } \\
\text { nais }\end{array}$ & $\begin{array}{l}\text { 1. Estabelecer mecanismo de comu- } \\
\text { nicação entre cliente e desenvolve- } \\
\text { dor } \\
\text { 2. Obter estórias e requisitos não- } \\
\text { funcionais com o cliente } \\
\text { 3. Produzir a lista de estórias e dos } \\
\text { requisitos não-funcionais. }\end{array}$ \\
\hline & $\begin{array}{l}\text { Modelo de negócios } \\
\text { do sistema }\end{array}$ & $\begin{array}{l}\text { 4. Interpretar a lista de estórias e re- } \\
\text { quisitos não-funcionais } \\
5 \text {. Produzir o modelo de negócios do } \\
\text { sistema }\end{array}$ \\
\hline \multirow{2}{*}{$\begin{array}{l}\text { INI.02 Recrutamento e } \\
\text { treinamento de pessoal }\end{array}$} & Plano de treinamento & $\begin{array}{l}\text { 6. Identificar habilidades e compe- } \\
\text { tências necessárias ao projeto } \\
\text { 7. Traçar um plano de treinamento. }\end{array}$ \\
\hline & $\begin{array}{l}\text { Indivíduos capacita- } \\
\text { dos e treinados }\end{array}$ & $\begin{array}{l}\text { 8. Recrutar indivíduos com as habi- } \\
\text { lidades e competências requeridas. } \\
\text { 9. Treinar os indivíduos recrutados }\end{array}$ \\
\hline $\begin{array}{l}\text { INI.03 Preparação do am- } \\
\text { biente de desenvolvimento }\end{array}$ & $\begin{array}{l}\text { Ambiente de desen- } \\
\text { volvimento }\end{array}$ & $\begin{array}{l}\text { 10. Identificar as necessidades de re- } \\
\text { cursos dos processos de desenvolvi- } \\
\text { mento } \\
\text { 11. Adquirir os recursos necessários } \\
\text { aos processos } \\
\text { 12. Realizar testes com os recursos } \\
\text { adquiridos no ambiente de desenvol- } \\
\text { vimento } \\
\text { 13. Disponibilizar o ambiente de de- } \\
\text { senvolvimento }\end{array}$ \\
\hline
\end{tabular}




\begin{tabular}{|c|c|c|}
\hline \multirow{3}{*}{$\begin{array}{l}\text { INI.04 Projeto arquitetural } \\
\text { do software e do sistema }\end{array}$} & $\begin{array}{l}\text { Projeto arquitetural } \\
\text { do sistema }\end{array}$ & $\begin{array}{l}\text { 14. Interpretar a lista de estórias e } \\
\text { requisitos não-funcionais } \\
\text { 15. Definir interfaces internas e ex- } \\
\text { ternas entre os elementos do sistema } \\
\text { 16. Criar o projeto arquitetural do } \\
\text { sistema }\end{array}$ \\
\hline & $\begin{array}{l}\text { Projeto arquitetural } \\
\text { do software }\end{array}$ & $\begin{array}{l}\text { 17. Interpretar a lista de estórias e } \\
\text { requisitos não-funcionais } \\
\text { 18. Definir interfaces internas e ex- } \\
\text { ternas entre os elementos do soft- } \\
\text { ware } \\
\text { 19. Criar o projeto arquitetural do } \\
\text { software }\end{array}$ \\
\hline & $\begin{array}{l}\text { Projeto de banco de } \\
\text { dados }\end{array}$ & $\begin{array}{l}\text { 20. Interpretar a lista de estórias e } \\
\text { requisitos não-funcionais } \\
21 \text {. Definir o sistema gerenciador de } \\
\text { banco de dados } \\
\text { 22. Definir os tipos e estruturas de } \\
\text { dados } \\
\text { 23. Criar o projeto de banco de da- } \\
\text { dos. }\end{array}$ \\
\hline $\begin{array}{l}\text { INI.05 Planejamento glo- } \\
\text { bal do projeto }\end{array}$ & $\begin{array}{l}\text { Plano global do pro- } \\
\text { jeto }\end{array}$ & $\begin{array}{l}\text { 24. Definir o escopo do software } \\
\text { 25. Realizar estimativas superficiais } \\
\text { 26. Definir cronograma de utiliza- } \\
\text { ção dos recursos } \\
\text { 27. Definir uma estratégia para a in- } \\
\text { tegração contínua } \\
\text { 28. Estabelecer mecanismo de mo- } \\
\text { nitoramento do feedback } \\
\text { 29. Criar um plano global para o } \\
\text { projeto. }\end{array}$ \\
\hline
\end{tabular}




\begin{tabular}{|c|c|c|}
\hline \multirow[t]{2}{*}{$\begin{array}{l}\text { DES.01 Planejamento das } \\
\text { iterações }\end{array}$} & Plano para a iteração & $\begin{array}{l}\text { 30. Priorizar estórias } \\
\text { 31. Realizar estimativas melhoradas } \\
\text { das estórias } \\
\text { 32. Definir quais estórias serão de- } \\
\text { senvolvidas na próxima iteração } \\
\text { 33. Criar um plano para a próxima } \\
\text { iteração }\end{array}$ \\
\hline & $\begin{array}{l}\text { Casos de teste de inte- } \\
\text { gração }\end{array}$ & $\begin{array}{l}\text { 34. Criar casos de teste para a in- } \\
\text { tegração das estórias a serem desen- } \\
\text { volvidas }\end{array}$ \\
\hline \multirow{3}{*}{$\begin{array}{l}\text { DES.02 Produção de estó- } \\
\text { rias }\end{array}$} & $\begin{array}{l}\text { Casos de teste unitá- } \\
\text { rio }\end{array}$ & $\begin{array}{l}\text { 35. Obter descrição detalhada das } \\
\text { estórias a serem produzidas } \\
\text { 36. Criar casos de teste unitários }\end{array}$ \\
\hline & Estória implementada & $\begin{array}{l}\text { 37. Produzir código de software que } \\
\text { represente as estórias }\end{array}$ \\
\hline & $\begin{array}{l}\text { Resultados dos testes } \\
\text { unitários }\end{array}$ & $\begin{array}{l}\text { 38. Executar procedimento de testes } \\
\text { unitários } \\
\text { 39. Armazenar os resultados dos } \\
\text { testes unitários realizados }\end{array}$ \\
\hline \multirow[b]{2}{*}{$\begin{array}{l}\text { DES.03 Tratamento de ris- } \\
\cos \end{array}$} & $\begin{array}{l}\text { Lista de riscos identi- } \\
\text { ficados }\end{array}$ & $\begin{array}{l}\text { 40. Identificar riscos do projeto } \\
\text { 41. Registrar os riscos identificados }\end{array}$ \\
\hline & $\begin{array}{l}\text { Atividades de geren- } \\
\text { ciamento de riscos }\end{array}$ & $\begin{array}{l}\text { 42. Analisar qualitativamente os ris- } \\
\text { cos identificados } \\
\text { 43. Priorizar os riscos } \\
\text { 44. Definir atividades de gerencia- } \\
\text { mento de riscos }\end{array}$ \\
\hline \multirow[b]{2}{*}{$\begin{array}{l}\text { DES.04 Integração contí- } \\
\text { nua }\end{array}$} & $\begin{array}{l}\text { Versão integrada da } \\
\text { estória }\end{array}$ & $\begin{array}{l}\text { 45. Executar procedimentos de inte- } \\
\text { gração }\end{array}$ \\
\hline & $\begin{array}{l}\text { Resultados dos testes } \\
\text { de integração }\end{array}$ & $\begin{array}{l}\text { 46. Realizar testes de integração } \\
\text { 47. Armazenar os resultados dos } \\
\text { testes de integração }\end{array}$ \\
\hline
\end{tabular}




\begin{tabular}{|c|c|c|}
\hline \multirow{3}{*}{$\begin{array}{l}\text { DES.05 Refinamento de } \\
\text { produtos e processos }\end{array}$} & $\begin{array}{l}\text { Falhas e problemas } \\
\text { encontrados }\end{array}$ & $\begin{array}{l}\text { 48. Identificar falhas ou problemas } \\
\text { durante o desenvolvimento } \\
\text { 49. Armazenar falhas ou problemas } \\
\text { identificados }\end{array}$ \\
\hline & $\begin{array}{l}\text { Atividades de refina- } \\
\text { mento (melhoria) }\end{array}$ & $\begin{array}{l}\text { 50. Definir atividades para refinar } \\
\text { (melhorar) os processos ou produtos }\end{array}$ \\
\hline & $\begin{array}{l}\text { Nova versão do pro- } \\
\text { duto e/ou do processo }\end{array}$ & $\begin{array}{l}\text { 51. Realizar atividades de refina- } \\
\text { mento (melhoria) }\end{array}$ \\
\hline \multirow{3}{*}{$\begin{array}{l}\text { OPE.01 Colocar versão } \\
\text { em produção }\end{array}$} & Guia de instalação & $\begin{array}{l}\text { 52. Definir critérios de instalação } \\
\text { 53. Criar um guia de instalação }\end{array}$ \\
\hline & $\begin{array}{l}\text { Relatório de inci- } \\
\text { dentes }\end{array}$ & $\begin{array}{l}\text { 54. Instalar a versão do software } \\
55 \text {. Verificar conformidade com cri- } \\
\text { térios de instalação } \\
\text { 56. Registrar os eventos e/ou resul- } \\
\text { tados relevantes }\end{array}$ \\
\hline & $\begin{array}{l}\text { Plano de treinamento } \\
\text { dos usuários }\end{array}$ & $\begin{array}{l}\text { 57. Definir um plano para o treinar } \\
\text { os usuários }\end{array}$ \\
\hline
\end{tabular}




\begin{tabular}{|c|c|c|}
\hline \multirow{4}{*}{ OPE.02 Manutenção } & $\begin{array}{l}\text { Plano de gerencia- } \\
\text { mento de manutenção }\end{array}$ & $\begin{array}{l}\text { 58. Definir atividades necessárias } \\
\text { para o gerenciamento da manuten- } \\
\text { ção } \\
\text { 59. Definir responsabilidades para } \\
\text { as atividades de manutenção } \\
\text { 60. Criar um plano para o gerencia- } \\
\text { mento de manutenção }\end{array}$ \\
\hline & $\begin{array}{l}\text { Versão modificada do } \\
\text { software }\end{array}$ & $\begin{array}{l}\text { 61. Receber solicitação de modifi- } \\
\text { cação do cliente } \\
\text { 62. Analisar impacto das solicita- } \\
\text { ções de modificação } \\
\text { 63. Avaliar as solicitações de } \\
\text { modificação, aprovando-a ou } \\
\text { reprovando-a } \\
\text { 64. Atualizar documentos afetados } \\
\text { pelas solicitações aprovadas } \\
\text { 65. Implementar e testar as solicita- } \\
\text { ções de modificação aprovadas } \\
\text { 66. Atualizar o sistema em operação } \\
\text { com as modificações implementa- } \\
\text { das }\end{array}$ \\
\hline & $\begin{array}{l}\text { Relatório de modifi- } \\
\text { cações }\end{array}$ & $\begin{array}{l}\text { 67. Relatar as modificações imple- } \\
\text { mentadas }\end{array}$ \\
\hline & Registro de aceitação & $\begin{array}{l}\text { 68. Apresentar as modificações im- } \\
\text { plementadas ao cliente } \\
\text { 69. Registrar aceitação do cliente }\end{array}$ \\
\hline OPE.03 Encerramento & $\begin{array}{l}\text { Versão completa do } \\
\text { sistema }\end{array}$ & $\begin{array}{l}\text { 70. Produzir/Atualizar documentos } \\
\text { a serem entregues ao cliente } \\
\text { 71. Apresentar ao cliente a versão } \\
\text { completa do sistema }\end{array}$ \\
\hline \multirow{2}{*}{$\begin{array}{l}\text { APO.01 Gerência de } \\
\text { configuração de software }\end{array}$} & $\begin{array}{l}\text { Repositório de itens } \\
\text { de configuração }\end{array}$ & $\begin{array}{l}\text { 72. Estabelecer um esquema para } \\
\text { identificar os itens de configuração } \\
\text { 73. Selecionar os itens de configura- } \\
\text { ção }\end{array}$ \\
\hline & $\begin{array}{l}\text { Plano de implantação } \\
\text { de gerência de confi- } \\
\text { guração }\end{array}$ & $\begin{array}{l}\text { 74. Definir uma estratégia de gerên- } \\
\text { cia de configuração }\end{array}$ \\
\hline
\end{tabular}




\begin{tabular}{|c|c|c|}
\hline \multirow[b]{2}{*}{$\begin{array}{l}\text { APO.02 Preparação / Evo- } \\
\text { lução da documentação }\end{array}$} & $\begin{array}{l}\text { Lista de documentos } \\
\text { a serem mantidos }\end{array}$ & $\begin{array}{l}\text { 75. Identificar quais documentos } \\
\text { precisam ser produzidos } \\
\text { 76. Criar uma lista de documentos a } \\
\text { serem mantidos }\end{array}$ \\
\hline & $\begin{array}{l}\text { Padrões de documen- } \\
\text { tação }\end{array}$ & $\begin{array}{l}\text { 77. Definir uma linguagem para os } \\
\text { documentos. } \\
\text { 78. Definir padrões para os docu- } \\
\text { mentos. } \\
\text { 79. Criar padrão de documentação. }\end{array}$ \\
\hline $\begin{array}{l}\text { APO.03 Revisão e garan- } \\
\text { tia de qualidade }\end{array}$ & Plano de qualidade & $\begin{array}{l}\text { 80. Definir um modelo de qualidade } \\
\text { 81. Definir as práticas ágeis para ga- } \\
\text { rantir a qualidade } \\
\text { 82. Definir estratégia para garantir a } \\
\text { correta execução das práticas } \\
\text { 83. Criar um plano de qualidade }\end{array}$ \\
\hline
\end{tabular}

Entre as atividades existem dependências que devem ser consideradas para a elaboração de um cronograma. Essas dependências podem ser representadas através de um dos métodos de sequenciamento de atividades, o Método de Diagrama de Setas (MDS). Esse método utiliza setas para representar as atividades, as quais conectam-se a outras atividades através de nós, que representam as dependências (Project Management Institute, 2004).

Na Figura 5.17 é apresentado um exemplo de um MDS que representa duas atividades, representadas pelas setas numeradas, e as dependências existentes entre elas, representadas através dos nós.

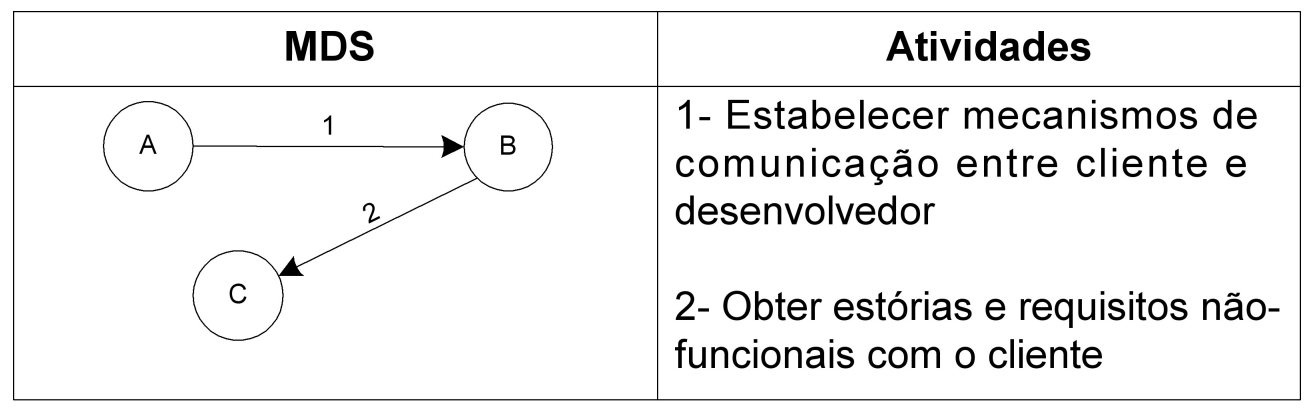

Figura 5.17: Exemplo de um MDS que representa o sequenciamento de atividades (Project Management Institute, 2004)

A representação utilizada na Figura 5.18, que representa as atividades referentes ao modelo de referência ágil, refere-se a uma maneira adaptada de utilizar o Método de Diagrama de Setas (MDS), descrito em (Project Management Institute, 2004). A figura utiliza-se de setas para representar as atividades, as quais conectam-se a outras através de nós, que representam as dependên- 
cias. As setas tracejadas representam movimentos vazios. Pode-se considerar como atividades de início aquelas que não dependendem de nenhuma outra (não é destino de nenhuma seta) e podese considerar com atividades finais aquelas que não são pré-requisitos de nenhuma outra (não é origem de nenhuma seta).

\subsection{Considerações Finais}

O Modelo de Referência Ágil apresentado neste capítulo é fruto dos estudos realizados sobre as metodologias ágeis de desenvolvimento. O modelo resume as características encontradas nas metodologias ágeis em dezesseis processos que orientam todo o ciclo de desenvolvimento de software.

Espera-se que este modelo sirva como um primeiro passo em busca de uma padronização dos processos de desenvolvimento ágeis. Espera-se ainda, que o Modelo de Referência Ágil sirva como referência para a implantação de processos de desenvolvimento ágeis e para o direcionamento de processos de melhoria.

O Modelo de Referência Ágil foi utilizado como referência em uma avaliação de processo que seguiu as especificações contidas no Modelo de Avaliação de Processos da norma ISO/IEC 15504. A avaliação é descrita em detalhes no Capítulo 6 


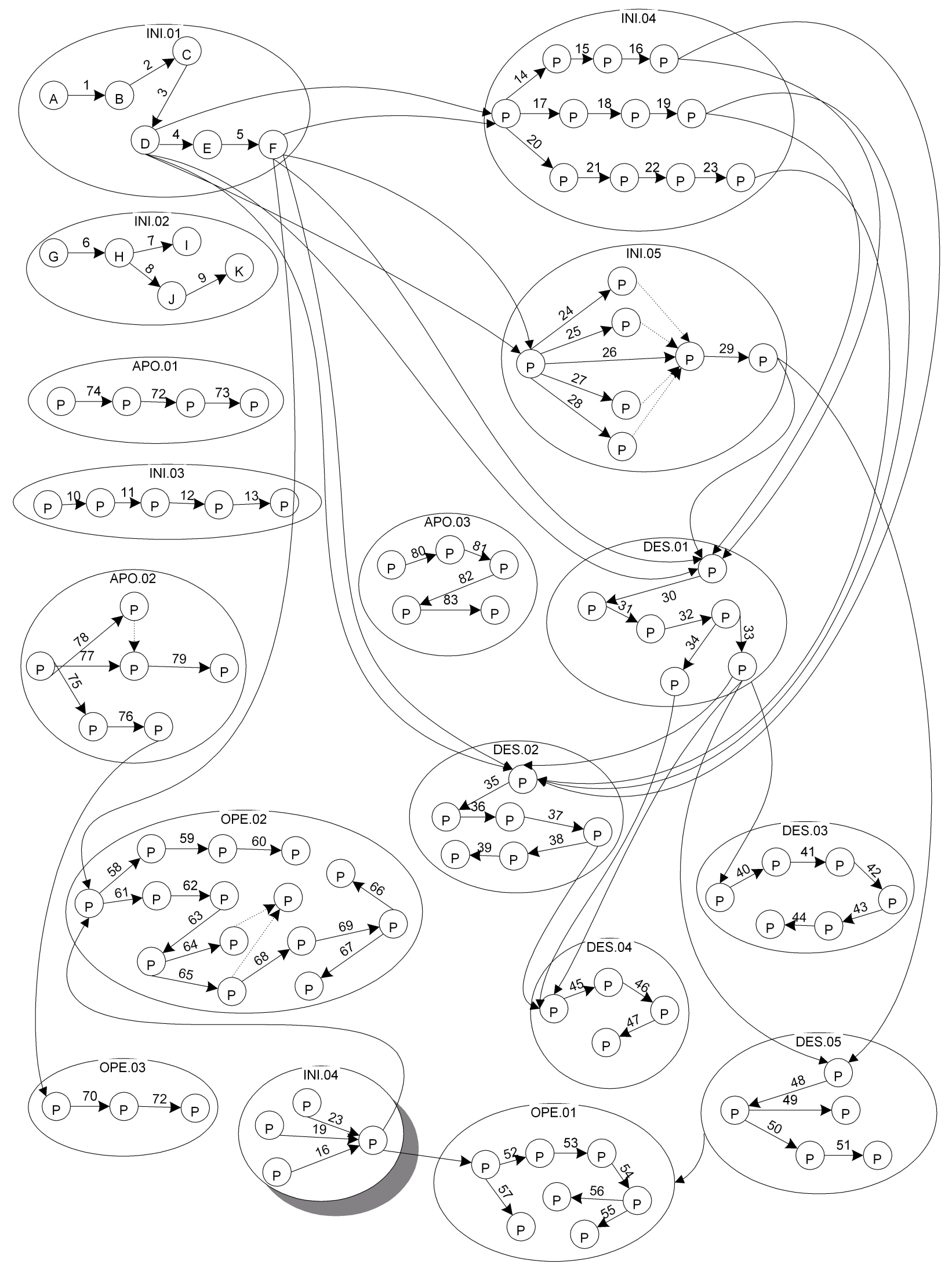

Figura 5.18: MDS que representa o sequenciamento das atividades que ocorrem nos processos do modelo de referência ágil 


\subsection{Considerações iniciais}

No Capítulo 5 foi descrito o principal produto deste trabalho, o Modelo de Referência para o Desenvolvimento Ágil de Software. Esse modelo, desde sua concepção inicial, vem sendo refinado e a versão apresentada concretiza as evoluções do modelo até o presente momento.

Neste capítulo é descrito um estudo de caso onde o modelo de referência foi utilizado como base para a avaliação de um processo de desenvolvimento. O estudo de caso teve o intuito de utilizar o modelo de referência para identificar "fragilidades" no processo avaliado e, com isso, direcionar melhorias para o processo, visando torná-lo um processo ágil. É válido ressaltar que a avaliação realizada seguiu as especificação do modelo para avaliação de processo da ISO/IEC 15504.

Este capítulo está organizado da seguinte forma. Na Seção 6.2 são apresentadas algumas informações sobre o processo de avaliação. Na Seção 6.3 são apresentadas a descrição do processo avaliado, o processo de avaliação documentado e os resultados da avaliação. Finalmente, na Seção 6.4 são apresentadas algumas considerações finais sobre este capítulo.

\subsection{O processo de avaliação}

Uma avaliação de processo serve para entender a capacidade dos processos realizados em uma organização. O modelo de referência para avaliação de processos da ISO/IEC 15504 (parte 2 da 
ISO/IEC 15504) é um modelo de avaliação amplamente reconhecido e permite avaliar um processo de desenvolvimento e determinar sua capacidade, com relação a um padrão fornecido.

Acredita-se que um processo de desenvolvimento avaliado com o Nível 2 de capacidade, através de uma avaliação que segue os requisitos da ISO/IEC 15504 e que utiliza o Modelo de Referência Ágil como padrão, é suficientemente gerenciável e aplica de forma efetiva e suficiente as práticas sugeridas pelas metodologias ágeis.

Na Seção 6.2.1 é apresentada uma visão geral do processo de avaliação proposto pela ISO/IEC 15504.

\subsubsection{O processo de avaliação segundo a norma ISO/IEC 15504}

De acordo com o modelo ISO/IEC 15504, uma avaliação de processo deve ser conduzida de acordo com um processo de avaliação documentado ${ }^{1}$ e capaz de atender ao propósito da avaliação.

Um processo de avaliação documentado compreende um conjunto de instruções para conduzir uma avaliação. As instruções devem agregar os seguintes aspectos (ISO/IEC, 2003e):

- Definição das entradas de uma avaliação, tais como: propósito, escopo, restrições e o modelo de avaliação de processo a ser utilizado;

- Definição dos papéis chave e responsabilidades;

- Orientações referentes ao planejamento, coleta de dados, validação de dados, pontuações de atributos de processo e relato de resultados da avaliação. As pontuações de atributos de processo são especificadas no modelo ISO/IEC 15504-2 e auxiliam na determinação da capacidade do processo, permitindo a classificação do processo em seis níveis de capacidade (níveis que variam de 0 a 5);

- Orientações para o armazenamento dos resultados da avaliação.

Além das instruções, um processo de avaliação documentado deve possuir a distinção de alguns papéis, dentre os quais destacam-se o patrocinador, o líder da equipe, os assessores e o coordenador local.

- O patrocinador é o indivíduo que deseja que um processo de avaliação seja realizado. Ele deve prover todas as condições para que os assessores realizem a avaliação de forma eficiente.

- O líder da equipe é a pessoa que lidera a execução de uma avaliação e garante que a mesma está conforme as especificações do modelo ISO/IEC 15504. O líder também é responsável pela organização da equipe de avaliação e pela distribuição das responsabilidades.

\footnotetext{
${ }^{1}$ Um processo de avaliação documentado descreve as atividades que devem ser realizadas durante um processo de avaliação e define as responsabilidades dos envolvidos no processo
} 
- Os assessores são os responsáveis pela execução da avaliação e são supervisionados por um líder.

- O coordenador local é responsável por gerenciar a logística e a comunicação dos avaliadores com a unidade organizacional. O coordenador, junto com o líder, tem a responsabilidade de garantir a compatibilidade e disponibilidade de equipamento técnico necessários para a avaliação e confirmar que o espaço de trabalho e os requisitos de cronograma serão encontrados.

\subsection{Avaliação do processo de desenvolvimento do Cen- tro de Informática}

\subsubsection{Descrição do processo de desenvolvimento do Centro de In- formática}

O Centro de Informática (CI) é um departamento de uma Instituição de Ensino Superior (IES). A IES é uma instituição bem conceituada, situada na região central paulista, mais precisamente na cidade de São Carlos. A IES, que é uma instituição particular, oferece, atualmente, cursos de graduação, pós-graduação latu-sensu e capacitação gerencial nas áreas de Exatas, de Humanas e da Saúde.

O CI produz software para consumo da própria IES. Ele possui um produto principal, denominado neste trabalho de Software de Gestão Educacional (SGE), que engloba diversos módulos direcionados aos diversos setores da IES. Os módulos Acadêmico, Financeiro e Vestibular são exemplos de módulos que, integrados, compõem o SGE.

O CI é composto, atualmente, por uma equipe de desenvolvimento formada por quatro pessoas. Um coordenador, responsável por direcionar o desenvolvimento e, junto com os diretores da IES, definir as prioridades, e três desenvolvedores, responsáveis pela construção do software propriamente dita. Os desenvolvedores participam de todas as fases do desenvolvimento (planejamento, análise, codificação, testes e manutenção).

$\mathrm{O}$ processo atual de desenvolvimento do CI é um processo evolutivo que adiciona funcionalidades ao sistema com o passar do tempo. Segundo os membros da equipe, o software evolui conforme as funcionalidades vão sendo solicitadas e implementadas. Não existe o conceito de versões e, consequentemente, não existe um controle sobre elas. Isso significa que o SGE só possui a versão atual, não sendo possível recuperar versões anteriores.

No processo, as modificações e solicitações são realizadas informalmente e, dependendo da criticalidade, precisam de uma autorização dos diretores, que também é feita informalmente. Não existe nenhum controle formal sobre as modificações. Ao realizar alterações, o desenvolvedor realiza testes para validá-las e integrá-las com a versão atual, e então disponibiliza para o usuário. 
Sempre que se inicia a concepção de um novo módulo, os desenvolvedores, o coordenador e os diretores reunem-se para realizar um planejamento. O planejamento é feito superficialmente e serve para dar um direcionamento ao processo, definir prazos de entrega (baseando-se nos requisitos conhecidos até o momento) e definir o responsável pelo módulo. O responsável pelo módulo é um desenvolvedor que tem a função de receber as solicitações referentes àquele módulo e implementá-las (ou indicar alguém para implementá-las).

Sempre que a construção de um módulo é completada, um treinamento com os usuários envolvidos é ministrado pelo responsável pelo módulo antes de disponibilizá-lo. A partir desse ponto, as modificações e evoluções vão sendo implementadas conforme descrito anteriormente.

Observa-se que o processo do CI é realizado de forma incremental, sem considerar o conceito de versões. Outro aspecto importante é que ao CI não se aplica um processo de encerramento, pois o fato dos projetos estarem em contínua evolução descarta essa possibilidade.

\subsubsection{O processo de avaliação documentado}

\section{Fase inicial do processo de avaliação}

Ao iniciar um processo de avaliação, é necessário definir alguns papéis e realizar algumas tarefas para que o processo seja condizente com o modelo ISO/IEC 15504. Os papéis e tarefas necessários são apresentados a seguir:

Líder da equipe: Gustavo Vaz Nascimento. O líder tem a função de liderar a equipe de desenvolvimento e garantir que as pessoas integrantes da equipe possuam competência e habilidades necessárias.

Propósito da avaliação: Este processo de avaliação tem o objetivo de determinar a capacidade do processo de desenvolvimento executado pelo CI. A avaliação deve identificar pontos fortes e fracos do desenvolvimento e direcioná-lo por um processo de melhoria, visando tornar o processo de desenvolvimento ágil.

Modelo de avaliação: O modelo de avaliação a ser utilizado é um modelo bi-dimensional, semelhante ao sugerido pela norma ISO/IEC 15504. Na dimensão de capacidade está o framework de medidas, apresentado no Apêndice B, e na dimensão de processos está o Modelo de Referência Ágil, apresentado no Capítulo 5.

Equipe de avaliação:

- Elby Vaz Nascimento: é mestrando em Engenharia de Produção e analista de sistemas com 5 anos de experiência. Sua função é de Assessor e Coordenador Local da Avaliação.

- Gustavo Vaz Nascimento: é mestrando em Engenharia de Software e analista de sistemas com 4,5 anos de experiência. Sua função é de Assessor e Líder da Equipe. 
Contexto da avaliação: A avaliação será realizada no ambiente de desenvolvimento do Centro de Informática.

Escopo da avaliação: Esta avaliação visa investigar todos os processos definidos na dimensão de processos do Modelo de Avaliação, que é composto pelo Modelo de Referência Ágil. A avaliação deve considerar os níveis 1 e 2 de capacidade, de acordo com o framework de medidas apresentado no Apêndice B. Um mapeamento dos processos da dimensão de processos do Modelo de Avaliação para os processos executados pelo CI é apresentado na Tabela 6.1.

\begin{tabular}{|l|l|}
\hline $\begin{array}{l}\text { Dimensão de processos do Modelo de } \\
\text { Avaliação }\end{array}$ & Mapeamento para os Proc. do CI \\
\hline $\begin{array}{l}\text { INI.01 Definição e evolução das estórias } \\
\text { e requisitos }\end{array}$ & Definição de requisitos \\
\hline $\begin{array}{l}\text { INI.02 Recrutamento e treinamento de } \\
\text { pessoal }\end{array}$ & Recrutamento e treinamento de pessoal \\
\hline $\begin{array}{l}\text { INI.03 Preparação do ambiente de desen- } \\
\text { volvimento }\end{array}$ & Preparação do ambiente de desenvolvimento \\
\hline $\begin{array}{l}\text { INI.04 Projeto arquitetural do software e } \\
\text { do sistema }\end{array}$ & Projeto do software \\
\hline INI.05 Planejamento global do sistema & Planejamento do projeto \\
\hline DES.01 Planejamento das iterações & Não realizado \\
\hline DES.02 Produção de estórias & Codificação \\
\hline DES.03 Tratamento de riscos & Não realizado \\
\hline DES.04 Integração contínua & Testes de integração \\
\hline $\begin{array}{l}\text { DES.05 Refinamento de produtos e pro- } \\
\text { cessos }\end{array}$ & Não realizado \\
\hline OPE.01 Colocar versão em produção & Instalação \\
\hline OPE.02 Manutenção & Manutenção \\
\hline OPE.03 Encerramento & Não se aplica \\
\hline $\begin{array}{l}\text { APO.01 Gerência de configuração de } \\
\text { software }\end{array}$ & Não realizado \\
\hline $\begin{array}{l}\text { APO.02 Preparação / Evolução da docu- } \\
\text { mentação }\end{array}$ & Documentação \\
\hline APO.03 Revisão e garantia de qualidade & Garantia de qualidade \\
\hline
\end{tabular}

Tabela 6.1: Mapeamento da dimensão de processos do Modelo de Avaliação para os processos realizados pelo $\mathrm{CI}$.

Restrições: O processo "OPE.03 Encerramento", descrito no Modelo de Avaliação, não é aplicável a realidade do CI. Dessa forma, o processo "OPE.03 Encerramento" foi excluído da avaliação. 
Responsabilidades dos participantes da avaliação:

- Gustavo Vaz Nascimento: Tem a responsabilidade de coletar e validar os dados para a execução da avaliação, apresentar os resultados da avaliação aos interesados e liderar a equipe durante a avaliação;

- Elby Vaz Nascimento: Tem a responsabilidade de coletar e validar os dados para a execução da avaliação e gerenciar a logística e a comunicação dos avaliadores com a unidade organizacional.

A realização dessas atividades iniciais formam a base para a execução de uma avaliação consistente e confiável. Além das atividades, é preciso traçar um planejamento para a realização da avaliação. O plano de avaliação é apresentado a seguir.

\section{Plano de avaliação}

Um plano de avaliação que descreve todas as atividades a serem realizadas na execução de uma avaliação precisa ser produzido e documentado junto com um cronograma. Para isso, é preciso identificar os recursos necessários para a execução da avaliação e garantir a disponibilidade dos mesmos. Além disso, é preciso definir o método que será utilizado para coletar, rever, validar e documentar todas as informações requeridas.

As atividades do plano de avaliação orientam os avaliadores a executarem a avaliação de forma organizada e disciplinada, tornando o processo de avaliação repetível. A seguir estão apresentadas as atividades previstas para a avaliação do processo realizado pelo CI.

1. Comunicado oficial: A unidade organizacional deve ser comunicada sobre os propósitos, escopo, restrições e modelos que serão utilizados na avaliação. O comunicado deve focar a importância dos benefícios que podem ser trazidos pelos resultados da avaliação. O líder da equipe é o responsável por realizar o comunicado oficial.

2. Coleta dos dados: A coleta dos dados deve ser realizada pelos assessores, principalmente, através da observação dos produtos de trabalho produzidos pelo processo e do comportamento dos desenvolvedores. A observação da infra-estrutura do local de desenvolvimento e os testemunhos dos envolvidos também devem ser considerados.

3. Validação dos dados: A validação dos dados deve ser feita em conjunto com a coleta dos dados. Os assessores devem coletar os dados e validá-los, verificando se os dados coletados têm relação com os indicadores de processo, definidos na dimensão de processos do Modelo de Avaliação de Processo.

4. Avaliação dos atributos de processo: A avaliação dos atributos de processo consiste da atribuição de pontuação para os atributos de processo, de cada processo avaliado. As pontuações 
devem ser atribuídas através de consenso entre a equipe de avaliação e devem respeitar o framework de medidas, apresentado no Apêndice B. Os processos de tomada de decisão, as pontuações dos atributos de processo e os cálculos dos níveis de capacidade de cada processo avaliado devem ser documentados. Os assessores e o líder da equipe são os responsáveis por julgar os dados coletados e atribuir as pontuações.

5. Apresentação dos resultados da avaliação: O líder da equipe deve preparar um relatório contendo os resultados da avaliação, os perfis dos processos, os pontos fortes e fracos, os fatores de risco encontrados e as potenciais ações de melhoria. Os resultados da avaliação devem ser apresentados aos envolvidos e devem ser documentados junto com uma descrição que garante que a avaliação satisfaz os requisitos especificados pela norma ISO/IEC 15504.

Cronograma: Na Figura 6.1 é apresentado o cronograma para a realização das atividades da avaliação.

\begin{tabular}{|l|c|c|c|c|c|c|c|c|c|c|}
\hline \multirow{2}{*}{ Atividades } & \multicolumn{7}{|c|}{ Tempo de duração das atividades } \\
\hline & $\mathbf{4 h}$ & $\mathbf{4 h}$ & $\mathbf{4 h}$ & $\mathbf{4 h}$ & $\mathbf{4 h}$ & $\mathbf{4 h}$ & $\mathbf{4 h}$ & $\mathbf{4 h}$ & $\mathbf{4 h}$ & $\mathbf{4 h}$ \\
\hline Comunicado oficial & & & & & & & & & & \\
\hline Coleta dos dados & & & & & & & & & & \\
\hline Validação dos dados & & & & & & & & & & \\
\hline Avaliação dos atributos de processo & & & & & & & & & & \\
\hline Apresentação dos resultados da avaliação & & & & & & & & & & \\
\hline
\end{tabular}

Figura 6.1: Cronograma para a realização da avaliação.

\subsubsection{Resultados da avaliação}

A avaliação permitiu identificar pontos fortes e fracos no processo realizado pelo CI. Os pontos fortes indicam características que aumentam as chances do processo ser um processo ágil, já os pontos fracos apontam aspectos a serem melhorados para que o processo possa ser considerado um processo ágil.

Ao final da avaliação foi criada uma Estrutura Analítica de Projetos (EAP) (Figura 6.2), que representa o estado no qual o processo de desenvolvimento realizado pelo CI foi encontrado. A EAP permite observar os processos e produtos de trabalho sugeridos pelo Modelo de Referência Ágil e os processos e produtos de trabalho que são, de alguma forma, executados ou produzidos pelo processo avaliado.

$\mathrm{Na}$ EAP, os "produtos de trabalho produzidos" e os "processos realizados total ou parcialmente" indicam, respectivamente, os produtos de trabalho sugeridos pelo modelo de referência e produzidos pelo processo do CI, e os processos de desenvolvimento sugeridos pelo modelo de referência e realizados pelo processo do CI. Essas indicações auxiliam na diferenciação do que é 
sugerido pelo modelo de referência e do que é realmente produzido ou executado pelo processo do CI.

Ainda na EAP, observa-se que o processo denominado "OPE.03 Encerramento" foi classificado como "Processo não aplicável". Essa classificação indica que o processo não se aplica a realidade do CI e, portanto, o processo foi desconsiderado na avaliação. Na Figura 6.2 é apresentada a EAP.

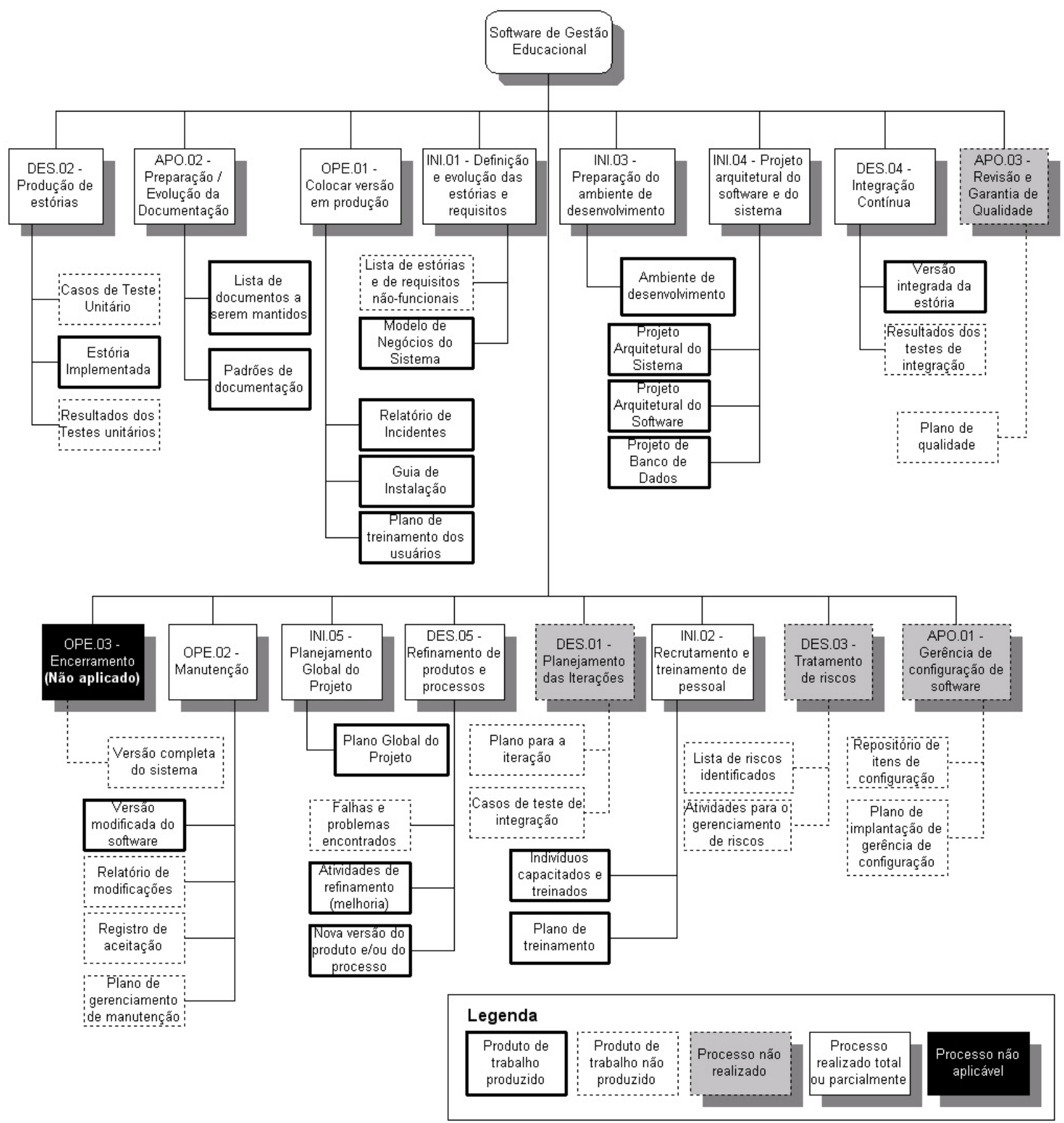

Figura 6.2: EAP que representa o estado no qual o processo de desenvolvimento realizado pelo CI foi encontrado.

Durante a avaliação, percebeu-se que para alguns processos não foram encontrados indícios de realização de processo. Para esses casos, foi atribuído a pontuação "N" para o Atributo de Realização do Processo e, consequentemente, os processos foram classificados com o Nível 0 de 
capacidade (ou "Processo não realizado na EAP"). Como complemento da avaliação, um plano de implantação para cada um desses processos foi elaborado e sugerido ao CI. O processo denominado "APO.01 Gerência de configuração de software" é um exemplo de processo para o qual não foram encontrados indícios de realização. O Plano de Implantação sugerido para esse processo é apresentado na Figura 6.3.

Para todos os processos, com exceção do processo “OPE.03 Encerramento", a avaliação seguiu os passos definidos no plano de avaliação. Foram realizadas as tarefas de coleta e validação de dados através da observação dos produtos de trabalho, do comportamento dos desenvolvedores, da infra-estrutura e dos testemunhos dos desenvolvedores. Os dados coletados foram avaliados pelo assessor e pelo líder da equipe. O consenso entre ambos possibilitou a atribuição das pontuações aos atributos de processo de cada processo avaliado e, consequentemente, permitiu a atribuição de níveis de capacidade aos processos. Na Tabela 6.2 são apresentadas as pontuações atribuídas aos atributos de processo de cada processo e o respectivo nível de capacidade.

Tabela 6.2: Processos avaliados e pontuações dos atributos de processo.

\begin{tabular}{|l|l|l|}
\hline Nome do processo & $\begin{array}{l}\text { Pontuação dos } \\
\text { Atributos de } \\
\text { Processo (AP) }\end{array}$ & $\begin{array}{l}\text { Nível de capaci- } \\
\text { dade }\end{array}$ \\
\hline $\begin{array}{l}\text { INI.01 Definição e evolução das estórias } \\
\text { e requisitos }\end{array}$ & $\begin{array}{l}\text { AP 1.1: P } \\
\text { AP 2.1: L } \\
\text { AP 2.2: P }\end{array}$ & Nível 0 \\
\hline $\begin{array}{l}\text { INI.02 Recrutamento e treinamento de } \\
\text { pessoal }\end{array}$ & $\begin{array}{l}\text { AP 1.1: F } \\
\text { AP 2.1: L } \\
\text { AP 2.2: F }\end{array}$ & Nível 2 \\
\hline $\begin{array}{l}\text { INI.03 Preparação do ambiente de desen- } \\
\text { volvimento }\end{array}$ & $\begin{array}{l}\text { AP 1.1: F } \\
\text { AP 2.1: F } \\
\text { AP 2.2: L }\end{array}$ & Nível 2 \\
\hline $\begin{array}{l}\text { INI.04 Projeto arquitetural do software e } \\
\text { do sistema }\end{array}$ & $\begin{array}{l}\text { AP 1.1: L } \\
\text { AP 2.1: L } \\
\text { AP 2.2: F }\end{array}$ & Nível 1 \\
\hline INI.05 Planejamento global do projeto & AP 1.1: L & Nível 1 \\
AP 2.1: F & AP 2.2: N & \\
\hline DES.01 Planejamento das iterações & AP 1.1: N & Nível 0 \\
AP 2.1: N & \\
\hline
\end{tabular}




\begin{tabular}{|c|c|c|}
\hline DES.02 Produção de estórias & $\begin{array}{l}\text { AP 1.1: } \mathrm{P} \\
\text { AP 2.1: L } \\
\text { AP 2.2: N }\end{array}$ & Nível 0 \\
\hline DES.03 Tratamento de riscos & $\begin{array}{l}\text { AP 1.1: } \mathrm{N} \\
\text { AP 2.1: N } \\
\text { AP 2.2: N }\end{array}$ & Nível 0 \\
\hline DES.04 Integração contínua & $\begin{array}{l}\text { AP 1.1: L } \\
\text { AP 2.1: F } \\
\text { AP 2.2: L }\end{array}$ & Nível 1 \\
\hline $\begin{array}{l}\text { DES.05 Refinamento de produtos e pro- } \\
\text { cessos }\end{array}$ & $\begin{array}{l}\text { AP 1.1: } \mathrm{P} \\
\text { AP 2.1: } \mathrm{N} \\
\text { AP 2.2: } \mathrm{N}\end{array}$ & Nível 0 \\
\hline OPE.01 Colocar versão em produção & $\begin{array}{l}\text { AP 1.1: } \mathrm{P} \\
\text { AP 2.1: L } \\
\text { AP 2.2: N }\end{array}$ & Nível 0 \\
\hline OPE.02 Manutenção & $\begin{array}{l}\text { AP 1.1: } \\
\text { AP 2.1: } \\
\text { AP 2.2: }\end{array}$ & Nível 0 \\
\hline $\begin{array}{l}\text { APO.01 Gerência de configuração de } \\
\text { software }\end{array}$ & $\begin{array}{l}\text { AP 1.1: } \mathrm{N} \\
\text { AP 2.1: } \mathrm{N} \\
\text { AP 2.2: N }\end{array}$ & Nível 0 \\
\hline $\begin{array}{l}\text { APO.02 Preparação / Evolução da docu- } \\
\text { mentação }\end{array}$ & $\begin{array}{l}\text { AP 1.1: L } \\
\text { AP 2.1: F } \\
\text { AP 2.2: L }\end{array}$ & Nível 1 \\
\hline APO.03 Revisão e garantia de qualidade & $\begin{array}{l}\text { AP 1.1: } \mathrm{N} \\
\text { AP 2.1: N } \\
\text { AP 2.2: N }\end{array}$ & Nível 0 \\
\hline
\end{tabular}

A classificação dos processos em níveis de capacidade revela possíveis "fragilidades" existentes na execução dos mesmos. Essas "fragilidades" indicam a necessidade de melhoria na realização do processo, visando uma realização suficientemente gerenciada e ágil.

Os processos classificados com Nível 0 e Nível 1 possuem, segundo o Modelo de Referência Ágil, alguns aspectos a serem melhorados em sua execução. Para esses processos, algumas ações de melhoria foram definidas e sugeridas ao CI.

As ações de melhoria tendem a minimizar as falhas detectadas no processo avaliado e, com isso, aumentar sua capacidade. Dessa forma, na Figura 6.4 é apresentado um Relatório de Apresentação de Resultados, referente ao processo "DES.04 Integração contínua", contendo pontos fortes 
e fracos encontrados durante a avaliação, as pontuações de cada item que compõe os atributos de processo e algumas sugestões de ações de melhoria.

Acredita-se que os planos de implantação, elaborados para os processos "não realizados" (APO.01, APO.03, DES.01, DES.03), e as ações de melhoria definidas nos relatórios de apresentação dos resultados, elaborados para os processos com Nível 0 e Nível 1 de capacidade (INI.01, INI.04, INI.05, DES.02, DES.04, DES.05, OPE.01, OPE.02, APO.02), podem proporcionar uma melhora substancial na qualidade do processo de desenvolvimento do CI e, mais do que isso, pode tornar o processo ágil.

\subsection{Considerações finais}

A avaliação apresentada neste capítulo permitiu destacar aspectos positivos e negativos do processo de desenvolvimento realizado pelo CI. Esses aspectos possibilitaram à avaliação apontar um caminho para uma melhoria.

Espera-se, como resultado de um processo de melhoria, que o processo a ser "melhorado" assemelhe-se ao modelo de processo utilizado como referência. Portanto, os resultados da avaliação do processo de desenvolvimento do CI possibilitaram direcionar um processo de melhoria, visando tornar o processo avaliado "semelhante" ao Modelo de Referência Ágil, utilizado como referência na avaliação. Acredita-se que um processo "semelhante" ao Modelo de Referência Ágil pode ser considerado um processo de desenvolvimento ágil.

Dessa forma, espera-se que o Modelo de Referência Ágil sirva como referência para processos de melhoria, com o objetivo de transformar processos de desenvolvimento em processos de desenvolvimento ágeis. Mais do que isso, espera-se que o Modelo de Referência Ágil sirva como referência para a implantação de processo de desenvolvimento ágil. 


\section{Plano de Implantação de Gerência de Configuração}

\section{Introdução:}

1.1. Propósito:

O objetivo deste plano é orientar a implantaçẫo de um processo de gerenciamento de configuraçẫo de software. Este plano contém instruçổes sobre as tarefas de gerenciamento de configuração de software, assim como a definiçẫo da ferramenta para o controle de versổes e o roteiro de institucionalizaçã̃o do gerenciamento de configuração de software.

1.2. Escopo:

0 processo de gerenciamento de configuração proposto é indicado para empresas de desenvolvimento de software que se enquadram nas seguintes características:

- Possuem aproximadamente cinco pessoas envolvidas com desenvolvimento de sistemas;

- Utilizam, no mínimo, equipamentos com capacidade de processamento de $1.2 \mathrm{MHz}$ e sistema operacional MS-

Windows 98 ou XP:

- Produzem alguma documentação de software, mas consideram importante produzir mais e manter a documentação atualizada;

- Desejam manter um histórico de alguns artefatos produzidos durante o desenvolvimento;

\subsection{Termos chave:}

- Árvore de versỗes: modo de descrever o histórico de versổes de cada item de informaçẫo:

- Configuração: conjunto de versões de itens de informaçẫo consistentes, correspondente a determinada versẩo do sistema;

- Equipe de desenvolvimento: grupo de programadores e analistas que trabalham na execução do sistema, sob coordenaçẫo do gerente de projeto;

- Documentaçẫo: conjunto de itens de informaçẫo que descrevem características do sistema. Geralmente sẫo diagramas, tabelas, gráficos ou texto;

- Item de configuraçẫo/ Item de informaçẫo: qualquer arquivo componente de um sistema, inclusive documentação;

- Versẫo: situação de um item de informaçẫo, após cada alteraçẩo.

\section{Tarefas}

2.1. Estabelecer estratégia de gerência de configuraçãa:

- Seleçẫo dos itens: Durante o desenvolvimento e manutençẫo de um sistema, muitos itens de informaçẫo sẫo produzidos. 0 conjunto de itens de informação a serem controlados é composto de:

- * Lista de estórias e de requisitos nẫo-funcionais - Modelo de negócios do sistema

- Projeto arquitetural do sistema

- Projeto de banco de dados

- * Casos de teste de integração

- * Resultados dos testes unitários

- Nova versão do produto e/ou do processo

- Projeto arquitetural do software

- Plano global do projeto

- * Casos de teste unitário

- *Versão completa do sistema

- Versão integrada da estória

- Versẫo modificada do software

*itens de informação não produzidos atuaimente

- Identificaçẫo dos itens de configuraçẫo:

- O nome de cada um dos itens começa com três caracteres que determinam o tipo do item, e, opcionalmente, mais cinco caracteres ou números que especificam o item. A identificação das versôes dos itens é deixado a cargo da ferramenta de controle de versôes.

Exemplo: Item: Modelo de negócios do sistema Identificaçã̃o: MNS

- Organizaçãoo do repositório: Os itens de informação sẫo criados no diretório de trabalho do projeto, que tem o mesmo nome do projeto (ex: proj1). Quando uma versẩo do item é retirada para alteraçẫo, a ferramenta bloqueia sua retirada por outros usuários até que seja desbloqueada pelo usuário que a retirou. A organização do repositório deve seguir o padrăo utilizado pela ferramenta de controle de versổes.

- Relato da situaçẩo da configuraçẫo: O gerente da configuraçẫo de software é o responsável pela disponibilizaçẫo das informaçổes sobre a situação da configuração de software às pessoas autorizadas. Para isso, ele pode utilizar ferramentas de divulgaçã̃o, e-mail banner, lousas, entre outros.

\section{Roteiro}

- Designar pessoa ao cargo de gerente de configuraçẫo;

- Fornecer cursos/treinamento em gerenciamento de configuraçẫo ao gerente designado;

- Fazer reuniỗes locais de motivaçẫo e estudos sobre gerenciamento de configuraçẫo de software entre todos membros da empresa;

- Adquirir a ferramenta para o controle de versôes e realizar treinamentos para sua correta utilização;

- Treinar a equipe de projeto nos novos procedimentos administrativos;

- Iniciar o gerenciamento de configuraçẫo em um projeto piloto.

\section{Recursos}

- Gerente de configuraçã̃o: analista de sistemas experiente e organizado;

- Ferramenta: Concurrent Version System (CVS)

- Banco de Dados: Access, Foxpro, Interbase

Figura 6.3: Plano de implantação de gerência de configuração. 


\section{Relatório de Apresentação de Resultados \\ Processo: DES.04 - Integraçẫo contínua}

\section{Objetivo}

Este documento tem o objetivo de apresentar os resultados da avaliaçẫo do processo denominado "DES.04 Integraçã̃o contínua". Considera-se como resultados da avaliaçẫo os aspectos positivos e negativos encontrados durante a avaliaçẫo. $O$ documento ainda tem o intuito de orientar um possivel processo de melhoria, através da sugestẫo de algumas açôes de melhoria, que visam minimizar a existência dos aspectos negativos.

\section{Resultados da avaliação}

O processo DES.04 possui alguns aspectos positivos e negativos em sua realização. Tais aspectos são apresentados a seguir.

\section{Aspectos positivos:}

- O processo executa, de forma gerenciada, os procedimentos de integraçẩo contínua, várias vezes ao dia;

- O processo respeita uma estratégia de integração pré-definida.

\section{Aspectos negativos:}

- O processo executa testes de integração sempre que uma nova estória é produzida, porém, nẫo existem casos de teste de integraçẫo pré-definidos;

- O processo nẫo armazena os resultados dos testes de integraçẫo realizados.

\section{Capacidade do processo e pontuação dos Atributos de Processo (AP)}

\section{Capacidade do processo: Processo Executado (Nivel 1)}

AP 1.1 Atributo de execuçẫo de processo - Pontuaçẫo: L

a) $O$ processo realiza as saídas definidas

Extensäo de realização: $L$

AP 2.1 Atributo de gerência de Execuçẫo - Pontuaçẫo: $F$

a) Os objetivos de realizaçẫo do processo sẫo identificados Extensão de realização: $F$

b) A realizaçẫo do processo é planejada e monitorada Extensão de realização: $F$

c) A realizaçẫo do processo é ajustada para seguir os planos Extensäo de realização: $F$

d) As responsabilidades e autoridades para realizaçẫo do processo sẫo definidas, nomeadas e comunicadas;

Extensão de realização: $F$

e) Recursos e informaçốes necessárias para realizar o processo sẫo identificados, disponibilizados, alocados e utilizados;

Extensão de realização: $F$

f) Interfaces entre as partes envolvidas são gerenciadas para garantir uma comunicação efetiva $e$ ainda desobstruir a nomeaçẫo de responsabilidades.

Extensão de realização: $F$

AP 2.2 Atributo de gerência de produtos de trabalho - Pontuaçẫo: L

a) Os requisitos dos produtos de trabalho sẵo definidos

Extensão de realização: $L$

b) Os requisitos para documentaçẫo e controle dos produtos de trabalho sẩo definidos; Extensäo de realização: $N$

c) Os produtos de trabalho sẫo apropriadamente identificados, documentados e controlados; Extensão de realização: $F$

d) Os produtos de trabalho sẫo revistos de acordo com os planos estabelecidos e ajustados quando necessários para satisfazer os requisitos.

Extensão de realização: $F$

\section{Sugestões de ações de melhoria}

- Executar os testes de integraçẫo baseando-se em casos de teste de integraçẫo previamente definidos. ;

- Armazenar os resultados dos testes de integraçẫo realizados;

- Definir, explicitamente, os requisitos para os produtos de trabalho produzidos pelo processo;

Figura 6.4: Relatório de Apresentação de Resultados. 


\section{CAPÍTULO}

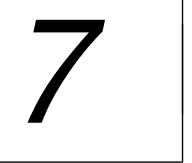

\section{Conclusões e trabalhos futuros}

\subsection{Síntese do trabalho}

Há algum tempo as metodologias tradicionais de desenvolvimento de software vêm ajudando as empresas do setor a produzirem software com qualidade. O alto nível de controle sobre os processos de desenvolvimento, proporcionado por essas metodologias, e o forte embasamento nos conceitos da engenharia de software são os responsáveis pelo sucesso dessas metodologias.

Mesmo com o alto nível de aceitação, algumas empresas de desenvolvimento estão optando por metodologias alternativas as tradicionais ou, mais especificamente, por metodologias ágeis. A busca por alternativas baseia-se no fato das metodologias ágeis serem menos burocráticas do que as tradicionais e por proporcionarem um desenvolvimento altamente adaptável e com respostas rápidas à mudanças. Essas características permitem um desenvolvimento ágil que prima por entregas rápidas de pequenas versões do software, pela satisfação do cliente, pela cooperação e pela comunicação.

Este trabalho apresentou os principais conceitos sobre as metodologias ágeis de desenvolvimento e uma análise sobre seis das principais metodologias ágeis existentes atualmente, destacando suas características e apontando semelhanças e diferenças entre elas.

Os assuntos abordados embasaram a concepção de um Modelo de Referência para o Desenvolvimento Ágil de Software, o principal resultado deste trabalho. O modelo reúne as principais características encontradas nas metodologias ágeis em dezesseis processos de desenvolvimento que visam servir como guia para a implantação de um processo de desenvolvimento ágil.

A partir dos resultados apresentados pela utilização do Modelo de Referência em um processo de melhoria, pode-se notar que as metodologias ágeis em geral, e o Modelo de Referência Ágil em 
particular, puderam ser considerados como alternativas à implantação de um processo de desenvolvimento que proporcione qualidade e controle ao processo a ser melhorado.

\subsection{Contribuições do trabalho}

As principais contribuições deste trabalho são:

- A definição de um Modelo de Referência para o Desenvolvimento Ágil de Software. O modelo, composto de dezesseis processos, visa orientar a implantação de processos de desenvolvimento ágeis.

- Uma análise comparativa das características existentes nas principais metodologias ágeis existentes atualmente. A análise permitiu identificar semelhanças e diferenças existentes nas metodologias analisadas.

- A possibilidade de utilização do Modelo de Referência para a Avaliação de Processos da ISO/IEC 15504 como guia para a avaliação de processos de desenvolvimento ágeis e, consequentemente, para a orientação de um processo de melhoria focado no paradigma ágil.

- Orientações para o planejamento e gerência de projetos de desenvolvimento ágeis, através das dependências existentes entre os processos e suas atividades e da Estrutura Analítica de Projetos, apresentados na Seção 5.4.7 do Capítulo 5.

\subsection{Trabalhos futuros}

Os processos de desenvolvimento em geral, e as metodologias ágeis em particular, são campos de pesquisas bastante férteis. As pesquisas realizadas nessas áreas crescem continuamente e, cada vez mais, aumentam as possibilidades de assuntos a serem abordados.

Dessa forma, os estudos realizados sobre processos de desenvolvimento e, especificamente, sobre as metodologias ágeis, permitiram a determinação de possíveis melhorias e desdobramentos do trabalho aqui apresentado. Dentre as possibilidades de trabalhos futuros, destacam-se:

- Desenvolvimento de ferramentas de suporte ao processo: O desenvolvimento de ferramentas de suporte ao Modelo de Referência Ágil é um campo fértil para trabalhos futuros. As possibilidades englobam ferramentas para o planejamento e gerenciamento das versões e das iterações, ferramentas para alocações de recursos, entre outras.

- Buscar o reconhecimento do Modelo de Referência Ágil dentro da comunidade: Embora o Modelo de Referência Ágil seja um modelo flexível, podendo ser adaptado a diversas situações, ele ainda não é reconhecido pela comunidade de interesse. A busca por um reconhecimento dentro da comunidade da engenharia de software, mais especificamente dentro da 
comunidade ágil, pode agregar aspectos ainda não contemplados pelo modelo, tornando-o um modelo mais maduro e confiável.

- Estudos específicos sobre gerência de projetos ágeis: O Modelo de Referência Ágil utilizase de práticas ágeis para auxiliar a gerência de projetos. No entanto, um estudo específico sobre gerência de projetos com características ágeis é um assunto com grandes possibilidades de trabalhos futuros, embora já existam alguns trabalhos nesse campo.

- Aplicação de um controle de mudanças adequado às metodologias ágeis: No Modelo de Referência Ágil não é descrita a necessidade de controle sobre as mudanças que ocorrem durante o processo, por acreditar-se que esse tipo de controle pode causar lentidão ao processo. Um controle de mudanças adequado às metodologias ágeis poderia aumentar as chances do Modelo de Referência Ágil ser aplicado com sucesso para projetos onde as equipes são numerosas e/ou estão separadas geograficamente. 


\section{Referências Bibliográficas}

Abrahamsson, P.; Salo, O.; Ronkainen, J.; Warsta, J. Agile software development methods. Review and analysis. Espoo 2002, v. VTT Publications 478, p. 107, 2002.

Agile Alliance Web Site Agile Alliance. [On-line].

Disponível em: http: / /www.agilealliance.org (Acessado em 10/02/2007)

Agile Modeling Web Site Agile Documentation. [On-line].

Disponível em: http://www.agilemodeling.com/essays/ agileDocumentation.htm (Acessado em 04/07/2006)

Ambler, S. W. Modelagem Ágil (AM) : Um apanhado geral. Ronin International, v. , 2002.

BAR, M.; Fogel, K. Open Source Development with CVS. 3 ed. Paraglyph Press, 2003.

Beck, K.; Beedle, M.; Bennekum, A.; Cockburn, A.; Cunningham, W.; Fowler, M.; Grenning, J.; Highsmith, J.; Hunt, A.; JefFries, R.; Kern, J.; MARick, B.; Martin, R. C.; Mellor, S.; Schwaber, K.; Sutherland, J.; Thomas, D. Manifesto for agile software development. [On-line].

Disponível em: http: / /www.agilemanifesto.org (Acessado em 17/10/2005)

Beck, K.; Beedle, M.; Bennekum, A.; Cockburn, A.; Cunningham, W.; Fowler, M.; Grenning, J.; Highsmith, J.; Hunt, A.; JefFries, R.; Kern, J.; MARick, B.; MARTin, R. C.; Mellor, S.; Schwaber, K.; Sutherland, J.; Thomas, D. Principles behind the agile manifesto. [On-line].

Disponível em: http://www.agilemanifesto.org/principles.html (Acessado em 17/10/2005)

Boenm, B. Get Ready for Agile Methods, with Care. IEEE Computer, v. , p. 64-69, 2002.

Boehm, B.; Turner, R. Management Challenges to Implementing Agile Processes in Traditional Development Organizations. IEEE Software, , n. 0740-7459, p. 30-39, 2005. 
Castro Magalhães, A. L. C.; Rouiller, A. C.; Vasconcelos, A. M. L. O gerenciamento de projetos de software desenvolvidos à luz das metodologias ágeis: Uma visão comparativa. PROQUALITY - Qualidade na Produção de Software, v. 1, n. 1, p. 29-46, 2005.

CATRINE JACOBSEN XPM - from idea to realization - critical approach to the concept of XPM. [On-line].

Disponível em: http://www.glyn.dk/download/synopsisXPM.pdf (Acessado em 25/03/2007)

Charles Ludwig Extreme Project Management. [On-line].

Disponível em: http://www.stickyminds.com/sitewide.asp?Function= edetail\&Object Type=ART\&Ob ject Id=6661 (Acessado em 10/03/2007)

Cockburn, A. Agile Software Development. 2 ed. Addison Wesley, 2002.

Cockburn, A.; Highsmith, J. Agile Software Development: The People Factor. IEEE Computer, v. , p. 131-133, 2001.

Collins-Sussman, B.; FitzPatrick, B. W.; Pilato, C. M. Version Control with Subversion: For Subversion 1.4: (Compiled from r2777). Paraglyph Press, 2004.

CorrêA, G. M.; Costa Figueiredo, R. M.; Oliveira, K. M.; Araujo, J. M. P. Diretrizes para a melhoria da gerência e desenvolvimento de requisitos em uma empresa de software. In: VI Simpósio Internacional de Melhoria de Processos de Software, São Paulo, SP, Brasil, 2004, p. 95-106.

Crocker, R. Large-Scale Agile Software Development. 1 ed. Addison-Wesley, 2003.

DARCI, P. S. Gerenciamento de projetos nas organizações. Editora de desenvolvimento gerencial, 2003.

DiRK RIEHLE A comparison of the value systems of adaptive software development and extreme programming: How methodologies may learn from each other. [On-line].

Disponível em: http: / / www.riehle.org (Acessado em 10/05/2006)

Dynamic System Development Method Web Site Dsdm introduction. [On-line]. Disponível em: http: / / www.dsdm.org (Acessado em 16/01/2006)

Dynamic System Development Method Web Site Quick overview. [On-line]. Disponível em: http: / / www.dsdm.org (Acessado em 16/01/2006)

Elrad, T.; Kiczales, G.; Aksit, M.; Lieberher, K.; Ossher, H. How Software Engineers Use Documentation: The State of the Practice. IEEE Computer, p. 35-39, 2003. 
Feature-driven Development Web Site Fdd process. [On-line].

Disponível em: http://www.featuredrivendevelopment.com (Acessado em 20/02/2006)

Figueiredo, A. L. G.; SANChES, R. ECO Ú Um ecossistema para desenvolvimento ágil de sistemas web. Dissertação de Mestrado, Instituto de Ciências Matemáticas e de Computação Universidade de São Paulo, São Carlos, SP, 2005.

Forward, A. Software Documentation Ú Building and Maintaining Artefacts of Communication. Dissertação de Mestrado, Ottawa-Carleton Institute for Computer Science - University of Ottawa, Ottawa, Ontario, Canadá, 2002.

FOWLER, M. The new methodology. [On-line].

Disponível em: http://martinfowler.com/articles/newMethodology.html (Acessado em 23/12/2005)

Goldman, A.; Kon, F.; Silva, P. J. S.; Yoder, J. W. Being Extreme in the Classroom: Experiences Teaching XP. Journal of the Brazilian Computer Society, p. 1-17, 2004.

Highsmith, J. Adaptive Management: Patterns For The E-Business Era. Cutter IT Journal, v. XII, n. 9, 1999.

Highsmith, J. Lifecycle Dinosaurs. Using Adaptive Software Development to meet the challenges of a high-speed, high-change environment. Software Testing \& Quality Engineering, p. 22-28, 2000.

Highsmith, J. Agile Software Development Ecosystems. 1 ed. Addison-Wesley, 2002.

Highsmith, J.; Cockburn, A. Agile Software Development: The Business of Innovation. IEEE Computer, v. , p. 120-122, 2001.

ISO/IEC 12207/PDAM 1 - Software Engineering - Life Cycle Processes. Relatório Técnico, International Organization for Standardization / International Electrotechnical Commission, 1999.

ISO/IEC Information Technology Ů Process Assessment U Part 1: Concepts and Vocabulary. Relatório Técnico, International Organization for Standardization / International Electrotechnical Commission, 2003a.

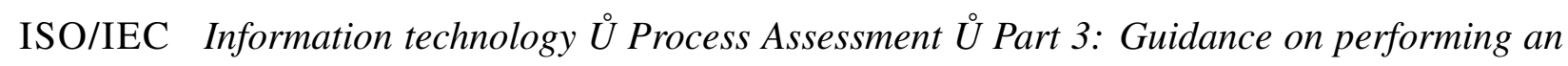
assessment. Relatório Técnico, International Organization for Standardization / International Electrotechnical Commission, 2003b.

ISO/IEC Information Technology Ů Process Assessment Ů Part 4: Guidance on use for Process Improvement and Process Capability Determination. Relatório Técnico, International Organization for Standardization / International Electrotechnical Commission, 2003c. 
ISO/IEC Information Technology Ů Process Assessment Ů Part 5: An exemplar Process Assessment Model. Relatório Técnico, International Organization for Standardization / International Electrotechnical Commission, 2003d.

ISO/IEC Software Engineering - Process Assessment - Part 2: Performing An Assessment. Relatório Técnico, International Organization for Standardization / International Electrotechnical Commission, 2003e.

Jim Highsmith Messy, Exciting, and anxiety-ridden: Adaptive Software Development. [Online].

Disponível em: http://www.jimhighsmith.com/articles/messy.htm (Acessado em 21/05/2006)

Keith Everette Agile Software Development Processes - A difference approach to software design. [On-line].

Disponível em: http: / / www . asd. com (Acessado em 21/05/2006)

KERZNER, H. Gestão de projetos: as melhores práticas. 2 ed. Bookman, 2006.

Khramtchenko, S. Comparing eXtreme Programming and Feature Driven Development in academic and regulated environments. In: , Harvard University, EUA, 2004.

Koskela, J. Software configuration management in agile methods. VTT Publications, v., n. 514, p. 54, 2003.

Kuhn, G. R.; PAmplona, V. F. Apresentando xp: Encante seus clientes com extreme programming. [On-line].

Disponível em: http://www.javafree.org/content/view.jf?idContent=5 (Acessado em 25/08/2005)

MARTIN Fowler Continuous Integration. [On-line].

Disponível em: http: / / www. martinfowler. com (Acessado em 10/01/2007)

MicrosofT Checklist: Managed Code Performance. [On-line].

Disponível em: http://msdn2.microsoft.com/en-us/library/ms 979052 . aspx (Acessado em 02/06/2007)

Mnkandla, E.; Dwolatzky, B. Defining Agile Software Quality Assurance. In: International Conference on Software Engineering Advances (ICSEA06), IEEE Computer, 2006.

PAUlK, M. Extreme Programming from a CMM Perspective. IEEE Software, v. , p. 19-26, 2001.

Pfleeger, S. Engenharia de Software. Teoria e Prática. 2 ed. Prentice Hall, 2004. 
Pressman, R. S. Software Engineering: A Practitionert's Approach . 6 ed. McGraw-Hill Science Engineering, 2006.

Project Management Institute PMBOK. In: Um guia do conjunto de conhecimentos em gerenciamento de projetos (Guia PMBOK), http://www.pmi.org. Last access: 01/03/2007: Project Management Institute, p. 405, 2004.

RISING, L. Agile Meetings: Putting frequent, short meetings to work for your team. STQE Magazine- The Software Testing and Quality Engineering , v. 4, 2002.

Rocha, A. R. C.; Maldonado, J. C.; Weber, K. C. Qualidade de Software. Teoria e Prática. 1 ed. Prentice Hall, 2001.

Rodrigues, A. G.; SAnches, R.; Ferrari, F. C.; Oliveira, J. L. Um Modelo de Maturidade para a Avaliação de Processos Ágeis, a ser submetido, 2005.

SAntos SoAres, M. Comparação entre Metodologias Ágeis e Tradicionais para o Desenvolvimento de Software. Dissertação de Mestrado, Faculdade de Tecnologia e Ciências de Conselheiro Lafaiete - Universidade Presidente Antônio Carlos, Conselheiro Lafaiete, MG, 2004.

SCHWABER, K. Scrum musing. a collection of thoughts on scrum and agile processes from ken schwaber during 2003 and 2004. [On-line].

Disponível em: http://www.controlchaos.com/download/ScrumMusings. pdf (Acessado em 20/02/2006)

SChWABER, K.; BeEdLe, M. Agile software development with scrum. [On-line].

Disponível em: http://www. controlchaos.com/download/BookExcerpt.pdf (Acessado em 20/02/2006)

SCRUM Web Site The philosophy of scrum. [On-line].

Disponível em: http: / / www. control chaos. com (Acessado em 31/10/2005)

Silva, A. F.; Kon, F.; Torteli, C. XP South of the Equator: An Experience Implementing $\mathrm{XP}$ in Brazil. In: Proceedings of th 6 th International Conference on eXtreme programming and Agile Processes in Software Engineering (XPŠ2005), Sheffield, England, 2005, p. 10-18.

Sliger, M. Relating PMBOK Practices to Agile Practices. StickyMinds.com, 2006.

Sommerville, I. Software Engineering. 8 ed. Addison Wesley, 2003.

The StANDish Group The CHAOS Report. [On-line].

Disponível em: http: / / standishgroup. com (Acessado em 04/01/2007)

TiJman, A. Tester Introduction to agile software development. Eurostar 2003, v. , 2003. 
Williams, L. Agile Software Development: The People Factor. IEEE Software, v. , p. 16-20, 2003.

Williams, L.; CoCKBURn, A. Agile Software Development: ItŠs about Feedback and Change. IEEE Computer, v. , n. 0018-9162/03, p. 39-42, 2003.

Williams, L.; Kessler, R. R.; Cunningham, W.; JefFries, R. Strengthening the Case for Pair Programming. IEEE Software, , n. 0740-7459, p. 19-25, 2000. 


\section{Características chave dos produtos de trabalho}

\begin{tabular}{|l|l|}
\hline Produto de trabalho & Características \\
\hline $\begin{array}{l}\text { Ambiente de desenvolvi- } \\
\text { mento }\end{array}$ & $\begin{array}{l}\text { - Atende os requisitos necessários para a realização de um } \\
\text { processo } \\
\text { - Alguns requisitos que devem ser considerados são: } \\
\text { - aspectos de segurança } \\
\text { - backup e recuperação } \\
\text { - equipamentos e espaço físico } \\
\text { - requisitos de apoio ao usuário } \\
\text { - facilidade de acesso remoto }\end{array}$ \\
\hline $\begin{array}{l}\text { Atividades de refinamento } \\
\text { (melhoria) }\end{array}$ & $\begin{array}{r}\text { - Indicam o caminho para melhorar um produto ou processo } \\
\text { Atividades para o gerencia- } \\
\text { mento de riscos }\end{array}$ \\
\hline
\end{tabular}




\begin{tabular}{|c|c|}
\hline Produto de trabalho & Características \\
\hline Casos de teste de integração & $\begin{array}{l}\text { - Definem os procedimentos que devem ser seguidos para a } \\
\text { realização dos testes de integração } \\
\text { - Definem entradas e saídas para os casos de teste } \\
\text { - Identificam circunstâncias necessárias para a realização } \\
\text { dos casos de teste } \\
\text { - Identificam procedimentos especiais } \\
\text { - Descobrem erros no software ou demonstra que as estórias } \\
\text { estão, aparentemente, trabalhando de acordo com as espe- } \\
\text { cificações }\end{array}$ \\
\hline Casos de teste unitário & $\begin{array}{l}\text { - Definem os procedimentos que devem ser seguidos para a } \\
\text { realização dos testes unitários } \\
\text { - Definem entradas e saídas para os casos de teste } \\
\text { - Descobrem erros na unidade de software ou demonstra que } \\
\text { está, aparentemente, trabalhando de acordo com as especi- } \\
\text { ficações }\end{array}$ \\
\hline Descrição do processo & $\begin{array}{l}\text { - Descreve o processo de forma detalhada } \\
\text { - A descrição detalhada do processo deve incluir: } \\
\text { - propósitos do processo } \\
\text { - resultados esperados } \\
\text { - tarefas e atividades que devem ser realizadas } \\
\text { - produtos de trabalho de entrada e de saída }\end{array}$ \\
\hline Estória implementada & $\begin{array}{l}\text { Û́ A estória foi codificada em conformidade com os padrões } \\
\text { estipulados } \\
\text { - Utiliza estruturas de dados eficientes } \\
\text { Û́ Utiliza algoritmos eficientes e de fácil entendimento } \\
\text { Û́ Possui interfaces funcionais eficientes } \\
\text { - Atende aos requisitos especificados }\end{array}$ \\
\hline $\begin{array}{l}\text { Falhas e problemas encontra- } \\
\text { dos }\end{array}$ & $\begin{array}{l}\text { - Descreve as falhas e problemas encontrados nos processos } \\
\text { ou produtos de trabalho }\end{array}$ \\
\hline Fatores de qualidade & $\begin{array}{l}\text { - Descreve quais fatores de qualidade podem ser considera- } \\
\text { dos em um processo de garantia de qualidade } \\
\text { - Exemplos de fatores de qualidade são: correti- } \\
\text { tude, manutenibilidade, extendibilidade, etc. }\end{array}$ \\
\hline
\end{tabular}




\begin{tabular}{|c|c|}
\hline Produto de trabalho & Características \\
\hline $\begin{array}{l}\text { Ferramentas de desenvolvi- } \\
\text { mento }\end{array}$ & $\begin{array}{l}\text { - As ferramentas de desenvolvimento auxiliam o desenvol- } \\
\text { vedor a produzir o código-fonte } \\
\text { - As ferramentas de desenvolvimento devem incluir recur- } \\
\text { sos como: } \\
\text { - depuração do código } \\
\text { - formatação do código } \\
\text { - facilidade de visualização de palavras-chave da } \\
\text { linguagem de programação utilizada }\end{array}$ \\
\hline $\begin{array}{l}\text { Ferramenta para o controle de } \\
\text { versões }\end{array}$ & $\begin{array}{l}\text { - A ferramenta para o controle de versões deve atender aos } \\
\text { seguintes aspectos: } \\
\quad \text { - permitir que as versões do software sejam recu- } \\
\text { peradas rapidamente } \\
\quad \text { - bloquear o acesso concorrente a um item de confi- } \\
\text { guração } \\
\text { - utilizar um esquema de identificação dos itens de } \\
\text { configuração que permita conhecer a versão de um determi- } \\
\text { nado item de configuração }\end{array}$ \\
\hline Guia de instalação & $\begin{array}{l}\text { - Define tarefas para colocar uma versão do software em } \\
\text { produção } \\
\text { - As tarefas são defindas sequencialmente e devem incluir: } \\
\text { - arquivos que devem ser carregados para a insta- } \\
\text { lação } \\
\text { - instruções para a instalação } \\
\text { - procedimentos de instalação } \\
\text { - procedimentos de configuração } \\
\text { - procedimentos de verificação } \\
\text { - instruções de backup e recuperação } \\
\text { - parâmetros de configuração }\end{array}$ \\
\hline $\begin{array}{l}\text { Indivíduos capacitados e trei- } \\
\text { nados }\end{array}$ & $\begin{array}{l}\text { - Possuem as habilidades e competências necessáris ao pro- } \\
\text { jeto } \\
\text { - Possuem conhecimento suficiente para aplicarem os } \\
\text { conhecimentos referentes ao paradigma ágil }\end{array}$ \\
\hline $\begin{array}{l}\text { Lista de documentos a serem } \\
\text { mantidos }\end{array}$ & $\begin{array}{l}\text { - Identifica quais documentos devem ser produzidos } \\
\text { - Define quando os documentos devem ser produzidos } \\
\text { - Define o momento em que os documentos devem ser atua- } \\
\text { lizados }\end{array}$ \\
\hline
\end{tabular}




\begin{tabular}{|c|c|}
\hline Produto de trabalho & Características \\
\hline $\begin{array}{l}\text { Lista de estórias e de requisi- } \\
\text { tos não-funcionais }\end{array}$ & $\begin{array}{l}\text { - Descreve características funcionais e não-funcionais dese- } \\
\text { jadas para o software e para o sistema - As características } \\
\text { funcionais e não-funcionais referem-se a: } \\
\text { - Performance do sistema } \\
\text { - Interfaces } \\
\text { - Segurança } \\
\text { - Restrições ou considerações importantes } \\
\text { - Define propósitos e objetivos das estórias }\end{array}$ \\
\hline Lista de itens de informação & $\begin{array}{l}\text { - Conjunto de itens de informação que são produzidos pelos } \\
\text { processos } \\
\text { - Uma lista de itens de informação pode incluir código, do- } \\
\text { cumentos, modelos, etc. }\end{array}$ \\
\hline Lista de riscos identificados & $\begin{array}{l}\text { - Identifica os riscos envolvidos com o projeto } \\
\text { - Descreve as possíveis causas do risco } \\
\text { - Descreve os impactos que o risco pode causar ao projeto }\end{array}$ \\
\hline $\begin{array}{l}\text { Modelo de negócios do sis- } \\
\text { tema }\end{array}$ & $\begin{array}{l}\text { - Descreve os relacionamentos e dependências existentes } \\
\text { entre os componentes do sistema - Pode ser representado } \\
\text { através de modelos de dados, diagramas, etc. }\end{array}$ \\
\hline $\begin{array}{l}\text { Nova versão do produto e/ou } \\
\text { do processo }\end{array}$ & $\begin{array}{l}\text { - Constitui-se de uma versão melhorada do produto e/ou do } \\
\text { processo }\end{array}$ \\
\hline Padrões de codificação & $\begin{array}{l}\text { - Define padrões para serem aplicados aos códigos-fonte } \\
\text { - Define a maneira como os identificadores serão denomi- } \\
\text { nados e organizados } \\
\text { - Define a estrutura global do código-fonte } \\
\text { - Define a maneira como o código-fonte será visualmente } \\
\text { organizado } \\
\text { - Define a maneira como os comentários serão inseridos no } \\
\text { código-fonte } \\
\text { - Pode ser concebido em forma de um checklist }\end{array}$ \\
\hline Padrões de documentação & $\begin{array}{l}\text { - Define padrões para a produção de documentos } \\
\text { - Os padrões devem conter informações de: } \\
\text { - formato, conteúdo, descrição, numeração de pá- } \\
\text { ginas, linguagem, localização de figuras e tabelas, etc. } \\
\quad \text { - organização e localização dos documentos }\end{array}$ \\
\hline $\begin{array}{l}\text { Plano de gerenciamento de } \\
\text { manutenção }\end{array}$ & $\begin{array}{l}\text { - Define atividades para modificar versões do software } \\
\text { - Define atividades para gerenciar as modificações } \\
\text { - Define atividades para incluir novas estórias à versão do } \\
\text { software }\end{array}$ \\
\hline
\end{tabular}




\begin{tabular}{|c|c|}
\hline Produto de trabalho & Características \\
\hline $\begin{array}{l}\text { Plano de implantação de ge- } \\
\text { rência de configuração }\end{array}$ & $\begin{array}{l}\text { - Define a ferramenta que será utilizada para controlar as } \\
\text { versões } \\
\text { - Define o gerente de configuração } \\
\text { - Define as atividades e um cronograma para implantar a } \\
\text { gerência de configuração } \\
\text { - Define o esquema de identificação dos itens de configura- } \\
\text { ção } \\
\text { - Define a maneira como o status dos itens de configuração } \\
\text { serão divulgados }\end{array}$ \\
\hline Plano de qualidade & $\begin{array}{l}\text { - Define os objetivos de qualidade } \\
\text { - Define tarefas para garantir a qualidade } \\
\text { - Define o modelo de qualidade }\end{array}$ \\
\hline Plano de treinamento & $\begin{array}{l}\text { - Define os usuários a serem treinados } \\
\text { - Define as habilidades requeridas para o treinamento } \\
\text { - Define atividades de treinamento para atingir os objetivos } \\
\text { pretendidos }\end{array}$ \\
\hline Plano global do projeto & $\begin{array}{l}\text { - Define o objetivo e escopo do software } \\
\text { - Define um cronograma geral para o projeto } \\
\text { - Define uma estratégia para a integração contínua } \\
\text { - Define mecanismos para monitorar o feedback do cliente } \\
\text { - Define as equipes que integrarão o projeto } \\
\text { - Define o tempo de duração das iterações }\end{array}$ \\
\hline Plano para a iteração & $\begin{array}{l}\text { - Identifica as estórias a serem implementadas na próxima } \\
\text { iteração } \\
\text { - Estima as estórias a serem implementadas } \\
\text { - Define os objetivos da iteração } \\
\text { - Define os casos de teste de integração } \\
\text { - Define as equipes e as responsabilidades durante a iteração }\end{array}$ \\
\hline Produto de trabalho & $\begin{array}{l}\text { - Um produto de trabalho é algum artefato produzido por } \\
\text { algum processo. }\end{array}$ \\
\hline $\begin{array}{l}\text { Projeto arquitetural do sis- } \\
\text { tema }\end{array}$ & $\begin{array}{l}\text { - Fornece uma visão da arquitetura do sistema } \\
\text { - Descreve os relacionamentos entre os componentes do sis- } \\
\text { tema } \\
\text { - Especifica um projeto para cada componente do sistema }\end{array}$ \\
\hline
\end{tabular}




\begin{tabular}{|c|c|}
\hline Produto de trabalho & Características \\
\hline $\begin{array}{l}\text { Projeto arquitetural do soft- } \\
\text { ware }\end{array}$ & $\begin{array}{l}\text { - Descreve a estrutura do software } \\
\text { - Identifica os componentes de software } \\
\text { - Identifica os relacionamentos entre os componentes do } \\
\text { software } \\
\text { - Define formatos de entrada e saída de dados } \\
\text { - Define formatos de estrutura de dados }\end{array}$ \\
\hline Projeto de banco de dados & $\begin{array}{l}\text { - Define o sistema gerenciador de banco de dados } \\
\text { - Define o formato dos registros, tabelas e objetos } \\
\text { - Define o modo de acesso } \\
\text { - Define visões lógicas e físicas para o modelo de dados } \\
\text { - Identifica restrições }\end{array}$ \\
\hline Registro de aceitação & $\begin{array}{l}\text { - Armazena a aceitação do cliente } \\
\text { - Identifica a data da aceitação } \\
\text { - Identifica os elementos entregues } \\
\text { - Identifica o responsável pela aceitação }\end{array}$ \\
\hline Relatório de incidentes & $\begin{array}{l}\text { - Descreve o evento ocorrido } \\
\text { - Define a gravidade do evento (grave, médio, pouco grave) } \\
\text { - Identifica os produtos ou versões de software afetados }\end{array}$ \\
\hline Relatório de modificações & $\begin{array}{l}\text { - Descreve as modificações realizadas } \\
\text { - Inclui referência para a solicitação de modificação de ori- } \\
\text { gem } \\
\text { - Inclui informações sobre o status da modificação }\end{array}$ \\
\hline $\begin{array}{l}\text { Repositório de itens de confi- } \\
\text { guração }\end{array}$ & $\begin{array}{l}\text { - Conjunto de itens de informação que estão sob controle de } \\
\text { configuração }\end{array}$ \\
\hline Requisição de evolução & $\begin{array}{l}\text { - Identifica o propósito da evolução } \\
\text { - Identifica o status da requisição (nova, aprovada, repro- } \\
\text { vada) } \\
\text { - Identifica qual requisito a requisição se refere } \\
\text { - Identifica o impacto na evlução no sistema } \\
\text { - Identifica a criticalidade da evolução }\end{array}$ \\
\hline Requisitos do documento & $\begin{array}{l}\text { - Identifica os pontos chave para o documento atingir seus } \\
\text { objetivos }\end{array}$ \\
\hline $\begin{array}{l}\text { Resultados dos testes de inte- } \\
\text { gração }\end{array}$ & $\begin{array}{l}\text { - Identifica a data de realização do teste } \\
\text { - Identifica o responsável pela realização do teste } \\
\text { - Identifica os resultados da realização do teste }\end{array}$ \\
\hline $\begin{array}{l}\text { Resultados dos testes unitá- } \\
\text { rios }\end{array}$ & $\begin{array}{l}\text { - Identifica a data de realização do teste } \\
\text { - Identifica o responsável pela realização do teste } \\
\text { - Identifica os resultados da realização do teste }\end{array}$ \\
\hline
\end{tabular}




\begin{tabular}{|l|l|}
\hline Produto de trabalho & Características \\
\hline Versão completa do sistema & $\begin{array}{l}\text { - Possui todas as estórias e requisitos não-funcionais previs- } \\
\text { tos para o sistema } \\
\text { - Possui produtos de software já integrados e possíveis da- } \\
\text { dos associados }\end{array}$ \\
- Possui toda a documentação prevista para o sistema \\
- Considera todos os hardwares necessários para a execução \\
adequada do sistema
\end{tabular}


A capacidade de processo é avaliada numa escala ordinal de três pontos, permitindo que o processo seja avaliado como Incompleto, Executado ou Gerenciado. A escala representa incremento de capacidade na implementação do processo, de não realização até a execução efetiva e gerenciada dos propósitos do processo.

O Framework de Medidas provê um esquema para ser utilizado na caracterização da capacidade na implementação de um processo com respeito ao Modelo de Avaliação de Processo. Cada nível de capacidade corresponde a um conjunto de atributos de processo que trabalham juntos para prover uma melhora na capacidade para executar um processo. Em outras palavras, os atributos de processo constituem uma maneira racional de progredir por meio da melhoria de capacidade de qualquer processo.

Dentro do Framework de Medidas, a medida da capacidade é baseada em um conjunto de Atributos de Processo (AP). Cada atributo define um aspecto particular da capacidade de processo. A extensão da realização do atributo de processo é caracterizada em uma escala de classificação definida e determina o nível de capacidade do processo. A seguir são apresentados os níveis de capacidade e os AP correspondentes.

\section{B.1 Níveis de Capacidade de Processo}

\section{B.1.1 Nível 0: Processo Incompleto}

O processo não é implementado, ou falha, em alcançar seus resultados de processo. Neste nível existe pouca ou nenhuma evidência da realização sistemática de qualquer atributo definido. 


\section{B.1.2 Nível 1: Processo Executado}

O processo implementado alcança os resultados do processo. Atributo que demonstra a obtenção deste nível:

AP 1.1 Atributo de Execução de Processo: É uma medida da extensão na qual o propósito do processo é obtido. Como resultado do atendimento total deste atributo:

a) O processo realiza as saídas definidas

\section{B.1.3 Nível 2: Processo Gerenciado}

O processo é implementado de uma maneira gerenciada e seus produtos de trabalho são apropriadamente estabelecidos, controlados e mantidos. Atributo que demonstra a obtenção deste nível:

AP 2.1 Atributo de Gerência de Execução: É uma medida da extensão na qual a realização do processo é gerenciada. Como resultado do atendimento total deste atributo:

a) os objetivos de realização do processo são identificados;

b) a realização do processo é planejada e monitorada;

c) a realização do processo é ajustada para seguir os planos;

d) as responsabilidades e autoridades para realização do processo são definidas, nomeadas e comunicadas;

e) recursos e informações necessárias para realizar o processo são identificados, disponibilizados, alocados e utilizados;

f) interfaces entre as partes envolvidas são gerenciadas para garantir uma comunicação efetiva e ainda desobstruir a nomeação de responsabilidades.

AP 2.2 Atributo de Gerência dos Produtos de Trabalho: É uma medida da extensão na qual os produtos de trabalho produzidos por um processo são apropriadamente gerenciados. Como resultado do atendimento total deste atributo:

a) os requisitos dos produtos de trabalho são definidos;

b) os requisitos para documentação e controle dos produtos de trabalho são definidos;

c) os produtos de trabalho são apropriadamente identificados, documentados e controlados;

d) os produtos de trabalho são revistos de acordo com os planos estabelecidos e ajustados quando necessários para satisfazer os requisitos.

\section{B.2 Avaliação dos Atributos de Processo}

\section{B.2.1 Indícios de Atributos de Processo (IAP)}

Os atributos de processo possuem associados a eles um conjunto de Indícios de Atributos de Processo (IAP), que indicam a extensão da execução do atributo na instanciação do processo. 
Esses indícios relacionam-se à atividades, recursos e resultados associados com a execução dos propósitos dos atributos.

Os Indícios de Atributos de Processo são:

- Indícios de Práticas Genéricas (PG): os indícios de PG são atividades genéricas que guiam a implementação de características dos atributos;

- Indícios de Recursos Genéricos (RG): os indícios de RG são associados aos recursos que podem ser utilizados pelo processo para alcançar o atributo;

- Indícios de Produtos de Trabalho Genéricos (PTG): os indícios de PTG são conjuntos de características que espera-se que sejam evidentes nos produtos de trabalho resultantes da realização de um processo. Eles formam a base para a classificação dos produtos de trabalho definidos nos Indícios de Execução de Processo.

Os três tipos de IAP auxiliam a estabelecer as evidências da extensão da execução de um atributo de processo. Como um indício adicional para apoiar a avaliação do Nível 1, cada processo possui associado um conjunto de Indícios de Execução de Processo, que são utilizados para medir o grau de execução do Atributo de Execução de Processo.

Os Indícios de Execução de Processo (IEP) são:

- Práticas Básicas (PB): A execução das PB provê um indício da extensão da execução dos propósitos do processo e sua aproximação com os resultados esperados do processo;

- Produtos de Trabalho (PT): Os Produtos de Trabalho (PT) são utilizados e/ou produzidos quando o processo é executado. Cada produto de trabalho tem definido um conjunto de características que deve ser utilizado para avaliar a implementação efetiva de um processo. Uma lista com as características chave de cada produto de trabalho é apresentada no Apêndice A.

Os indícios IAP e IEP fornecem as evidências que um avaliador pode obter, ou observar, na execução de uma avaliação. Um indício é definido como uma característica objetiva, de uma prática ou produto de trabalho, que apóia o julgamento da capacidade de um processo implementado. Em outras palavras, os indícios são utilizados para confirmar que certas práticas são executadas, além de auxiliarem na coleta de evidências de objetivos da avaliação.

As evidências a serem coletadas e validadas, juntamente com as características definidas no modelo de referência, devem servir como guia para a pontuação dos atributos de processo.

\section{B.2.2 Escala de classificação dos atributos de processo}

A extensão da realização dos atributos de processo é medida utilizando uma escala ordinal de medidas. A escala ordinal definida a seguir deve ser utilizada para expressar os níveis de realização dos atributos de processo. 
- N (Não Realizada): Acontece quando há pouca ou nenhuma evidência da realização do atributo definido na avaliação de processo.

- P (Parcialmente Realizada): Há algumas evidências de uma abordagem e de alguma realização dos atributos definidos no processo de avaliação. Alguns aspectos da realização do atributo podem ser imprevisíveis.

- L (Amplamente Realizada): Há evidências de uma abordagem sistemática e significante realização do atributo definido na avaliação do processo. Alguns pontos fracos relacionados a esses atributos podem existir no processo de avaliação.

- F (Completamente Realizada): Há evidências da completa e sistemática abordagem e completa realização dos atributos definidos na avaliação de processo.

A escala ordinal definida deve ser compreendida em termos de uma escala de porcentagem, representando a extensão da sua realização. Os valores correspondentes a escala ordinal são apresentados a seguir:

- N: 0 até $15 \%$ de realização

- P: $15 \%$ até $50 \%$ de realização

- L: $50 \%$ até $85 \%$ de realização

- F: $85 \%$ até $100 \%$ de realização.

\section{B.3 Classificação dos atributos de processo}

Cada atributo de processo deve ser classificado utilizando a escala de classificação ordinal definida. Um processo deve ser avaliado até o maior nível de capacidade definido no escopo da avaliação.

\section{B.4 Modelo de nível de capacidade de processo}

O nível de capacidade alcançado por um processo deve ser derivado da classificação dos atributos de processo realizada para esse processo, de acordo com o modelo de nível de capacidade de processo apresentado na Tabela B.1: 


\begin{tabular}{|l|l|l|}
\hline Escala & Atributos de processo & Classificação \\
\hline Nível 0 & AP 1.1 Execução do processo & N \\
\hline Nível 1 & AP 1.1 Execução do processo & L ou F \\
\hline Nível 2 & AP 1.1 Execução do processo & F \\
& AP 2.1 Gerência da execução & L ou F \\
& AP 2.2 Gerência dos produtos de trabalho & L ou F \\
\hline
\end{tabular}

Tabela B.1: Modelo de nível de capacidade de processo. 